\title{
DESIGN OF A RURAL WATER PROVISION SYSTEM TO DECREASE ARSENIC EXPOSURE IN BANGLADESH
}

January 9, 2009

\author{
Johanna Louise Mathieu \\ Department of Mechanical Engineering \\ University of California, Berkeley \\ and \\ Environmental Energy Technologies Division \\ Lawrence Berkeley National Laboratory \\ Berkeley, CA 94720
}

This work was supported by the Director, Office of Science, of the U.S. Department of Energy under Contract No. DE-AC02-05CH11231. Funders include the National Collegiate Inventors and Innovators Alliance (NCIIA) and the University of California, Berkeley's Richard C. Blum Center for Developing Economies, Bears Breaking Boundaries Contest, Sustainable Products and Solutions (SPS) Program, and Big Ideas Marketplace. Past funders include the Lawrence Berkeley National Laboratory's Technology Transfer Office, the Blue Planet Run Foundation, the California Energy Commission (CEC), and the American Water Works Association Research Foundation (AwwaRF). 


\section{DISCLAIMER}

This document was prepared as an account of work sponsored by the United States Government. While this document is believed to contain correct information, neither the United States Government nor any agency thereof, nor The Regents of the University of California, nor any of their employees, makes any warranty, express or implied, or assumes any legal responsibility for the accuracy, completeness, or usefulness of any information, apparatus, product, or process disclosed, or represents that its use would not infringe privately owned rights. Reference herein to any specific commercial product, process, or service by its trade name, trademark, manufacturer, or otherwise, does not necessarily constitute or imply its endorsement, recommendation, or favoring by the United States Government or any agency thereof, or The Regents of the University of California. The views and opinions of authors expressed herein do not necessarily state or reflect those of the United States Government or any agency thereof or The Regents of the University of California. 


\begin{abstract}
Researchers at the Lawrence Berkeley National Laboratory have invented ARUBA (Arsenic Removal Using Bottom Ash) a material that effectively and affordably removes high concentrations of arsenic from contaminated groundwater. The technology is cost-effective because the substrate-bottom ash from coal fired power plants - is a waste material readily available in South Asia. During fieldwork in four sub-districts of Bangladesh, ARUBA reduced groundwater arsenic concentrations as high as $680 \mathrm{ppb}$ to below the Bangladesh standard of $50 \mathrm{ppb}$. Key results from three trips in Bangladesh and one trip to Cambodia include (1) ARUBA removes more than half of the arsenic from contaminated water within the first five minutes of contact, and continues removing arsenic for 2-3 days; (2) ARUBA's arsenic removal efficiency can be improved through fractionated dosing (adding a given amount of ARUBA in fractions versus all at once); (3) allowing water to first stand for two to three days followed by treatment with ARUBA produced final arsenic concentrations ten times lower than treating water directly out of the well; and (4) the amount of arsenic removed per gram of ARUBA is linearly related to the initial arsenic concentration of the water. Through analysis of existing studies, observations, and informal interviews in Bangladesh, eight design strategies have been developed and used in the design of a low-cost, community-scale water treatment system that uses ARUBA to remove arsenic from drinking water. We have constructed, tested, and analyzed a scale version of the system. Experiments have shown that the system is capable of reducing high levels of arsenic (nearly 600 $\mathrm{ppb}$ ) to below $50 \mathrm{ppb}$, while remaining affordable to people living on less than $\$ 2$ per day. The system could be sustainably implemented as a public-private partnership in rural Bangladesh.
\end{abstract}




\section{Contents}

1 Introduction $\quad 11$

2 Background $\quad 11$

2.1 Health Effects of Arsenic Exposure . . . . . . . . . . . . . . . . . . 12

2.2 Economic Effects of Arsenic Exposure . . . . . . . . . . . . . . . . . . . 12

2.3 Arsenic Standards for Drinking Water . . . . . . . . . . . . . . . . . . . . . 12

2.4 Current State of Affairs in Bangladesh . . . . . . . . . . . . . . . . . . . . 13

2.5 Proposed Solutions to the Arsenic Crisis . . . . . . . . . . . . . . . . . . . 13

2.5 .1 Source Switching . . . . . . . . . . . . . . . . . . . . . 13

2.5 .2 Arsenic Remediation . . . . . . . . . . . . . . . . . . . . . . . 14

2.6 ARUBA Arsenic Project at LBNL \& UC Berkeley . . . . . . . . . . . . . . 16

$2.6 .1 \quad$ Project History . . . . . . . . . . . . . . . . . . . . . . . . 16

2.6 .2 Fieldwork Details . . . . . . . . . . . . . . . . . . . . . . . 16

3 Arsenic Testing Methods $\quad 17$

3.1 Arsenic QuickTest . . . . . . . . . . . . . . . . . . . . . 17

3.2 Inductively Coupled Plasma - Mass Spectroscopy (ICP-MS) . . . . . . . . . . . . . . 18

3.3 Hydride Generation Atomic Absorption Spectrophotomery (HG-AAS) . . . . . . . . . 18

3.4 Graphite Furnace Atomic Absorption Spectrometry (GF-AAS) . . . . . . . . . . . . 19

$3.5 \quad$ As(III) Speciation Cartridges . . . . . . . . . . . . . . . . . . . . . 20

4 ARUBA Laboratory Methods \& Results 20

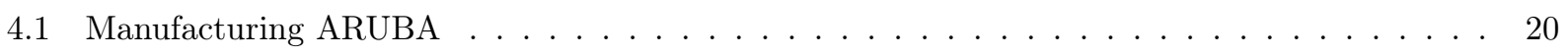

4.2 Arsenic Removal Capacity . . . . . . . . . . . . . . . . . . . . . . . . . . . 22

4.2 .1 Capacity Test - Laboratory Protocol _ . . . . . . . . . . . . . . . . . . . 22

$4.2 .2 \quad$ Laboratory Results . . . . . . . . . . . . . . . . . . . . . . . . . 22

4.2.3 Arsenic Removal Capacity Versus Initial Arsenic Concentration in the Laboratory . . 23

4.2.4 Arsenic Removal Capacity of Un-coated Bottom Ash . . . . . . . . . . . . . . . . . . 24

4.3 Arsenic Removal Kinetics . . . . . . . . . . . . . . . . . . . . . . . . 25

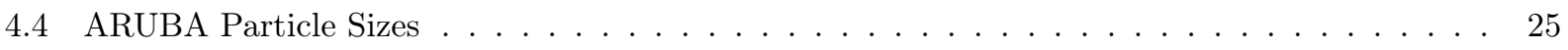

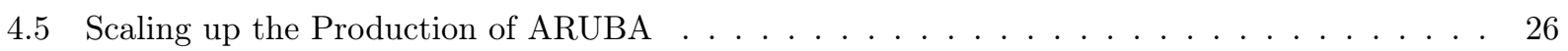

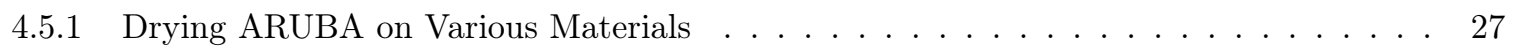

4.5.2 Varying the Thickness of the Drying Layer f . . . . . . . . . . . . . . . 27

4.5.3 Direct Scale-up of the ARUBA Manufacturing Protocol . . . . . . . . . . . . . . . 28

$4.5 .4 \quad$ Heat Drying . . . . . . . . . . . . . . . . . . . . . . . . 29 
5 ARUBA Field Methods \& Results $\quad 31$

5.1 Arsenic Removal Capacity . . . . . . . . . . . . . . . . . . . . . . . . . 31

5.1.1 Capacity Test - Field Protocol . . . . . . . . . . . . . . . . . . . . 31

5.1 .2 Methods and Results from Bangladesh Trip 1 . . . . . . . . . . . . . . . . . . . . 32

5.1.3 Results from Bangladesh Trip 2 . . . . . . . . . . . . . . . . . . . . . 38

5.1.4 Results from Bangladesh Trip 3. . . . . . . . . . . . . . . . . . . . . . 38

5.1.5 Results from Cambodia ........................ . . . 41

5.1.6 Arsenic Removal Capacity Versus Initial Arsenic Concentration in the Field . . . . . 41

5.2 ARUBA Properties . . . . . . . . . . . . . . . . . . . . . . . 43

5.2.1 Treatment Repeatability . . . . . . . . . . . . . . . . . . . . 43

5.2.2 Arsenic Removal Kinetics . . . . . . . . . . . . . . . . . . . . . . . . 44

5.2.3 Treatment Scalability ........................... . . . 45

5.2 .4 ARUBA Dosing . . . . . . . . . . . . . . . . . . . . 46

5.2.5 Water Storage before Treatment . . . . . . . . . . . . . . . . . . . . . . 49

5.2.6 Removing Manganese with ARUBA . . . . . . . . . . . . . . . . . . . 55

5.3 Performance of ARUBA made in Bangladesh . . . . . . . . . . . . . . . . . . . . . . 55

6 Designing an Arsenic Removal Device 56

6.1 Design Strategies . . . . . . . . . . . . . . . . . . . . . . 57

6.1.1 Strategy 1: Maximize Effectiveness of Technology . . . . . . . . . . . . 57

6.1.2 Strategy 2: Community-Scale Treatment . . . . . . . . . . . . . . . . . 57

6.1.3 Strategy 3: Minimize Distance to Safe Water . . . . . . . . . . . . . . . . . . 58

6.1.4 Strategy 4: Enhance Perception of Treated Water . . . . . . . . . . . . . . 58

6.1.5 Strategy 5: Build Trust in Technology . . . . . . . . . . . . . . . . . 58

6.1.6 Strategy 6: Minimize Cost to the Consumer . . . . . . . . . . . . . . . . . . 59

6.1.7 Strategy 7: Ease of Local Water Management . . . . . . . . . . . . . . . . . . 59

6.1.8 Strategy 8: Feasibility of Waste Management . . . . . . . . . . . . . . . . . 60

6.2 Prototype Development . . . . . . . . . . . . . . . . . . . . . . . 60

6.2.1 Mixing ARUBA into Water . . . . . . . . . . . . . . . . . . . 60

6.2 Removing Spent ARUBA From Treated Water . . . . . . . . . . . . . . . . . 62

6.2.3 Conceptual Water Treatment Center Design . . . . . . . . . . . . . . . . 69

6.2.4 One Hundred Liter per Hour Prototype System . . . . . . . . . . . . . . . . . . . . . 69

6.3 Possible Implementation Model . . . . . . . . . . . . . . . . . . . . . . . . . 70

6.4 Projected Costs . . . . . . . . . . . . . . . . . . . . . . . 71

7 Waste Disposal and Reuse 73

7.1 Leachate Testing . . . . . . . . . . . . . . . . . . . . . . . . . 73

7.2 TCLP \& EPA Approvals . . . . . . . . . . . . . . . . . . . . . . . . . 75

7.3 Spent ARUBA Processing \& Reuse . . . . . . . . . . . . . . . . . . . . . . . . 75 
8 Potential Future Research

9 Conclusions

76 


\section{Acronyms}

ARUBA: Arsenic Removal Using Bottom Ash

As: arsenic

As(III): trivalent arsenite

$\operatorname{As}(\mathrm{V})$ : pentavalent arsenate

BAAG: Berkeley Arsenic Alleviation Group

BEAR: Berkeley Electrocoagulation Arsenic Remediation

BGS: British Geological Survey

BRAC: Bangladesh Rural Advancement Committee

BUET: Bangladesh University of Engineering and Technology

DO: dissolved oxygen

DRI: Dietary Reference Intake

ECAR: ElectroChemical Arsenic Remediation

HG-AAS: Hydride Generation - Atomic Adsorption Spectroscopy

ICP-MS: Inductively Coupled Plasma - Mass Spectroscopy

GF-AAS: Graphite Furnace - Atomic Adsorption Spectroscopy

GFH: Granular Ferric Hydroxide

LBNL: Lawrence Berkeley National Laboratory

MCL: Maximum Contaminant Level

Mn: Manganese

NTU: Nephelometric Turbidity Units

NGO: Non-Governmental Organization

PSF: Pond Sand Filter

ppb: parts per billion

TCLP: Toxicity Characteristics Leaching Procedure

UC: University of California

UNICEF: United Nations Children's Fund

US EPA: United States Environmental Protection Agency

WHO: World Health Organization 


\section{List of Figures}

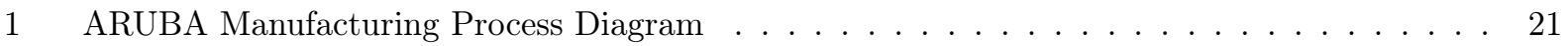

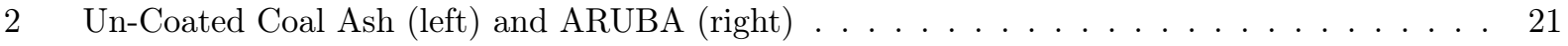

3 Arsenic Removal Capacity v. Initial Arsenic Concentration (ICP-MS) . . . . . . . . . . . . 24

4 Arsenic Removal Capacity v. Initial Arsenic Concentration: Projected to Origin (ICP-MS) . 24

5 Scanning Electron Micrographs of Un-coated Bottom Ash (left) and ARUBA (right). . . . . 26

6 Drying ARUBA in Thin Layers on Laboratory Glassware, Part of the Former ARUBA Man-

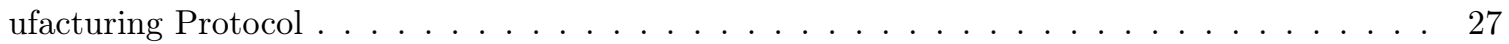

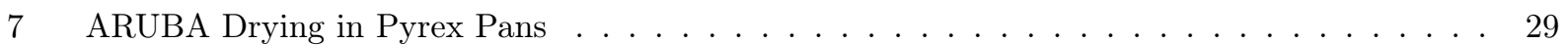

8 ARUBA Drying in a Pyrex Dish on a Hot Plate . . . . . . . . . . . . . . . 30

9 Maintaining Particle Suspension during a Capacity Test in Bangladesh . . . . . . . . . . . . 32

10 Single Dose ARUBA Treatment in Bangladesh: $1 \mathrm{~g}$ per $250 \mathrm{ml}$ (ICP-MS) . . . . . . . . . . 34

11 Double Dose ARUBA Treatment in Bangladesh: 2 g per $250 \mathrm{ml}$ (ICP-MS) . . . . . . . . . 35

12 Quadruple Dose ARUBA Treatment in Bangladesh: 2 g per $250 \mathrm{ml} \& 4 \mathrm{~g}$ per $250 \mathrm{ml}$ (ICP-MS) 36

13 All Bangladesh Trip 1 ARUBA Treatment Experiments (ICP-MS) . . . . . . . . . . . . 37

14 Bangladesh Trip 2 ARUBA Treatment Experiment (ICP-MS) … . . . . . . . . . . . 39

15 Arsenic(III) and Arsenic(V) Concentrations of TW3.1 - TW3.4 (GF-AAS) . . . . . . . . . 40

16 Bangladesh Trip 3 ARUBA Treatment Experiment (GF-AAS) . . . . . . . . . . . . . . 40

17 Cambodia ARUBA Treatment Experiment (ICP-MS) . . . . . . . . . . . . . . . . 42

18 Bangladesh \& Cambodia Arsenic Removal Capacity v. Initial Arsenic Concentration (ICP-MS

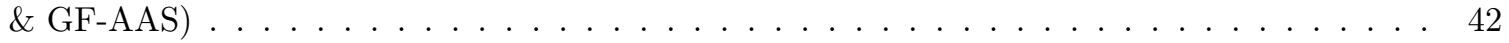

19 Bangladesh, Cambodia, \& Laboratory Arsenic Removal Capacity v. Initial Arsenic Concentration $(\mathrm{ICP}-\mathrm{MS} \& \mathrm{GF}-\mathrm{AAS}) \ldots \ldots \ldots \ldots \ldots$

20 Arsenic Concentration v. Treatment Time for TW2.1 and TW2.3 (ICP-MS) . . . . . . . . 44

21 Arsenic Concentration v. Treatment Time for TW3.1 and TW3.2 (GF-AAS) . . . . . . . 45

22 Comparison of the Final Arsenic Concentration of Different Fractionated Dosing Schemes in the Laboratory: $0.5 \mathrm{~g}$ Total Dose $(\mathrm{ICP}-\mathrm{MS}) \ldots \ldots \ldots$

23 Comparison of the Final Arsenic Concentration of Different Fractionated Dosing Schemes in the Laboratory: $1 \mathrm{~g}$ Total Dose $(\mathrm{ICP}-\mathrm{MS}) \ldots \ldots \ldots$. . . . . . . . . . . . 47

24 Comparison of the Final Arsenic Concentration of Different Dosing Schemes in Bangladesh: $1 \mathrm{~g}$ Total Dose $(\mathrm{ICP}-\mathrm{MS}) \ldots \ldots \ldots \ldots \ldots$. . . . . . . . . . . . . . . 48

25 Comparison of the Final Arsenic Concentration of Different Dosing Schemes in Bangladesh: $2 \mathrm{~g}$ Total Dose $(\mathrm{ICP}-\mathrm{MS}) \ldots \ldots \ldots \ldots \ldots$

26 Final Arsenic Concentrations of TW2.1 \& TW2.3 Water Stored Before Treatment (ICP-MS) 49

27 Final Arsenic Concentration of TW3.1 \& TW3.2 Water Stored Before Treatment (GF-AAS) . 51

28 DO Measurements of the Stored Water . . . . . . . . . . . . . . . . . . . 52

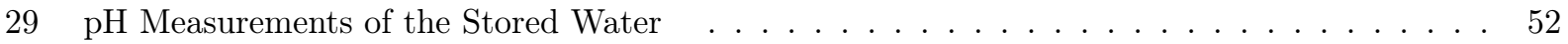

30 Discrepancies between ICP-MS and GF-AAS Measurements (ICP-MS \& GF-AAS) $\ldots \ldots$. . 53 


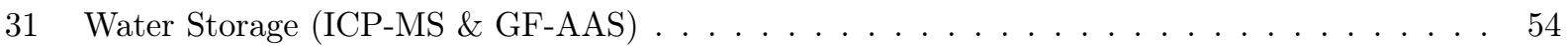

32 Bangladesh, Cambodia, Laboratory, \& Post-Storage Arsenic Removal Capacity v. Initial Arsenic Concentration (ICP-MS \& GF-AAS) . . . . . . . . . . . . . . . 55

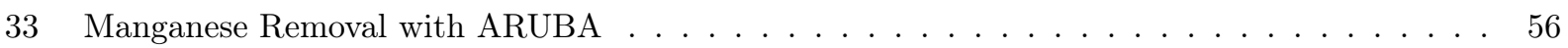

34 Capacity Test Results of ARUBA Made in Bangladesh, Initial Arsenic Concentration: 1750

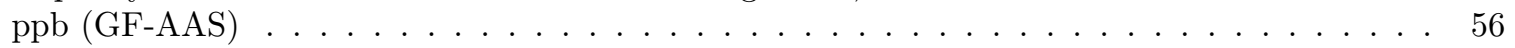

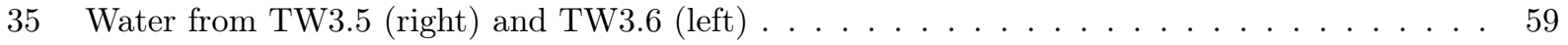

36 Aeration Pumps Mixing ARUBA into 20 Liters of Contaminated Water . . . . . . . . . . . 61

37 Treating 20 Liters of Water Using Aeration Pumps for Mixing (QuickTest) . . . . . . . . . 61

38 Electric Kitchen Mixer Mixing ARUBA into 20 Liters of Contaminated Water . . . . . . . . 62

39 Treating 20 Liters of Water Using a Mechanical Mixer for Mixing (GF-AAS) . . . . . . . 63

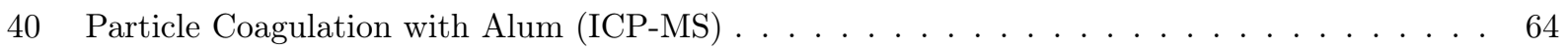

41 Particle Coagulation with Polyacrylamide (ICP-MS) . . . . . . . . . . . . . . . . 64

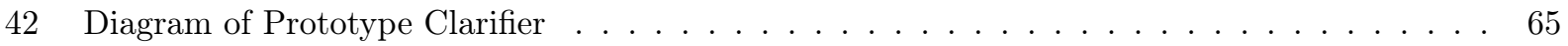

43 Ten Liter per Hour Prototype Clarifier . . . . . . . . . . . . . . . . . . . . . . 66

44 Shefah Qazi Tests the 10 liter per hour Prototype Clarifier . . . . . . . . . . . . . . . . 67

45 Comparison of Three Spent ARUBA Removal Methods (ICP-MS) _ . . . . . . . . . . 67

46 Coagulated ARUBA Particles, Ten Minutes after Addition of the Polyelectrolyte . . . . . . 68

47 Removing Spent ARUBA with a Filter v. a Clarifier and Coagulant (ICP-MS) . . . . . . 68

48 Water Treatment Center Design . . . . . . . . . . . . . . . . . . . . . . . . 69

49 One Hundred Liter per Hour Prototype System ～. . . . . . . . . . . . . . . . . . . . . 70

50 Structure of the Proposed Public-Private Partnership ～. . . . . . . . . . . . . . . . . 71

51 ARUBA Cost (per household per year) v. Arsenic Concentration of Water Supply . . . . . 72

52 Benefits and Costs of Arsenic Remediation v. Arsenic Concentration of Water Supply . . . 73 


\section{List of Tables}

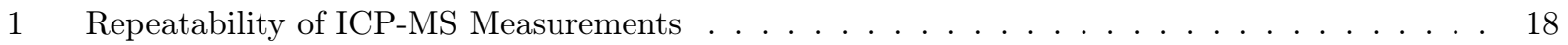

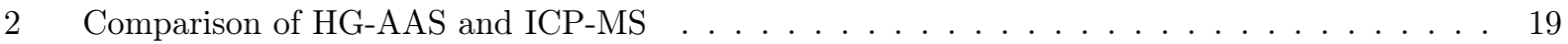

3 Comparison of GF-AAS and ICP-MS, July $2007 \ldots \ldots \ldots \ldots$

4 Comparison of GF-AAS and ICP-MS, June $2008 \ldots \ldots \ldots \ldots \ldots$

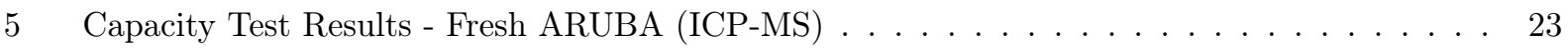

6 Capacity Test Results - Reuse of Spent ARUBA (ICP-MS) . . . . . . . . . . . . . 23

$7 \quad$ Performance of Un-coated Ash v. ARUBA (ICP-MS) . . . . . . . . . . . . . . . . . 25

8 Final Arsenic Concentration v. Length of ARUBA Treatment (ICP-MS) . . . . . . . . . 25

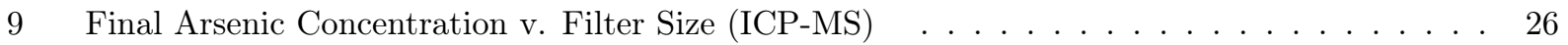

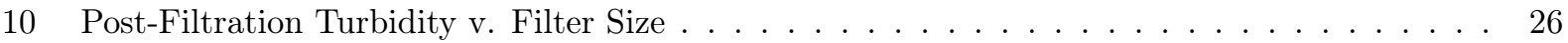

11 Arsenic Removal Capacity v. Drying Surface Material (QuickTest) . . . . . . . . . . . . . 28

12 Arsenic Removal Capacity v. Drying Layer Thickness (QuickTest) . . . . . . . . . . . . 28

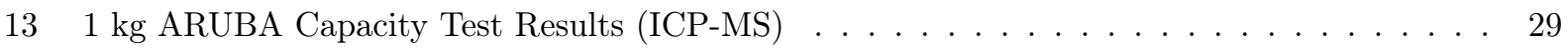

14 Heat Drying Methods v. Final Arsenic Concentrations (QuickTest) . . . . . . . . . . . . . 30

15 Bangladesh Tubewells Sampled March 28, 2007 - April 5, 2007 (QuickTest) . . . . . . . . 33

16 Analysis of Tubewells $1,7, \& 12 \ldots \ldots \ldots \ldots \ldots \ldots$

17 Bangladesh Tubewells Sampled July 2, 2007 - July 5, 2008 (ICP-MS) ․ . . . . . . . . . . 38

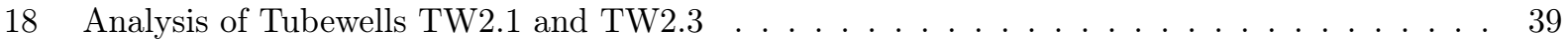

19 Bangladesh Tubewells Sampled June 1, 2008 - June 27, 2008 (GF-AAS) ～. . . . . . . . . . 39

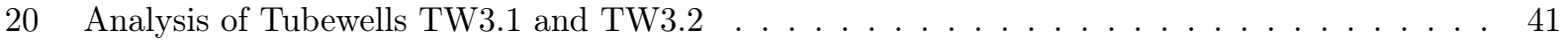

21 Cambodia Tubewells Sampled July 2, 2008 - July 11, 2008 (ICP-MS) ～. . . . . . . . . . . 41

22 Repeatability of ARUBA Treatment (ICP-MS) . . . . . . . . . . . . . . . . 44

23 ARUBA Treatment Scalability (ICP-MS) $\ldots \ldots \ldots \ldots \ldots \ldots$

24 Eight Key Design Strategies for Designing an Arsenic Removal Device . . . . . . . . . . . 57

25100 Liter per Hour Prototype Costs ～. . . . . . . . . . . . . . . . . . . . . . . . 70

26 MCL Standards and Un-Coated Coal Ash Leachate Results (ppb) . . . . . . . . . . . . . 74

27 MCL Standards and ARUBA Leachate Results $(\mathrm{ppb}) \ldots \ldots \ldots \ldots$ 


\section{Introduction}

Naturally-occurring arsenic in drinking water is a public health problem threatening the well-being (and in many cases, lives) of more than a hundred million people worldwide. In Bangladesh alone, 20 million people drink from arsenic-laden water from shallow tubewells (89). The vast majority of these wells were installed by the Bangladesh government, international agencies such as the United Nations Children's Fund (UNICEF), various non-governmental organizations (NGOs), and private citizens within the past forty years as an alternative to drinking biologically contaminated surface water. High levels of arsenic were first noted in the shallow tubewells in 1993. Smith et al. (2000) rightly term the crisis in Bangladesh "the largest mass poisoning of a population in history" (80).

As of 2007, arsenic-laden ground and surface water has been found in Argentina, Australia, Austria, Cambodia, Chile, China, El Salvador, Finland, France, Germany, Ghana, Greece, Honduras, Hungary, India, Iran, Italy, Japan, Macedonia, Mexico, Mongolia, Nepal, New Zealand, Peru, Romania, Russia, Serbia, South Africa, Taiwan, Thailand, the United Kingdom, the United States, Vietnam, and Zimbabwe (72). It is likely that more countries will be added to this list as more water is tested for arsenic.

Scientists at the Lawrence Berkeley National Laboratory (LBNL) have developed a simple material called ARUBA - Arsenic Removal Using Bottom Ash - that inexpensively and effectively removes arsenic from drinking water $(29,70,20)$. ARUBA (also referred to as "media" in this document) uses bottom ash as a substrate. Bottom ash, mainly composed of silica, is obtained as a finely powdered waste material from coal-fired power plants, which are common in India. The ash is sterile because the coal has been fired at extremely high temperatures (close to $800^{\circ} \mathrm{C}$ ). Particles of bottom ash are coated with a complex consisting of oxides, hydroxides, and/or oxyhydroxides of iron, using relatively inexpensive chemicals (ferrous sulfate and sodium hydroxide). The process is conducted at room-temperature and atmospheric pressure. Thus, ARUBA can be produced with relatively simple equipment at low cost.

Removing arsenic from contaminated drinking water with ARUBA does not require local handling of corrosive or toxic chemicals, or complex engineering operations. ARUBA is mixed into water, where it reacts with and immobilizes arsenic by adsorption and/or co-precipitation. The resulting arsenic-iron complex is settled out of the water, and is safe enough for disposal in municipal landfills per the United States Environmental Protection Agency (US EPA) standards. Importantly, because of ARUBA's large surface to volume ratio, only a small amount of media is needed to remove a given amount of arsenic. Therefore, ARUBA arsenic removal produces less waste than most comparable technologies.

This report details the design of a community-based water treatment system that uses ARUBA to remove arsenic from contaminated drinking water. The system has been developed for application in rural Bangladesh. Section 2 begins with background information including a discussion of the arsenic crisis and many of the proposed solutions including source switching and arsenic remediation. In addition, this section presents the history of the ARUBA Arsenic Project at LBNL and the University of California (UC) Berkeley. Section

3 discusses each of the arsenic testing methods used in our work. Section 4 details ARUBA's performance in the laboratory, while Section 5 covers ARUBA's performance in the field. Field data was gathered over three trips to Bangladesh in 2007 and 2008 and one trip to Cambodia in 2008. Section 6 presents a user needs analysis based on past literature and field observations. This section also includes the evolution of the design of a community based water treatment system that uses ARUBA to remove arsenic. Section 7 explores the issue of waste disposal. Future research possibilities are presented in Section 8 and Section 9 concludes.

\section{Background}

This section includes a description of the health effects of arsenic poisoning, the economic effects of arsenic exposure, and Maximum Contaminant Level (MCL) standards. It also lists many of the proposed solutions including source switching and arsenic remediation. Finally, it recounts the history of the ARUBA Arsenic Project at LBNL/UC Berkeley. 


\subsection{Health Effects of Arsenic Exposure}

It can take many years of chronic ingestion before a person starts showing symptoms of arsenic poisoning (arsenicosis) so they may not immediately realize that they are being exposed to the toxin. Smith et al. (2000) explain that the average latency period for arsenic-induced skin lesions - generally the first symptom that a person exposed to chronic arsenic poisoning experiences - is approximately ten years (80). Unfortunately, this means that people are often hesitant to switch to arsenic-free drinking water sources until their symptoms become obvious, at which point a number of serious health problems could have already started to develop.

The National Research Council (NRC) has classified arsenic as a human carcinogen associated with cancers of the skin, bladder, lungs, liver, kidney, and prostate (68). Several studies in Bangladesh have also connected arsenic exposure through groundwater ingestion to cancer $(4,12,16)$. Drinking arsenic contaminated water also raises the risk of diabetes mellitus (65). Other effects of chronic arsenic exposure include problems with kidney and liver function, damage to internal organs, and hypertension (72). Vascular problems caused by arsenic can also lead to gangrene in the legs, necessitating amputations (72, 23). Arsenic exposure is correlated with neurological, developmental, and reproductive problems (27). Recent work by the World Bank has found that children exposed to arsenic are more likely to perform poorly in mathematics (7). On top of medical problems, arsenicosis patients are often discriminated against because of physical manifestations of their illness $(46,19)$.

In addition to arsenic exposure through drinking water, Bangladeshi villagers are further exposed to arsenic through consuming rice that has been irrigated with arsenic-contaminated water $(25,61)$. Other foods such as wheat and maize have been shown to up-take arsenic to varying degrees (25).

Since current medical treatment can not adequately address the long-term effects of arsenic poisoning, a preventative solution is necessary to address this issue (72). Fortunately, a person who stops drinking arseniccontaminated water can mitigate or reverse the symptoms of chronic arsenic exposure, if those symptoms have not already caused irreversible health damage.

\subsection{Economic Effects of Arsenic Exposure}

In 1997, Bangladesh was ranked 12th worldwide on the United Nations Development Programme (UNDP) Human Poverty Index (88). Unfortunately, the health effects of arsenic exposure increase poverty by decreasing productivity. For instance, arsenic-induced skin lesions, which primarily form on the hands and feet, are painful and make manual labor difficult. Chronic illnesses, such as cancers, can make work impossible and ultimately shorten lifespans. Roy (2008) has determined that the net economic benefit of reducing drinking water arsenic concentrations to $50 \mathrm{ppb}$ is $\$ 7$ per month per household (or INR 0.49 per ppb arsenic per household per month) in West Bengal, India. In Bangladesh, we assume that this number would be similar, albeit a bit lower since Bangladesh's GNI is lower than that of India.

Importantly, the poor suffer the most from arsenic poisoning (96). One main reason is that poor nutrition correlates with a likeliness to show symptoms of arsenic poisoning $(96,12,17,89)$. In addition, the poor

have less financial means to seek alternative water sources or receive medical treatment for symptoms of arsenic exposure.

\subsection{Arsenic Standards for Drinking Water}

As a result of the health effects of arsenic exposure, governments and international organizations have set drinking water arsenic standards. Formerly the accepted MCL for arsenic in drinking water was $50 \mu \mathrm{g} / \mathrm{L}$ or ppb. However, the US EPA, the World Health Organization (WHO), and the European Union lowered the MCL to $10 \mathrm{ppb}$. The Government of Bangladesh and many other governments, especially those who have been unable to meet the more stringent standard, still mandate the old MCL of $50 \mathrm{ppb}$. 


\subsection{Current State of Affairs in Bangladesh}

Around $95 \%$ of rural Bangladeshis rely on shallow tubewells for drinking water. UNICEF reports that of the 4.7 million tubewells that have been tested in Bangladesh (out of a total of 8.6 million tubewells) 1.4 million have arsenic levels above $50 \mathrm{ppb}$, and in more than 8,000 villages greater than $80 \%$ are contaminated (89). The best current estimate for the number exposed to arsenic above the Bangladesh MCL is 20 million people (89). Estimates for the number of current arsenicosis cases range from 40,000 to 100,000 people, though due to the long latency period of symptoms up to one million people could shows symptoms in the future $(72,89)$. While many NGOs, companies, and universities have worked on solutions to the arsenic crisis, only small gains have been made in reducing arsenic exposure in rural Bangladeshi villages.

\subsection{Proposed Solutions to the Arsenic Crisis}

Proposed solutions to the Bangladesh arsenic crisis fit into two categories: switching to arsenic-free water sources and removing arsenic from contaminated sources. This section discusses the advantages and disadvantages to many of these proposed solutions.

\subsubsection{Source Switching}

Bangladesh has no shortage of water, though the quality of that water varies between sources and the seasons. When the extent of the arsenic crisis first became known, researchers suggested Bangladeshi villagers switch to drinking surface water (23). However, the primary reason why so many organizations previously urged villagers to switch from surface water to groundwater is that surface water in Bangladesh is heavily contaminated with pathogens that cause diarrhea and other serious illnesses. Severe surface water contamination stems from the fact that Bangladesh is the most densely populated country in the world (excluding city-states and small island nations) and in rural areas waste water is not treated. In addition, domesticated animals are free to move in and out of ponds.

Treating surface water generally involves boiling; however, high fuel prices make treating all drinking water impractical (though surface water is commonly used for cooking) (14). In addition, boiling does not remove most chemical contaminants, and surface waters typically contain high levels of agricultural run-off including synthetic pesticides and fertilizers. Instead of boiling, Pond Sand Filters (PSFs), serving around 50 families, have been proposed and/or analyzed in several studies $(18,2)$. However, they have proven costly and difficult to maintain (18).

A decision to use pond water as drinking water would necessitate strict watershed management to minimize both biological and chemical contamination $(17,23)$. However, many ponds once used for drinking water have now been converted to fish-farming ponds and so converting them back would result in the loss of an important income generating activity.

Rain water could be a viable safe water source though it would necessitate construction of safe storage tanks to hold rain throughout the dry season. Unfortunately, stored rain water often becomes contaminated with pathogens (1). While rain water collection has played a small role in safe water provision in Bangladesh, acceptance has not been wide-spread, in part because the systems are too expensive for households (18).

Another arsenic-free water source is from extremely shallow wells called dug wells (usually less than 30 feet deep). Dug wells are generally lined with concrete to prevent intrusion from surface waters. Some involve dropping a bucket to collect the water; however, newer dug wells are outfitted with hand pumps to reduce contamination (36). While dug wells are generally arsenic-free they are susceptible to bacterial contamination (1). Hira-Smith et al. (2007) report that 35\% of dug wells tested in their study were contaminated with high levels of fecal coliform (in addition, several of the dug wells tested in this study contained high levels of arsenic). Therefore, dug well owners must generally adopt a chlorination regiment to insure that the well water is free of pathogens.

Many believe that the most effective way to reduce arsenic exposure in Bangladesh is to encourage villagers to switch to arsenic-free shallow tubewells, or deep tubewells $(31,80)$. Due to Bangladesh's complex 
geochemistry, tubewells 10 meters apart can deliver water of vastly different arsenic concentrations because they tap different aquifers. Also, deep tubewells (generally drawing water from greater than $200 \mathrm{~m}$ ) are usually arsenic-free.

At the on-set of the crisis, several studies suggested that all shallow tubewells in Bangladesh should be tested and painted red if contaminated or painted green if safe $(17,14)$. Campaigns were conducted in the early 2000s to mark each tubewell. While this has proven effective in helping researchers understand the extent of the crisis and helping villagers understand their options, it has not solved the problem. In some villages, most or all shallow tubewells are contaminated. Since shallow tubewells are usually privately owned, social dynamics have prevented many families from gaining access to arsenic-free tubewells.

There are other problems with marking un-safe tubewells. Many of the villages we visited had tubewells that had previously been painted red, but most of the paint had flaked off. One villager reported that the paint only lasts about six months. In addition, Kinniburgh and Kosmus (2002) report significant mis-classification of wells due to in accurate field test kits meaning that some villagers, who think they are drinking arsenic-free water because they are obtaining water from a green painted source, are actually being poisoned (50).

Drilling deep tubewells for every household has been impossible because they are significantly more expensive to install than shallow tubewells. Therefore, despite the fact that the Bangladesh government mandates that less than 50 users share one water point (Rick Johnston, personal communication, June 2008), in several villages we visited in Sonargaon District, villagers reported that the entire village (more than 1,000 people) shared one deep tubewell. Unfortunately, some villagers simply do not have the time or patience to walk across the village and then stand in line to obtain water from a safe source and so they continue to drink from contaminated sources (46).

In addition to all of the issues described above, some previously arsenic-free shallow and deep tubewells have started delivering arsenic-contaminated water $(1,80)$. This occurs through diffusion of contaminated water into newly tapped clean aquifers, from biogeochemistry that has started releasing arsenic into water, and could occur due to irrigation pumping which introduces young organic carbon into the aquifers, mobilizing arsenic (34).

Howard et al. $(2006,2007)$ have estimated the burden of disease from several of the arsenic-free sources discussed in this section, namely dug wells, PSFs, rainwater harvesting, and deep tubewells. Dug wells and PSFs were found to have a significantly higher disease burden than both rainwater harvesting and deep tubewells, due primarily to biological contamination and also potential unsafe arsenic levels $(39,40)$. It is important to note that all of these unmonitored water sources have significant estimated disease burdens.

\subsubsection{Arsenic Remediation}

Many approaches have been investigated for removing arsenic from drinking water. Useful reviews of techniques for removing arsenic from water supplies are presented in several documents $(47,66,3)$.

Arsenic appears in two forms in Bangladesh groundwater: trivalent arsenite [As(III)] and pentavalent arsenate $[\mathrm{As}(\mathrm{V})]$, depending on the $\mathrm{pH}$ and redox potential of the water. $\mathrm{As}(\mathrm{V})$ can adsorb to and co-precipitate with naturally-occurring iron hydr(oxides) in groundwater. In water containing high levels of iron, passive sedimentation (storing water to allow natural precipitation) followed by filtration or decanting can produce water of lower arsenic concentrations (49). However, this method is seldom sufficient in reducing arsenic concentrations below MCLs because there is not enough natural iron in the groundwater to adsorb all of the arsenic $(75,3)$.

Another problem with passive sedimentation is that As(III), which composes 50-100\% of groundwater arsenic, does not adsorb to iron hydr(oxides). However, in the presence of iron and high levels of dissolved oxygen (such as in water exposed to the atmosphere, as opposed to water underground), As(III) can oxidize to As(V) $(75,54,55)$. Chemicals such as chlorine dioxide can speed-up arsenic oxidation. Note that high dissolved oxygen levels alone do not oxidize As(III) to $\mathrm{As}(\mathrm{V})$ as had been previously postulated (55).

Many arsenic removal technologies exploit the phenomena seen in passive sedimentation, specifically oxidation of $\mathrm{As}(\mathrm{III})$ to $\mathrm{As}(\mathrm{V})$ and adsorption on to iron or another arsenic adsorbent. Processes that have 
demonstrated successful arsenic removal include coagulation with ferric chloride, ferric sulfate, or alum followed by filtration $(1,35)$; adsorption on iron oxide-coated sand/silicate $(27,1,86)$, iron-impregnated sand (90), or iron oxide-coated polymer beads (51); direct adsorption on metallic (zero-valent) iron (83, 54, 21) or granulated ferric hydroxide $(\mathrm{GFH})(69,9,21)$; adsorption on carbon-based absorbents including charcarbon derived from fly ash (71, 92, 24), activated carbon and zirconium-loaded activated carbon (21), and $\mathrm{Fe}^{2+}$ treated activated carbon (41); adsorption on magnetite nanocyrstals (97); adsorption on treated zeolites (15); removal through ligand-exchange with iron-chelated resins (74); and adsorption on titanium dioxide (10). Other studies have addressed removal by membranes or biomembranes $(93,91)$.

Each of the above methods varies in terms of arsenic removal efficiency (for adsorption media this is usually measured as the amount of arsenic removed per unit of media) and kinetics (speed of arsenic removal). While these technologies have all been deemed effective, many have not been considered for rural Bangladesh because they are too expensive (in terms of material costs and treatment process costs), too complex, and/or use corrosive and toxic chemicals, which rural communities have no ability to properly dispose.

Several institutions have developed simple and inexpensive arsenic removal technologies, specifically for use in the developing world. The Kanchan filter, developed at the Massachusetts Institute of Technology (MIT) for rural Nepal, is a combined arsenic and biological treatment unit and uses rusted nails to remove arsenic $(67,27)$. A replica Kanchan filter, constructed in Berkeley in 2005, was unable to lower arsenic concentrations to acceptable limits because the nails used did not rust fast enough (13).

The 3-Kolshi (Kalshi) filter, composed of iron, coarse sand, fine sand, and charcoal was developed and disseminated in Bangladesh with the help of the Bangladesh Rural Advancement Committee (BRAC) (48, 49). While initially effective at removing high levels of arsenic to below the MCL, over time the filter clogs and therefore requires significant maintenance.

In 2007, the Grainger Challenge Prize for Sustainability was awarded to Dr. Abul Hussam of George Mason University for his invention, the SONO filter, a point-of-use filter that is an improved version of the 3-Kolshi filter. It uses a composite iron matrix and coarse river sand to remove arsenic from solution $(44,64)$. Like all household filters it requires maintenance (taking 20-30 minutes) when the flow rate decreases due to clogging, which is reportedly less frequent than with the 3-Kolshi filter. The SONO filter is rated for five years of use and costs $\$ 40-50$ dollars. Thirty thousand filters have been disseminated to date. Hussam and Munir (2007) report that some of the SONO filters disseminated in Bangladesh have become contaminated with fecal coliform. Similar biological contamination was seen in other iron-based filters $(1,85)$.

Other arsenic removal systems designed for rural Bangladesh include that of the Steven's Institute of Technology which developed a method involving coagulation and co-precipitation with iron sulfate and calcium hypochloride (85); the Bangladesh University of Engineering and Technology (BUET) which has developed a household filter that uses activated alumina (85) and, together with the United Nations University (UNU), has developed a household filter that uses iron-coated sand (5); Rajshashi University and International Development Enterprises (IDE) which has developed the Shapla Arsenic Filter that uses rust-coated brick powder (5); SIDKO Ltd. which has developed community-scale arsenic removal plants that use GFH (5); EAWAG (the Swiss Federal Institute of Aquatic Science and Technology) which has developed 'Solar Oxidation and Removal of Arsenic' (SORAS) that uses sunlight, iron, and lemon juice to enhance oxidation of $\mathrm{As}(\mathrm{III})$ to $\mathrm{As}(\mathrm{V})$ and form ferric hydr(oxides) that absorb arsenic $(42,43)$; ADA Technologies (Littleton, CO) which has developed a ferric oxide coated silicate sorbent (27); and Lehigh University which has developed activated alumina arsenic removal units that attach directly to well heads and serve about 300 households (77). Lehigh University and the organization Water for People won second place in the Grainger Prize competition for the latter technology (64).

The Children's Safe Drinking Water Program at Procter \& Gamble (P\&G) won third place in the Grainger Prize competition for PUR ${ }^{\mathrm{TM}}$, water treatment sachets that include chemicals for disinfection, coagulation, and flocculation (64).

A team of researchers at Queen's University in Belfast has developed an innovative water treatment plan to aerate groundwater and then recharge it back into the aquifer. The increased levels of dissolved oxygen slows the release of arsenic into the groundwater, and allows microorganisms, iron, and manganese to reduce dissolved arsenic concentrations (73). Recently the group won the DELPHE Award from the British Council. 


\subsection{ARUBA Arsenic Project at LBNL \& UC Berkeley}

This section presents the history of the ARUBA Arsenic Project at LBNL and UC Berkeley including a project history and logistical details of three trips to Bangladesh in 2007 and 2008. This section also includes references to all major publications from the project team over the past several years.

\subsubsection{Project History}

ARUBA was invented by Dr. Ashok Gadgil at LBNL. From 2000-2004, Team Arsenic, a group of scientists and engineers at LBNL and UC Berkeley, explored the potential of ARUBA in removing arsenic from arsenic-spiked laboratory water. Their preliminary work (together with some of the work presented in this document) is detailed in a chapter of the book Arsenic Contamination of Groundwater: Mechanism, Analysis, and Remediation (29). Highlights of the work were also presented at the 2006 University of North Carolina, Chapel Hill Conference on Safe Drinking Water: Where Science Meets Policy (70). Through a grant from the American Water Works Association Research Foundation (AWWARF) and the California Energy Commission (CEC) Team Arsenic also explored the potential application of ferric-coated U.S. bottom ash and fly ash for arsenic removal in the United States, though this proved an inefficient method of arsenic remediation of U.S. groundwater (30).

In 2004, Professor Gadgil won a research grant from the National Collegiate Inventors and Innovators Alliance (NCIIA) to form a team of engineering and business students research ARUBA's potential application in Bangladesh. The team, which was to become the Berkeley Arsenic Alleviation Group (BAAG), began work in November 2006. The goal of BAAG was to design a device and/or process that utilizes ARUBA to effectively remove arsenic from drinking water. Alongside the scientific and engineering development, the team worked to develop a business model for system implementation taking into account economic costs/benefits, social acceptability, affordability, and sustainability. In addition, the team explored the socioeconomic and public health implications of arsenic remediation using ARUBA. Though initially four students (the author, Kosar Jahani, Tasnuva Khan, and Mehmet Seflek), the team expanded to include other students: William Babbitt, Kristin Kowolik, Nadia Madden, and Shefah Qazi. At the present time (Fall 2008), the team has merged with a student team working on a competing arsenic remediation technology, ElectroChemical Arsenic Remediation (ECAR), developed at LBNL, and is also working with a team of student participants in the Berkeley Energy and Resources Collaborative (BERC) \& LBNL CleanTech to Market (C2M) program to develop a licensing strategy for both technologies. Throughout the past two years the team has collaborated with a number of institutions in Bangladesh, most significantly BRAC, BUET, and BRAC University.

\subsubsection{Fieldwork Details}

Members of BAAG travelled to Bangladesh three times in 2007-2008. The first trip to Bangladesh occurred March 23 to April 7, 2007. The objective of the trip was to demonstrate the ability of ARUBA to reduce the concentration of arsenic in Bangladeshi contaminated groundwater to below the Bangladesh MCL, and ideally below the WHO MCL. Secondary objectives included socioeconomic observations, assessment of the accuracy of in-country arsenic testing facilities, and resource identification. The author, along with UC Berkeley physics graduate student Susan Amrose, arrived in Dhaka, Bangladesh on March 25 and traveled to the city of Jessore on March 27. On March 28 and 29, together with officials from BRAC, we visited contaminated tubewells in five villages in Jhikargachha Upazila and Abhaynagar Upazila (both of Jessore district in Khulna division) where we treated water samples from eight different tubewells. We returned to Dhaka on March 30. On April 5, again with BRAC officials, we traveled to one village in Sonargaon Upazila, just outside of Dhaka, and treated water samples from one more tubewell.

In July 2007, the author and UC Berkeley undergraduate Tasnuva Khan traveled to Bangladesh to conduct fieldwork in a village in Sonargaon District. The goal of the trip was to better understand the chemical properties of ARUBA (arsenic removal kinetics, effectiveness of treatment protocol variations, scalability and repeatability of ARUBA treatment) and develop in-country research collaborations. We arrived in 
Dhaka on July 1, 2007, and with BRAC officials we visited Neel Kanda, a small village of about 110 families in Sonargaon Upazila, each day from July 2 to July 5, 2007. Experiments were conducted on site, in the Sonargaon BRAC office, and in Dhaka. During our time in Bangladesh, we also met with professors at both BUET and BRAC University. We returned to the United States on July 16, 2007.

The third trip to Bangladesh during the Summer of 2008 involved five members of the BAAG team. Technical work was conducted between May 30, 2007 and July 3, 2007 by the author, Kristin Kowolik, Shefah Qazi, and Bangladeshi collaborator Mahbuba Iasmin Ahmed, a graduate student at BUET. The goal of this trip was to develop a proof-of-concept prototype of a community based water treatment system that uses ARUBA to remove arsenic, in addition to conducting a number of experiments to further understand ARUBA's arsenic removal kinetics and behavior in water as water parameters change over time. With the help of researchers at BUET, we visited Sreenagar Upazila in Munshiganj District three times on June 1, 17, and 27, 2008, and, with the help of researchers at BRAC University, two BAAG members visited Matlab Upazila in Chandpur District on June 13, 2008 to collect water samples. Most of our experiments and prototype development were conducted in the Department of Civil Engineering at BUET. With the help of BRAC University, the team also deployed a socioeconomic study with the goal of understanding the value attributed to arsenic-free water using econometric and contingent valuation methodology, determine factors that could explain why certain families placed a higher value on clean water than others, and discover the relationship between the villagers attitudes and previous efforts at arsenic remediation. Data from summer 2008 fieldwork are still being processed and will be supplemented with data to be collected in the winter of 2009. Results will be presented in a future publication.

In addition to our work in Bangladesh, during the summer of 2008 the Berkeley Electrocoagulation Arsenic Remediation (BEAR) Team working on ECAR technology tested ARUBA in Cambodia. ARUBA has been found to work comparably in both countries. Results are presented in this document.

A selection of fieldwork results have been presented in two recent conference papers $(58,59)$. The first of these was presented at the 2008 University of North Carolina Conference on Safe \& Sustainable Drinking Water in Developing and Developed Countries: Where Science Meets Policy. The second was recently submitted to the 2009 Water Engineering Development Center (WEDC) Conference, Addis Ababa, Ethiopia. Paper acceptance is still pending as of December 2008.

\section{Arsenic Testing Methods}

Several arsenic testing methods were employed throughout the course of this project including Arsenic QuickTest, Inductively Coupled Plasma - Mass Spectroscopy (ICP-MS) Arsenic, Hydride Generation - Atomic Absorption Spectrophotometry (HG-AAS), Graphite Furnace - Atomic Absorption Spectroscopy (GF-AAS), and Aluminum Silicate As(III) Speciation Cartridges. Each of these methods is discussed below.

\subsection{Arsenic QuickTest}

In the laboratory and in the field Arsenic QuickTest ${ }^{\mathrm{TM}}$ was employed to get rough estimates for arsenic concentrations. The QuickTest kits are available from Industrial Test Systems, SC, USA. The test involves adding three reagents (tartaric acid, potassium peroxymonopersulfate, and zinc duct, respectively) to a sample of contaminated water. In the ensuing reaction, arsine gas is formed, which bonds to a mercuric bromide test strip. The strip changes color in proportion to the amount of arsenic in the water. Final total arsenic concentration is determined by matching the strip to a color chart. Arsenic QuickTest Kits used for this research measure arsenic concentrations from $0 \mathrm{ppb}$ to $500 \mathrm{ppb}$. Arsenic levels greater than $500 \mathrm{ppb}$ were determined through dilution. In the laboratory de-ionized water was used for dilutions, while in the field tap water that had been measured to have $0 \mathrm{ppb}$ arsenic (by QuickTest) was used for dilutions.

Previous research has shown laboratory-based QuickTest results to be within $+/-20 \%(+2 \mathrm{ppb})$ of ICP-MS measurements. Field-based QuickTest results are often shown to be much less accurate. Therefore, QuickTest measurements are generally disregarded after more accurate measurements (ICP-MS or GF-AAS) became 
Table 1: Repeatability of ICP-MS Measurements

\begin{tabular}{|c|c|c|}
\hline & $\begin{array}{c}\text { Sample A }(\sim 100 \mathrm{ppb}) \\
\mathrm{ppb}\end{array}$ & $\begin{array}{c}\text { Sample B } \sim 250 \mathrm{ppb}) \\
\mathrm{ppb}\end{array}$ \\
\hline \hline 1 & 97 & 260 \\
\hline 2 & 96 & 240 \\
\hline 3 & 98 & 240 \\
\hline
\end{tabular}

available. In a few cases, ICP-MS or GF-AAS samples were not taken and QuickTest results have been reported; however, these results are generally used in order to understand trends, not to pinpoint absolute arsenic concentrations.

Trace amounts of arsenic in the zinc dust used in arsenic test kits has been shown to interfere with arsenic measurements and scientists recommend replacing zinc dust with sodium borohydride (50). Unfortunately, we were unaware of this research until we had nearly completed our third field visit. Other problems with field test kits such as the one we used include:

1. As(III) produces arsine gas faster than $\mathrm{As}(\mathrm{V})$,

2. reading color strips can be more of an art than a science,

3. arsenic that has precipitated with existing iron oxides will generally not be gassified,

4. hydrogen sulfide interferes with measurements, and

5. arsenic can adsorb to the plastic test container.

\subsection{Inductively Coupled Plasma - Mass Spectroscopy (ICP-MS)}

Inductively Coupled Plasma - Mass Spectroscopy is a very accurate method of measuring trace metals. A water sample is aspirated with high velocity argon, and small particles are vaporized in a plasma torch. A mass spectrum of the plasma is taken to determine the constituents of the sample. Many of our samples, were acidified (generally $1 \mathrm{ml}$ of $1 \%$ nitric acid in $10 \mathrm{ml}$ of water) and sent to Curtis and Tompkins Ltd. (Berkeley, CA) a commercial laboratory certified with the US EPA, for ICP-MS analysis. Curtis and Tompkins reports arsenic recovery of $80-120 \%$, or an error of $+/-10 \%$. Note that ICP-MS measurements are only good to two significant figures, as arsenic concentrations above $99 \mathrm{ppb}$ must be measured through dilution. Since samples are acidified measurements must be adjusted by the correct dilution factor.

The repeatability of ICP-MS measurements was ascertained by sending three copies of two different samples to the laboratory. Samples were all sent the same day and therefore the ICP-MS machine was probably not re-calibrated between measurements. The results are presented in Table 1.

The repeatability of ICP-MS measurements over time was not ascertained, though a blank (de-ionized water) was always sent for analysis. The arsenic concentration of the blank was not always reported as zero, though it was always less than $10 \mathrm{ppb}$. It was assumed that this difference was a combination of trace amounts of arsenic in the water sample along with measurement error.

\subsection{Hydride Generation Atomic Absorption Spectrophotomery (HG-AAS)}

During our first trip to Bangladesh we sent several acidified (10\% nitric acid) water samples were to a local laboratory (Exonics Technology Center, Uttara, Dhaka), which used Hydride Generation - Atomic Absorption Spectrophotomery (HG-AAS). Our goal was to find a suitable laboratory in Bangladesh where we could send samples during subsequent trips instead of bringing samples back to Berkeley for ICP-MS 
Table 2: Comparison of HG-AAS and ICP-MS

\begin{tabular}{|c|c|c|}
\hline Sample & $\begin{array}{c}\text { HG-AAS, Bangladesh } \\
\mathrm{ppb}\end{array}$ & $\begin{array}{c}\text { ICP-MS, Berkeley } \\
\mathrm{ppb}\end{array}$ \\
\hline \hline 1 & 4.49 & 5.0 \\
\hline 2 & 333 & 440 \\
\hline 3 & 515 & 670 \\
\hline 4 & 67.8 & 98 \\
\hline 5 & 92.6 & 130 \\
\hline 6 & 2.2 & 0 \\
\hline 7 & 267 & 310 \\
\hline 8 & 265 & 310 \\
\hline
\end{tabular}

Table 3: Comparison of GF-AAS and ICP-MS, July 2007

\begin{tabular}{|c|c|c|}
\hline Sample & $\begin{array}{c}\text { GF-AAS, Bangladesh } \\
\text { ppb }\end{array}$ & $\begin{array}{c}\text { ICP-MS, Berkeley } \\
\text { ppb }\end{array}$ \\
\hline \hline 1 & 0 & 0 \\
\hline 2 & 480 & 460 \\
\hline 3 & 43 & 41 \\
\hline 4 & 43 & 41 \\
\hline 5 & 200 & 200 \\
\hline 6 & 170 & 170 \\
\hline
\end{tabular}

analysis. Eight samples were sent for both HG-AAS analysis and ICP-MS analysis. Results are presented in Table 2. Samples 1-5 are Bangladesh groundwater, sample 6 is de-ionized water taken from LBNL, and samples 7-8 are the same: As(V)-spiked de-ionized water samples made in Berkeley. Exonics HG-AAS lab results were consistently lower than ICP-MS results. We decided not to use HG-AAS for our future work.

\subsection{Graphite Furnace Atomic Absorption Spectrometry (GF-AAS)}

During our second trip to Bangladesh we sent (un-acidified) water samples to the Environmental Engineering Laboratory in the Department of Civil Engineering at BUET. Again we sent duplicate samples for GF-AAS analysis and ICP-MS analysis. Results are in Table 3. Sample 1 is de-ionized water taken from LBNL, samples 2-4 are standards $(\mathrm{As}(\mathrm{V})$ spiked de-ionized water) that were made in Berkeley (note that 3 and 4 are the same), and samples 5 and 6 are Bangladesh groundwater. ICP-MS and GF-AAS results were similar and it was decided to use GF-AAS in Bangladesh during our third trip. BUET reports a standard error of $+/-10 \%$ for GF-AAS measurements.

We also had four standards (As(V) spiked de-ionized water) analyzed by GF-AAS at BUET during our third trip to Bangladesh. We had the same standards analyzed by ICP-MS in Berkeley. Table 4 shows that again GF-AAS and ICP-MS results were similar, although the ICP-MS measurements seem biased high given the measurement of $9.1 \mathrm{ppb}$ arsenic in de-ionized water (sample 1).

Note that a number of discrepancies arose between GF-AAS and ICP-MS measurements of Bangladesh groundwater during the third trip to Bangladesh. Further discussion is in section 5.2.5. 
Table 4: Comparison of GF-AAS and ICP-MS, June 2008

\begin{tabular}{|c|c|c|}
\hline Sample & $\begin{array}{c}\text { GF-AAS, Bangladesh } \\
\text { ppb }\end{array}$ & $\begin{array}{c}\text { ICP-MS, Berkeley } \\
\mathrm{ppb}\end{array}$ \\
\hline \hline 1 & 0 & 9.1 \\
\hline 2 & 9.9 & 13 \\
\hline 3 & 100 & 120 \\
\hline 4 & 1100 & 1200 \\
\hline
\end{tabular}

\subsection{As(III) Speciation Cartridges}

Bangladesh groundwater generally contains $50-100 \%$ As(III). As(III) speciation cartridges were obtained from MetalSoft Center, NJ, USA. The cartridges consist of a sand filter containing aluminum silicate. Water containing $\mathrm{As}(\mathrm{III})$ and $\mathrm{As}(\mathrm{V})$ can be forced through the cartridge with a plastic syringe. As(V) adsorbs to the aluminum silicate, while As(III) passes through the cartridge. Total As(III) can then be determined by measuring the total arsenic concentration of the effluent using any of the arsenic testing methods above. Unfortunately, if precipitates have formed it is possible for As(III) to form complexes which can not pass through the cartridge's sand filter. Therefore, if precipitates are present, As(III) measurements are actually a lower bound on the As(III) in the sample.

\section{ARUBA Laboratory Methods \& Results}

This section presents laboratory analysis of ARUBA's performance. It starts with a description of the ARUBA manufacturing process, and the laboratory procedure used to treat water with ARUBA. Results of tests to determine ARUBA's arsenic removal capacity are presented. ARUBA's particle size and arsenic removal kinetics are discussed. This section also includes results of experiments that aimed to scale-up the ARUBA manufacturing process.

\subsection{Manufacturing ARUBA}

Bottom ash is a finely powdered residue found at the bottom of coal-fired boilers after combustible matter has been burned off. It is sterile because it is baked at close to $800{ }^{\circ} \mathrm{C}$. Several researchers have investigated using bottom ash to remove hazardous textile dyes from water $(63,33)$. In addition, others have investigated the use of fly ash (the even more finely powdered residue that becomes airborne and is generally trapped in coal plant chimneys) to treat waste water, remove dyes, and remove toxic ions such as boron, fluoride, and arsenic $(92,24)$.

ARUBA is manufactured through a simple process of coating bottom ash with oxides, hydroxides, and oxyhydroxides of iron. The process, illustrated in Figure 1, requires readily available, inexpensive chemicals, and does not require advanced equipment. To make $100 \mathrm{~g}$ of ARUBA, $156.75 \mathrm{~g}$ of solid hydrated ferrous sulfate $\left(\mathrm{FeSO}_{4}\right)$ is added to $600 \mathrm{ml}$ of de-ionized water and stirred for five minutes. One hundred grams of bottom ash (obtained from a coal fired power plant in Eklahare, Nasik, Maharashtra, India) ${ }^{1}$ is added to the $\mathrm{FeSO}_{4}$ solution and stirred for one hour. After 15 minutes of settling, the solution is decanted. Next, 100 $\mathrm{ml}$ of $0.5 \mathrm{M}$ of $\mathrm{NaOH}$ solution (2 grams of $\mathrm{NaOH}$ in $100 \mathrm{ml}$ of water) is added and stirred for five minutes. Again, the solution is left to settle for 15 minutes and then decanted. The remaining mixture is spread evenly onto a large Pyrex dish (13" x 9") and set in a fume hood to air-dry overnight, allowing for oxidation of the ferric coating. The following day, the media is scraped into a beaker using a metal spatula and rinsed three consecutive times with $\sim 500 \mathrm{ml}$ of de-ionized water, decanting between each rinse. This process lowers

\footnotetext{
${ }^{1}$ Note that we currently do not wash the coal ash before it is coated with rust. However, in the future it would be worthwhile to integrate a washing step in to our protocol in order to remove chemical contaminants.
} 
Figure 1: ARUBA Manufacturing Process Diagram

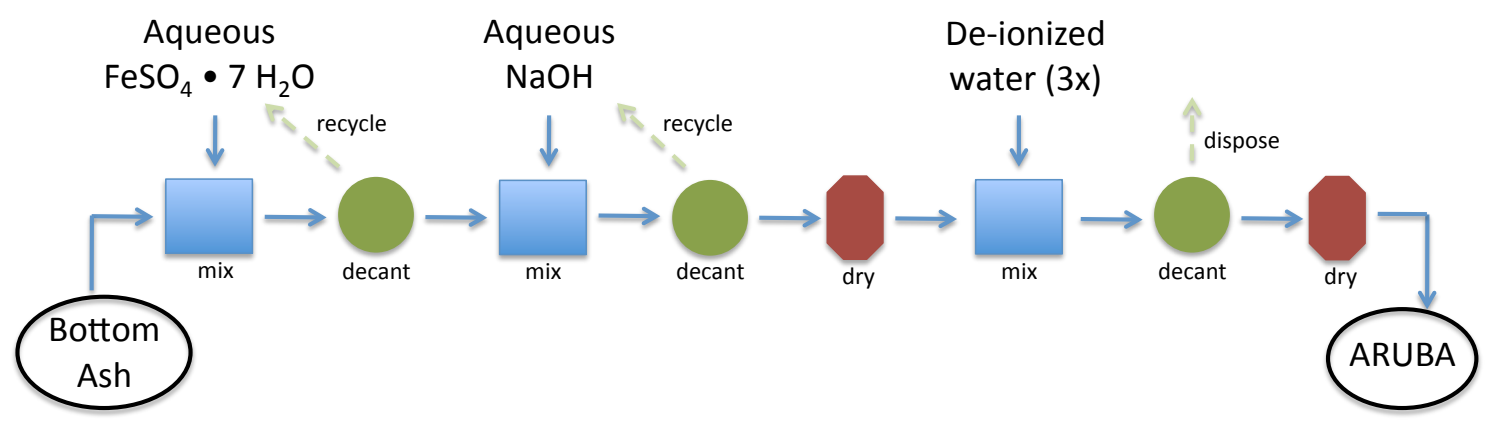

Figure 2: Un-Coated Coal Ash (left) and ARUBA (right)

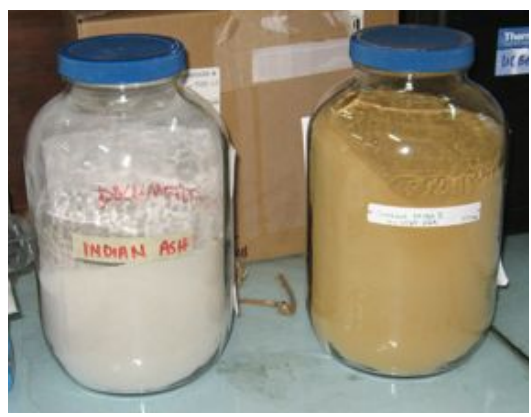

its $\mathrm{pH}$ and removes excess iron. The media is again spread onto Pyrex dish and dried overnight in a fume hood. On the third day the media is scraped and stored. Figure 2 shows jars of un-coated coal ash and ARUBA.

The process chemistry can be approximated as follows:

1. Ash is soaked in $\mathrm{FeSO}_{4}$ solution, depositing hydrated $\mathrm{Fe}(\mathrm{II})$ on the ash surface. The unknown extent of hydration is indicated by $\alpha$.

$$
\mathrm{Ash}_{\mathrm{s}}+\mathrm{Fe}^{2+}+\alpha \mathrm{H}_{2} \mathrm{O} \Rightarrow \mathrm{Ash} \bullet \mathrm{Fe}\left(\mathrm{H}_{2} \mathrm{O}\right)^{2+}{ }_{\alpha, s}
$$

2. Ash is soaked in $\mathrm{NaOH}$ and $\mathrm{OH}^{-}$displaces water ligands to produce ferrous hydroxide on the ash surface.

$$
\text { Ash } \bullet \mathrm{Fe}\left(\mathrm{H}_{2} \mathrm{O}\right)^{2+}{ }_{\alpha, s}+2 \mathrm{OH}^{-} \Rightarrow \mathrm{Ash} \bullet \mathrm{Fe}(\mathrm{OH})_{2, s}+\alpha \mathrm{H}_{2} \mathrm{O}
$$

3. During the drying process, exposure to air oxidizes the ferrous hydroxide to ferric hydroxide on the ash surface. The molar ratios of oxygen, water and $\mathrm{H}+$ are indicated below by $\beta, \gamma$ and $\eta$, respectively.

$$
\operatorname{Ash} \bullet \mathrm{Fe}(\mathrm{OH})_{2, \mathrm{~s}}+\beta \mathrm{O}_{2}+\gamma \mathrm{H}_{2} \mathrm{O} \Rightarrow \mathrm{Ash} \bullet \mathrm{Fe}(\mathrm{OH})_{3, \mathrm{~s}}+\eta \mathrm{H}^{+}
$$


The method used to deposit iron hydroxide on to substrate surfaces has been shown to affect significantly the adsorptive capacity of the resulting media $(95,41)$. Huang et al. (1989) found that ferrous perchlorate produced better results than ferrous sulfate in coating activated carbon with ferric oxides. We have not tried using ferrous perchlorate to make ARUBA.

Huang et al. (1989) also found that the optimal time for soaking their substrate in aqueous iron salt was 4-6 hours. It is possible that increasing the length of time that bottom ash is mixed in the ferrous sulfate solution during the ARUBA manufacturing process could enhance ARUBA's ability to remove arsenic.

\subsection{Arsenic Removal Capacity}

Every batch of ARUBA is tested for its ability to remove arsenic. Arsenic removal capacity is defined as the milligrams of arsenic removed per gram of ARUBA added. This number can be computed by subtracting the final arsenic concentration from the initial arsenic concentration of the water treated and dividing by the concentration of ARUBA used.

The exact mechanism for arsenic removal is still unknown, but likely complex. Any number of reactions could allow arsenic to bind to ARUBA's rust coating. Possible reactions between $\mathrm{As}(\mathrm{V})$ and iron hydroxide $[\mathrm{Fe}(\mathrm{III})]$ and iron oxide $[\mathrm{Fe}(\mathrm{II})]$ include:

$$
\begin{gathered}
\mathrm{Fe}(\mathrm{OH})_{3}+\mathrm{As}^{+5}+\mathrm{H}_{2} \mathrm{O} \Rightarrow \mathrm{FeAsO}_{4}+5 \mathrm{H}^{+} \\
\mathrm{Fe}(\mathrm{OH})_{3}+\mathrm{H}_{3} \mathrm{AsO}_{4} \Rightarrow \mathrm{FeAsO}_{4} \bullet 2 \mathrm{H}_{2} \mathrm{O}+\mathrm{H}_{2} \mathrm{O} \\
\mathrm{Fe}(\mathrm{OH})_{3}+\mathrm{AsO}_{4}{ }^{3-}+5 \mathrm{H}+\mathrm{FeH}_{2} \mathrm{AsO}_{4}+3 \mathrm{H}_{2} \mathrm{O} \\
\mathrm{Fe}(\mathrm{OH})_{3}+\mathrm{AsO}_{4}{ }^{3-}+4 \mathrm{H}^{+} \Rightarrow \mathrm{FeHAsO}_{4}^{-}+3 \mathrm{H}_{2} \mathrm{O} \\
\mathrm{Fe}(\mathrm{OH})_{3}+\mathrm{AsO}_{4}{ }^{3-} \Rightarrow \mathrm{FeAsO}_{4}+3 \mathrm{OH}^{-} \\
\mathrm{Fe}(\mathrm{OH})_{2}+\mathrm{As}^{+5} 2 \mathrm{H}_{2} \mathrm{O} \Rightarrow \mathrm{FeAsO}_{4}+6 \mathrm{H}^{+} \\
\mathrm{Fe}(\mathrm{OH})_{2}+\mathrm{H}_{3} \mathrm{AsO}_{4} \Rightarrow \mathrm{FeAsO}_{4} \bullet 2 \mathrm{H}_{2} \mathrm{O}+2 \mathrm{H}^{+} \\
\mathrm{Fe}(\mathrm{OH})_{2}+\mathrm{AsO}_{4}{ }^{3-}+4 \mathrm{H}^{+} \Rightarrow \mathrm{FeH}_{2} \mathrm{AsO}_{4}+2 \mathrm{H}_{2} \mathrm{O} \\
\mathrm{Fe}(\mathrm{OH})_{2}+\mathrm{AsO}_{4}{ }^{3-}+3 \mathrm{H}^{+} \Rightarrow \mathrm{FeHAsO}_{4}^{-}+2 \mathrm{H}_{2} \mathrm{O} \\
\mathrm{Fe}(\mathrm{OH})_{2}+\mathrm{AsO}_{4}{ }^{3-} \Rightarrow \mathrm{FeAsO}_{4}+2 \mathrm{OH}^{-}
\end{gathered}
$$

\subsubsection{Capacity Test - Laboratory Protocol}

Arsenic removal capacity of a given batch of ARUBA is tested in the laboratory by adding $0.50 \mathrm{~g}$ of ARUBA to $250 \mathrm{ml}$ of $2 \mathrm{ppm} \mathrm{As}(\mathrm{V})$ spiked de-ionized water and stirring, using a magnetic stir plate, for one hour. The solution is left to settle for 15 minutes and then filtered through Whatman Grade Number 40 Quantitative filter paper (particle retention of $8 \mu \mathrm{m}$ ) with a vacuum pump. The filtered water is sampled and tested for total arsenic by ICP-MS. Two capacity tests are always performed side-by-side and results are averaged for accuracy.

\subsubsection{Laboratory Results}

Capacity test results of ten $100 \mathrm{~g}$ batches of ARUBA made between 2005 and 2007 are as presented in Table 5. Initial and final arsenic concentrations reported are ICP-MS measurements, adjusted by the appropriate dilution factor. Though ICP-MS measurements are only good to two significant figures, more have been included in this table to illustrate our calculations. Additional figures were dropped after computation of the averages. In each case, our aim was to start with a concentration of $2000 \mathrm{ppb}$; however, initial concentrations 
Table 5: Capacity Test Results - Fresh ARUBA (ICP-MS)

\begin{tabular}{|c|c|c|c|c|}
\hline $\begin{array}{c}\text { ARUBA } \\
\text { Batch }\end{array}$ & $\begin{array}{c}\text { Initial Concentration } \\
\mathrm{ppb}\end{array}$ & $\begin{array}{c}\text { Final Concentration } \\
\mathrm{ppb}\end{array}$ & $\begin{array}{c}\text { Arsenic Removal } \\
\mathrm{ppb}\end{array}$ & $\begin{array}{c}\text { Capacity } \\
\mathrm{mg} \text { As / g ARUBA }\end{array}$ \\
\hline \hline 1 & 2111 & 98 & 2013 & 1.01 \\
\hline 2 & 1778 & 52 & 1726 & 0.86 \\
\hline 3 & 2111 & 114 & 1997 & 1.00 \\
\hline 4 & 2111 & 156 & 1956 & 0.98 \\
\hline 5 & 2000 & 8.9 & 1991 & 1.00 \\
\hline 6 & 2000 & 16 & 1984 & 0.99 \\
\hline 7 & 1889 & 5.8 & 1883 & 0.94 \\
\hline 8 & 1889 & 11 & 1878 & 0.94 \\
\hline 9 & 1889 & 12 & 1877 & 0.94 \\
\hline 10 & 1889 & 8.6 & 1880 & 0.94 \\
\hline 11 & 2000 & 12 & 1988 & 0.99 \\
\hline \hline Averages & $\mathbf{2 0 0 0}$ & $\mathbf{4 5}$ & $\mathbf{1 9 0 0}$ & $\mathbf{0 . 9 6}$ \\
\hline
\end{tabular}

Table 6: Capacity Test Results - Reuse of Spent ARUBA (ICP-MS)

\begin{tabular}{|c|c|c|c|c|}
\hline $\begin{array}{c}\text { ARUBA } \\
\text { Batch }\end{array}$ & $\begin{array}{c}\text { Initial Concentration } \\
\mathrm{ppb}\end{array}$ & $\begin{array}{c}\text { Final Concentration } \\
\mathrm{ppb}\end{array}$ & $\begin{array}{c}\text { Arsenic Removal } \\
\mathrm{ppb}\end{array}$ & $\begin{array}{c}\text { Capacity } \\
\mathrm{mg} \mathrm{As} / \mathrm{g} \text { ARUBA }\end{array}$ \\
\hline \hline 3 & 2111 & 517 & 3591 & 1.80 \\
\hline 5 & 1889 & 59 & 3821 & 1.91 \\
\hline 6 & 1889 & 37 & 3837 & 1.92 \\
\hline 7 & 1889 & 18 & 3754 & 1.88 \\
\hline 8 & 1889 & 37 & 3730 & 1.87 \\
\hline 9 & 1889 & 21 & 3745 & 1.87 \\
\hline 10 & 1889 & 35 & 3734 & 1.87 \\
\hline 11 & 1889 & 50 & 3827 & 1.91 \\
\hline \hline Averages & $\mathbf{1 9 0 0}$ & $\mathbf{9 7}$ & $\mathbf{3 8 0 0}$ & $\mathbf{1 . 9}$ \\
\hline
\end{tabular}

range from $1778 \mathrm{ppb}$ to $2111 \mathrm{ppb}$. This is due to the fact that the capacities tests were conducted with several different water batches and dilutions were not perfect. The variation may also be in part due to error in ICP-MS measurements.

In some cases, the spent ARUBA was dried and used in a second capacity test (again starting with $\sim 2 \mathrm{ppm}$ $\mathrm{A}(\mathrm{V})$ spiked de-ionized water) to determine if the spent ARUBA was able to remove more arsenic. Results are presented in Table 6 . Here the arsenic removal capacity includes the total amount of arsenic removed in both the first and second water treatment. As can be seen, 'spent' ARUBA can remove even more arsenic, though is unable to achieve final arsenic concentrations as low as after the first water treatment. This has important implications for efficient ARUBA use. A water treatment system could re-use the same ARUBA several times to remove the bulk of the arsenic from the water. Then, fresh ARUBA could be added to achieve final arsenic concentrations below the MCL desired.

\subsubsection{Arsenic Removal Capacity Versus Initial Arsenic Concentration in the Laboratory}

Arsenic removal capacity (of fresh ARUBA) can be plotted versus initial arsenic concentration, as seen in Figure 3. The relationship is approximately linear with arsenic removal capacity increasing with increased initial arsenic concentration. Arsenic removal capacity over a larger range of initial arsenic concentrations 
Figure 3: Arsenic Removal Capacity v. Initial Arsenic Concentration (ICP-MS)

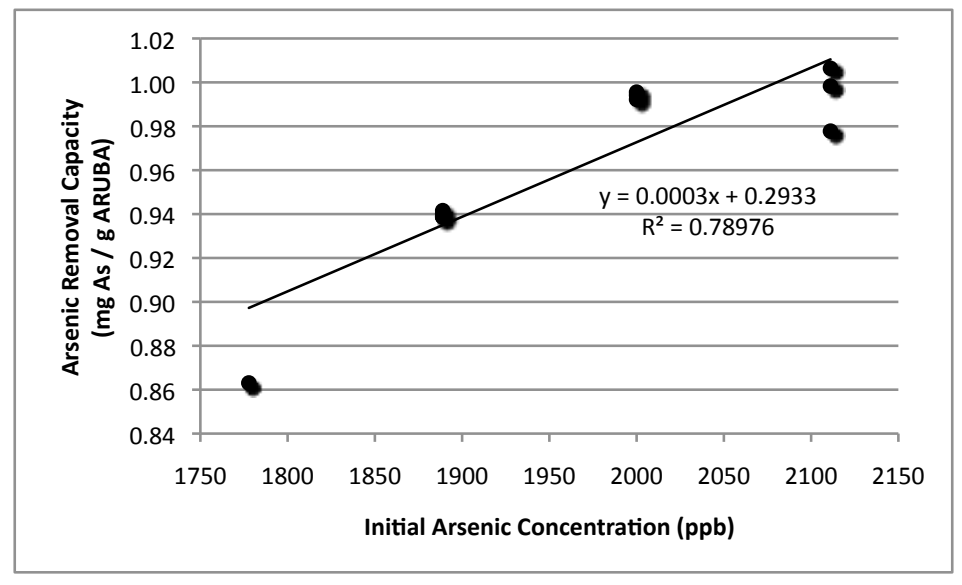

Figure 4: Arsenic Removal Capacity v. Initial Arsenic Concentration: Projected to Origin (ICP-MS)

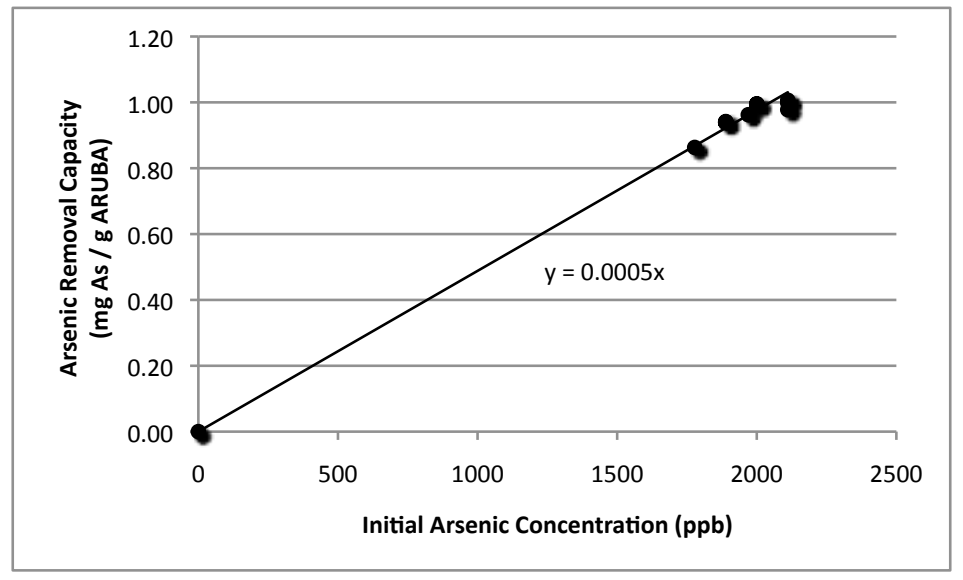

has not been tested in the laboratory; however, based on field results presented in Section 5.1.6, we believe that this linear trend holds.

Forcing the regression line to converge to the origin, which is reasonable given that we expect the arsenic removal capacity to be zero for water with no arsenic, we get the plot in Figure 4. This regression can be used to predict the performance of ARUBA in treating $\mathrm{As}(\mathrm{V})$ spiked de-ionized water. In Sections 5.1.6 and 5.2 .5 , this regression will be compared to that of the field data.

\subsubsection{Arsenic Removal Capacity of Un-coated Bottom Ash}

Given the success that some researchers have seen in removing arsenic and other toxins with un-coated coal ash, as described in Section 4.1, we sought to compare the arsenic removal capacity of un-coated bottom ash to that of ARUBA. Two capacity tests were performed, one with $0.50 \mathrm{~g}$ of un-coated ash and a second with $0.50 \mathrm{~g}$ of ARUBA, using $250 \mathrm{ml}$ of $1300 \mathrm{ppb}^{2} \mathrm{As}(\mathrm{V})$ spiked de-ionized water. Results are presented in Table 7. ARUBA far out-performs un-coated Indian bottom ash, indicating that ARUBA's ferric coating is essential for arsenic removal.

\footnotetext{
${ }^{2}$ Due to an inaccurate dilution the initial arsenic concentration was $1300 \mathrm{ppb}$ instead of $2000 \mathrm{ppb}$.
} 
Table 7: Performance of Un-coated Ash v. ARUBA (ICP-MS)

\begin{tabular}{|c|c|c|}
\hline & $\begin{array}{c}\text { Initial Arsenic Concentration } \\
\mathrm{ppb}\end{array}$ & $\begin{array}{c}\text { Final Arsenic Concentration } \\
\mathrm{ppb}\end{array}$ \\
\hline \hline Un-coated Indian Bottom Ash & 1300 & 1200 \\
\hline ARUBA & 1300 & 5.6 \\
\hline
\end{tabular}

Table 8: Final Arsenic Concentration v. Length of ARUBA Treatment (ICP-MS)

\begin{tabular}{|c|c|c|c|}
\hline Water Batch & $\begin{array}{c}\text { Initial As Concentration } \\
\mathrm{ppb}\end{array}$ & $\begin{array}{c}\text { Final As Conc (1h 15min) } \\
\mathrm{ppb}\end{array}$ & $\begin{array}{c}\text { Final As Conc (25h) } \\
\mathrm{ppb}\end{array}$ \\
\hline \hline 1 & 1900 & 90 & 33 \\
\hline 2 & 1900 & 64 & 43 \\
\hline
\end{tabular}

\subsection{Arsenic Removal Kinetics}

Initial results seemed to imply that arsenic treatment is completed after one hour of stirring ARUBA into contaminated water (70). However, subsequent results from both the field and laboratory indicated that one hour might not be sufficient time for treatment. In addition, several studies on arsenic adsorbents indicate that optimal treatment periods of much more than one hour. Roberts et al. (2004) found that equilibrium is not reached for adsorption of arsenic to $\mathrm{Fe}(\mathrm{II}) / \mathrm{Fe}$ (III) for four to five hours and Diamadopoulos et al. (1993) found that equilibrium of adsorption of arsenic to un-coated fly ash is reached in 72 hours.

A simple test was done to determine if treatment is completed after one hour. Capacity tests were performed by adding $0.25 \mathrm{~g}$ of ARUBA to $250 \mathrm{ml}$ of $1900 \mathrm{ppb} \mathrm{As}(\mathrm{V})$ spiked de-ionized water. Samples were taken after one hour of stirring, 15 minutes of settling, and filtration. Samples were also taken after one hour of stirring, 24 hours of settling, and filtration. Results are presented in Table 8. Results indicate that treatment is not complete after 1 hour. This also implies that arsenic removal capacity results presented in the previous section under-estimate ARUBA's actual arsenic removal capacity. A thorough analysis was not performed on $\mathrm{As}(\mathrm{V})$ spiked de-ionized water to determine when equilibrium is reached. However, this experiment was performed in the field and Section 5.2.2 presents these results for Bangladesh groundwater.

\subsection{ARUBA Particle Sizes}

Though Scanning Electron Micrograph (SEM) imaging (Figure 5) it has been inferred that ARUBA particles are spherical and approximately 1 to $10 \mu \mathrm{m}$ in diameter.

Particle size can also be indirectly assessed through comparison of the performance of ARUBA when filtered through filter paper of different pore sizes. An experiment was run using a modified version of the capacity test protocol presented above. For this experiment $0.25 \mathrm{~g}$ of ARUBA was used to treat $250 \mathrm{ml}$ of $2100 \mathrm{ppb}$ $\mathrm{As}(\mathrm{V})$ spiked de-ionized water (the purpose of the lower dose of ARUBA was to be able to better differentiate the results). Four different filters, each with a different nominal pore size, were used to remove ARUBA from the treated water. Samples of the filter effluents were analyzed with ICP-MS, which measures both dissolved arsenic and arsenic bound to ARUBA particles that pass through the filters. Results are presented in Figure 9.

Final arsenic concentrations of water filtered through Whatman Grade Number 42 filter paper and Millipore filter paper are approximately the same, while final arsenic concentrations of for the larger pore sized filter paper are much higher, indicating that the smallest ARUBA particles are greater than $\sim 2.5 \mu \mathrm{m}$.

The above experiment was repeated; however, instead of taking samples for arsenic analysis turbidity was measured with an Nephelometric Turbidity Units (NTU) meter. Results in Table 10 are consistent with those 
Figure 5: Scanning Electron Micrographs of Un-coated Bottom Ash (left) and ARUBA (right).
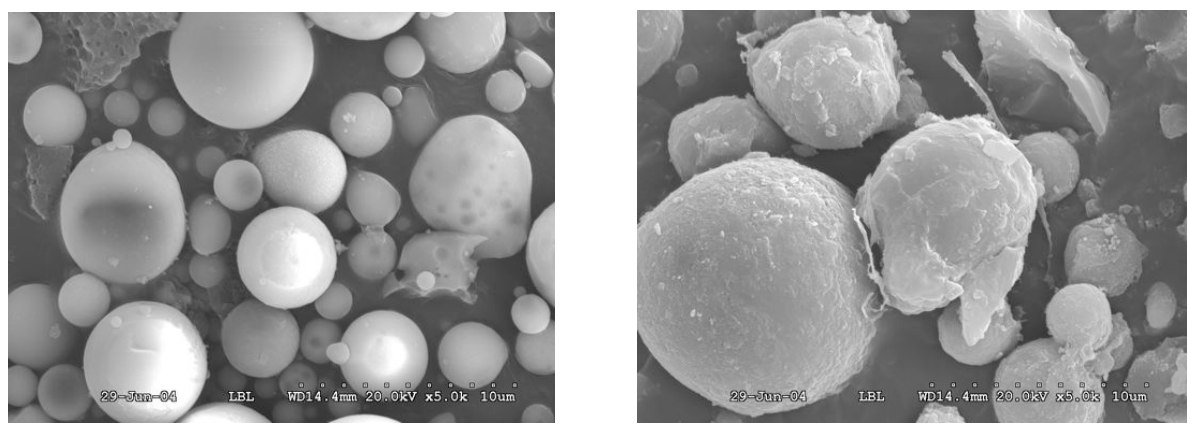

Table 9: Final Arsenic Concentration v. Filter Size (ICP-MS)

\begin{tabular}{|c|c|c|}
\hline Filter & $\begin{array}{c}\text { Nominal Pore Size } \\
\mu \mathrm{m}\end{array}$ & $\begin{array}{c}\text { Final Arsenic Concentration } \\
\mathrm{ppb}\end{array}$ \\
\hline \hline \#1 Whatman & 11 & 320 \\
\hline \#40 Whatman & 8 & 190 \\
\hline \#42 Whatman & 2.5 & 110 \\
\hline Millipore & 0.1 & 120 \\
\hline
\end{tabular}

presented above since the post-filtration turbidity decreases with decreased nominal pore size, indicating that less particles pass through filter paper with smaller pores.

The size of ARUBA is lower-bounded by the fact that small particles of ash (less than $1 \mu \mathrm{m}$ ) become fly ash, not bottom ash. In order to upper-bound the size of ARUBA particles one would need to sieve the ash. Our current ARUBA manufacturing protocol does not include a sieving step; however, this would be worthwhile because we have noted large rocky particles in Indian bottom ash, some of which we have picked out by hand in the past.

\subsection{Scaling up the Production of ARUBA}

Commercial use of ARUBA would necessitate the production of large quantities of the material in a manufacturing facility. To discover ways in which ARUBA could be manufactured efficiently at large-scale, a number of experiments were conducted to determine how ARUBA's arsenic removal capacity varies with changes in the manufacturing protocol. Our goal was to make the process both easier and faster.

Prior to the adoption of the ARUBA manufacturing protocol outlined in Section 4.1, ARUBA was spread to

Table 10: Post-Filtration Turbidity v. Filter Size

\begin{tabular}{|c|c|c|}
\hline Filter & $\begin{array}{c}\text { Nominal Pore Size } \\
\mu \mathrm{m}\end{array}$ & $\begin{array}{c}\text { Post-Filtration Turbidity } \\
\text { NTU }\end{array}$ \\
\hline \hline Whatman Grade Number 1 & 11 & 2.970 \\
\hline Whatman Grade Number 40 & 8 & 2.307 \\
\hline Whatman Grade Number 42 & 2.5 & 0.940 \\
\hline Millipore & 0.1 & N/A \\
\hline
\end{tabular}


Figure 6: Drying ARUBA in Thin Layers on Laboratory Glassware, Part of the Former ARUBA Manufacturing Protocol

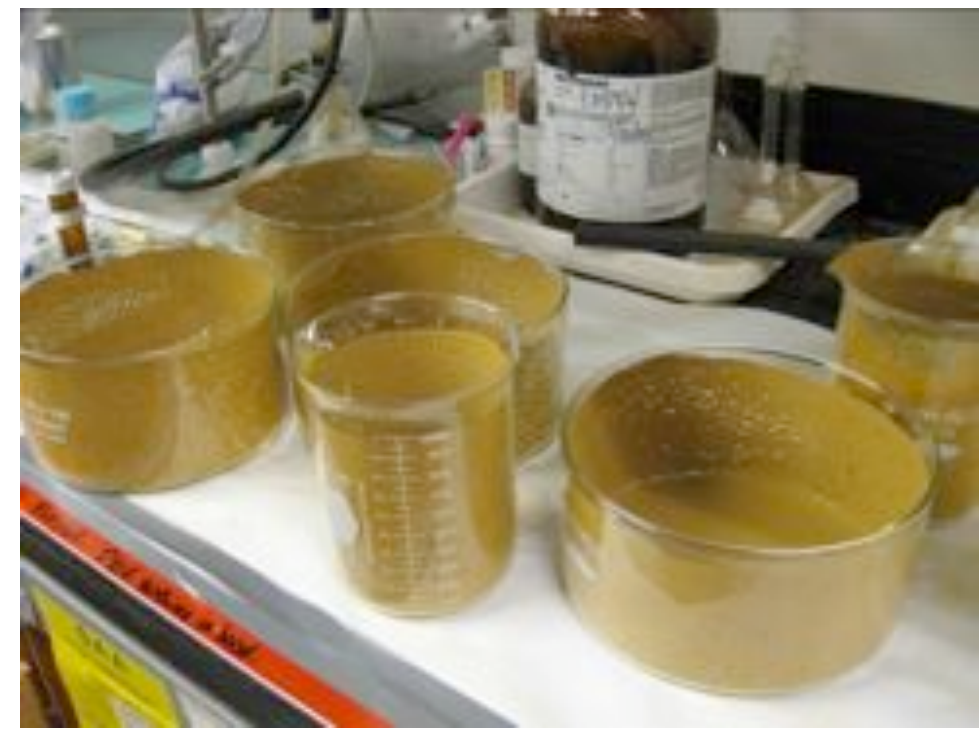

dry in very thin layers on borosilicate glassware (laboratory beakers) as it was believed that a thin drying layer was needed to ensure proper oxidation of the ferrous coating to ferric hydr(oxides). See Figure 6. One $100 \mathrm{~g}$ batch of ARUBA would be spread over upwards of ten large pieces of glassware, a labor- and time-intensive process. Results presented in this section show that using borosilicate glassware and spreading ARUBA in thin layers is not necessary, and so the manufacturing protocol was amended to the one presented in Section 4.1 above.

\subsubsection{Drying ARUBA on Various Materials}

A number of new surfaces were proposed on which we could dry ARUBA including metal racks and ceramic pans. An experiment was conducted to determine if the material on which ARUBA is set to dry affects ARUBA's arsenic removal capacity. Five materials were compared: Pyrex (baking pans), stainless steel (sheeting), Teflon (flexible sheeting), ceramic (old photo tray), and glass (borosilicate beakers), which was used as a control.

ARUBA was manufactured and set to dry on each of the materials. ${ }^{3}$ Initial and final arsenic concentrations for water treated with ARUBA that was made on each material are shown in Table 11. Samples were not sent for ICP-MS analysis and so QuickTest results are reported. Note that since QuickTest is not particularly accurate, the difference between these results is not significant. Therefore, ARUBA made on each material seems to perform comparably. As the Pyrex dish proved the easiest to work with, it has been incorporated into the current manufacturing protocol.

\subsubsection{Varying the Thickness of the Drying Layer}

As mentioned above, initially it was thought that spreading ARUBA as thinly as possible on a drying surface was integral to the oxidation of the iron coating. However, repeated tests showed that drying ARUBA in thicker layers did not diminish its arsenic removal capacity. One $100 \mathrm{~g}$ batch of ARUBA was made and spread unequally into three Pyrex dishes (each 9" x 13"). The thickness of each drying layer was inferred

\footnotetext{
${ }^{3}$ Note that it was not easy to spread ARUBA on the Teflon or the stainless steel because it beaded up.
} 
Table 11: Arsenic Removal Capacity v. Drying Surface Material (QuickTest)

\begin{tabular}{|c|c|c|}
\hline Material & $\begin{array}{c}\text { Initial Arsenic Concentration } \\
\mathrm{ppb}\end{array}$ & $\begin{array}{c}\text { Final Arsenic Concentration } \\
\mathrm{ppb}\end{array}$ \\
\hline \hline Glass & 2000 & 30 \\
\hline Pyrex & 2000 & 14 \\
\hline Stainless Steel & 2000 & 35 \\
\hline Teflon & 2000 & 18 \\
\hline Ceramic & 2000 & 35 \\
\hline
\end{tabular}

Table 12: Arsenic Removal Capacity v. Drying Layer Thickness (QuickTest)

\begin{tabular}{|c|c|c|}
\hline Thickness & $\begin{array}{c}\text { Initial Arsenic Concentration } \\
\mathrm{ppb}\end{array}$ & $\begin{array}{c}\text { Final Arsenic Concentration } \\
\mathrm{ppb}\end{array}$ \\
\hline \hline$\sim 0.2 \mathrm{~cm}$ & 2000 & 37.5 \\
\hline$\sim 0.3 \mathrm{~cm}$ & 2000 & 25 \\
\hline$\sim 0.5 \mathrm{~cm}$ & 2000 & 7.5 \\
\hline
\end{tabular}

from the mass of ARUBA recovered from each dish. ARUBA from each dish underwent capacity tests. Table 12 shows the initial and final arsenic concentrations for each capacity test. Samples were not sent for ICP-MS analysis and so QuickTest results are reported. Since QuickTest is not very accurate, the most we can say is that ARUBA dried in layers between 0.2 and $0.5 \mathrm{~cm}$ performs comparably.

Later, a $100 \mathrm{~g}$ batch of ARUBA was made and poured to dry in one Pyrex dish (thickness $1 \mathrm{~cm}$ ). Again, it performed comparably to ARUBA made using the original manufacturing procedure. Unfortunately, using even thicker layers (e.g. $200 \mathrm{~g}$ in one Pyrex dish) lengthened the needed air dry time to beyond 24 hours, which was deemed unacceptable (though the media's arsenic removal capacity was comparable to that of ARUBA made using the original manufacturing procedure). The ARUBA manufacturing protocol was therefore modified from the original (spreading as thinly as possible on glassware) to simply pouring $100 \mathrm{~g}$ of ARUBA into one Pyrex dish and spreading evenly. We have not found an upper bound to the thickness of the drying layer that could be used.

\subsubsection{Direct Scale-up of the ARUBA Manufacturing Protocol}

The ARUBA manufacturing protocol presented above has been successfully scaled many times by making 200 to $1000 \mathrm{~g}$ batches of ARUBA. Due to constraints in the size of laboratory equipment, no more than $500 \mathrm{~g}$ of coal ash are mixed into one beaker at a time. Also, given the results in the previous section, no more than $100 \mathrm{~g}$ of ARUBA are poured into a single Pyrex pan (Figure 7). Therefore, $1 \mathrm{~kg}$ ARUBA batches require two large mixing beakers and ten Pyrex pans.

Six $1 \mathrm{~kg}$ batches have been made. Arsenic removal capacity results are presented in Table 13. Again, though ICP-MS measurements are only good to two significant figures, more have been included in this table to illustrate our calculations. Additional figures were dropped after computation of the averages. Average capacity is high since the average initial arsenic concentration is greater than $2000 \mathrm{ppb}$, due to errors in dilutions. These results show that the $1 \mathrm{~kg}$ batches of ARUBA perform as well as $100 \mathrm{~g}$ batches of ARUBA.

Note that ARUBA batch 6 performed the worst of all the $1 \mathrm{~kg}$ batches in removing arsenic. While batches 1-5 used coal ash obtained from India several years ago, batch 6 used a new shipment of coal ash obtained in 2008. This coal ash seemed to contain impurities such as rocks and sandy aggregates. On the whole, it was not as finely grained as the previous shipment had been. Sieving the ash could have removed many of 
Figure 7: ARUBA Drying in Pyrex Pans

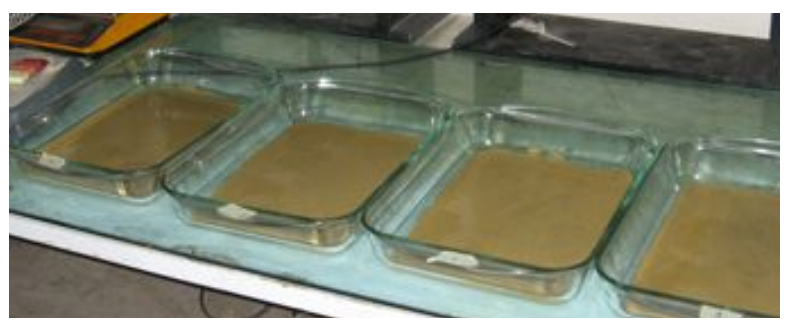

Table 13: $1 \mathrm{~kg}$ ARUBA Capacity Test Results (ICP-MS)

\begin{tabular}{|c|c|c|c|c|}
\hline $\begin{array}{c}\text { ARUBA } \\
\text { Batch }\end{array}$ & $\begin{array}{c}\text { Initial Concentration } \\
\mathrm{ppb}\end{array}$ & $\begin{array}{c}\text { Final Concentration } \\
\mathrm{ppb}\end{array}$ & $\begin{array}{c}\text { Arsenic Removal } \\
\mathrm{ppb}\end{array}$ & $\begin{array}{c}\text { Capacity } \\
\mathrm{mg} \text { As / g ARUBA }\end{array}$ \\
\hline \hline 1 & 2700 & 39 & 2661 & 1.33 \\
\hline 2 & 2200 & 38 & 2162 & 1.08 \\
\hline 3 & 2200 & 30 & 2170 & 1.09 \\
\hline 4 & 2200 & 54 & 2146 & 1.07 \\
\hline 5 & 2200 & 47 & 2153 & 1.08 \\
\hline 6 & 2200 & 83 & 2117 & 1.06 \\
\hline Averages & $\mathbf{2 3 0 0}$ & $\mathbf{4 9}$ & $\mathbf{2 2 0 0}$ & $\mathbf{1 . 1}$ \\
\hline
\end{tabular}

these large impurities, but this was not done. The presence of larger particles and impurities could have contributed to ARUBA's slightly diminished arsenic removal capacity.

These results may indicate that batches of ARUBA made from different batches of Indian bottom ash may perform differently. However, in order to assess this, more analysis would need to be done to quantify variations in ARUBA performance as a function of various bottom ash properties.

\subsubsection{Heat Drying}

The most time consuming part of the manufacturing procedure is waiting for the particles to dry after coating with sodium hydroxide and ferrous sulfate, and after the last de-ionized water wash. Therefore, we focused much of our effort on ways to speed-up the drying process, specifically through heat drying.

To determine if heat itself affects ARUBA's arsenic removal properties ARUBA was baked at various temperatures for 30 minutes and its arsenic removal capacity was measured. It was found that ARUBA baked between 220 and $400{ }^{\circ} \mathrm{F}$ removed the same amount of arsenic as un-baked ARUBA, as measured by QuickTest. Therefore, temperatures up to $400{ }^{\circ} \mathrm{F}$ do not seem to change the chemical properties of ARUBA.

Several different methods were used to heat dry ARUBA. Initially, a heat gun (pointed directly at the ARUBA in a Pyrex pan) and a hot plate kept at approximately $50{ }^{\circ} \mathrm{C}$ (on which a Pyrex pan containing was placed) were used to heat dry batches of ARUBA. Faster drying meant that the batches could be made in one day instead of three days. Arsenic removal results for batches made with heat drying were compared to a control batch that had been made over three days using air drying. QuickTest Results are presented in Figure 14.

The heat gun, which dried ARUBA the fastest, performed significantly worse than the the others. ARUBA dried by the heat gun appeared charred and was hard to scrape off the pan. Also, it did not turn its characteristic red-orange color indicating that the oxidation process was likely incomplete. ${ }^{4}$

\footnotetext{
${ }^{4}$ Several of the $1 \mathrm{~kg}$ ARUBA batches did not appear as deeply red-orange as ARUBA made in $100 \mathrm{~g}$ batches. Therefore, color may not directly correlate to the amount oxidation and/or the arsenic removal capacity.
} 
Table 14: Heat Drying Methods v. Final Arsenic Concentrations (QuickTest)

\begin{tabular}{|c|c|c|}
\hline & $\begin{array}{c}\text { Initial Arsenic } \\
\text { ppb }\end{array}$ & $\begin{array}{c}\text { Final Arsenic Concentration } \\
\text { ppb }\end{array}$ \\
\hline \hline Heat Gun (1 Day Process) & 2000 & 180 \\
\hline Hot Plate (1 Day Process) & 2000 & 38 \\
\hline Control (3 Day Process) & 2000 & 14 \\
\hline
\end{tabular}

Figure 8: ARUBA Drying in a Pyrex Dish on a Hot Plate

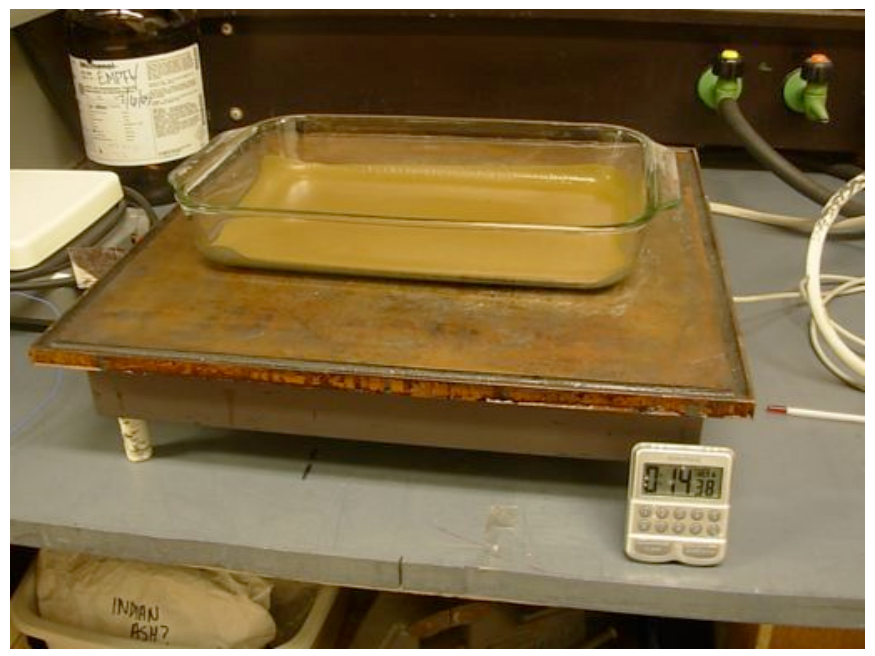

While ARUBA dried on the hot plate did not perform significantly worse than the control, it did not seem to dry evenly- the top remained moist while the bottom charred and was also hard to remove from the pan. See Figure ARUBA dried over the hot plate also appeared duller in color than the control batch. During the experiment it had been very difficult to maintain a constant temperature on the hot plate. Therefore, though this result left us hopeful that heat drying could work, it was decided not to continue using the hot plate. Instead, we sought a more controlled environment for future heat experiments.

The experiment was repeated using an oven. After adding and decanting both the ferrous sulfate and sodium hydroxide, $200 \mathrm{~g}$ of ARUBA was poured into two Pyrex pans, which was were placed in an oven at $120{ }^{\circ} \mathrm{C}$ for one hour. ARUBA was the scraped, rinsed with de-ionized water, decanted, and poured back into the pans. They were placed back in the oven at $120{ }^{\circ} \mathrm{C}$ until dry: $\sim 45$ minutes. Capacity test results using $2700 \mathrm{ppb}$ $\mathrm{As}(\mathrm{V})$ spiked de-ionized water showed a final arsenic concentration of $1300 \mathrm{ppb}$, as measured by ICP-MS.

Given this result, it was hypothesized that one hour is simply not sufficient time for ARUBA particles to oxidize. However, we were still hopeful that we could use heat drying for the second of the two drying steps since we presumed that oxidation is completed after the first drying step.

The above experiment was repeated with the exception that ARUBA was left to air dry after contact with ferrous sulfate and sodium hydroxide. After rinsing with de-ionized water, ARUBA was placed in the oven at $110{ }^{\circ} \mathrm{C}$ for approximately one hour. Capacity test results using $2100 \mathrm{ppb} \mathrm{As}(\mathrm{V})$ spiked de-ionized water showed a final arsenic concentration of $99 \mathrm{ppb}$, as measured by ICP-MS. While this is a significantly lower result than when ARUBA is heat dried twice, it is still worse than most (though not all) of ARUBA batches made with the three day air drying procedure. Unfortunately, this experiment was not repeated and so we do not know if this protocol modification would always produce high final arsenic concentrations, or if this is simply an outlier (like capacity test results of batches 3 and 4 in Section 4.2.2). If this protocol always produced high final arsenic concentrations this would imply that oxidation of ARUBA's coating continues 
during the drying period after the de-ionized water rinses.

All and all, these results were inconclusive. A more thorough analysis would need to be performed to determine if heat drying could be employed in the ARUBA manufacturing process. Perhaps lower temperatures and longer dry times would produce better results, while still speeding up the three day process. Also, perhaps a hot plate is a better solution than an oven after all because there is potential for more air to flow over the drying ARUBA.

\section{$5 \quad$ ARUBA Field Methods \& Results}

In 2007 and 2008, three trips were made to Bangladesh and one to Cambodia to test ARUBA's performance in removing arsenic from real groundwater. In addition, to determining ARUBA's arsenic removal capacity in the field we also aimed to determine a number of ARUBA's properties in interacting with groundwater. While ARUBA is able to lower arsenic concentrations in groundwater to below the Bangladesh and WHO MCL, unsurprisingly its arsenic removal capacity is diminished from that in the laboratory due to a number of differences between $\mathrm{As}(\mathrm{V})$ spiked de-ionized water and actual groundwater (namely, $\mathrm{As}(\mathrm{III})$ concentrations and competing ions). Results of all field experiments are discussed below.

\subsection{Arsenic Removal Capacity}

Our first goal in the field was to assess ARUBA's ability to remove arsenic from Bangladesh groundwater and compare results to those obtained in the laboratory.

\subsubsection{Capacity Test - Field Protocol}

In Bangladesh, arsenic removal capacity is measured using a different protocol than in the laboratory because logistical difficulties prevent the use of laboratory equipment. ARUBA treatment involves adding some amount (usually $1 \mathrm{~g}$ ) of ARUBA to $250 \mathrm{ml}$ of arsenic contaminated groundwater, collected in a $250 \mathrm{ml}$ bottle at the tubewell. The bottle is shaken vigorously for 30 seconds and then set down. Every 30 seconds for a total of half an hour the bottle is flipped to prevent the ARUBA from settling (Figure 9). After 30 minutes the solution is filtered through Whatman Grade Number 1 filter paper (particle retention of $11 \mu \mathrm{m}$ ) using a plastic funnel positioned over a clean $250 \mathrm{ml}$ bottle. The filtered water is sampled and tested for total arsenic.

Several different methods have been used to measure the amount of ARUBA required in a field experiment. A combination of small plastic scoops (taken from the QuickTest kit) were found to consistently dole out $\sim 1 \mathrm{~g}$ of ARUBA. In the laboratory, it was experimentally determined that one small and one large leveled scoops of ARUBA produced $0.95+/-0.01 \mathrm{~g}$ of ARUBA. The scoop method was used during the first trip to Bangladesh, though we did not consistently level the scoops and so the amount of ARUBA used in experiments was generally more than $0.95 \mathrm{~g}$ and less precise. The scoop method (including leveling) was used on the second trip to Bangladesh (and also by the team in Cambodia), with the exception of the dosing experiment discussed below, which required higher accuracy ARUBA mass measurements. An electronic balance was used to measure ARUBA for the dosing experiment. A portable electronic balance was used to measure ARUBA during the third trip to Bangladesh. Overall the precision of our ARUBA mass measurements vary between two and three significant figures.

Through several laboratory experiments conducted before our first trip to Bangladesh, it was found in that treating $\mathrm{As}(\mathrm{V})$ spiked de-ionized water with our field treatment protocol (which includes 30 minutes of waterARUBA contact time) produced results similar to that of the lab protocol (which includes 75 minutes of water-ARUBA contact time). However, we later learned that 30 minutes is not a sufficient amount of time for treating arsenic contaminated water, especially Bangladesh groundwater. Therefore, arsenic removal capacity results presented in the next few sections underestimate ARUBA's potential arsenic removal capacity. See Section 5.2.2 for details on ARUBA's arsenic removal kinetics in the field. 
Figure 9: Maintaining Particle Suspension during a Capacity Test in Bangladesh

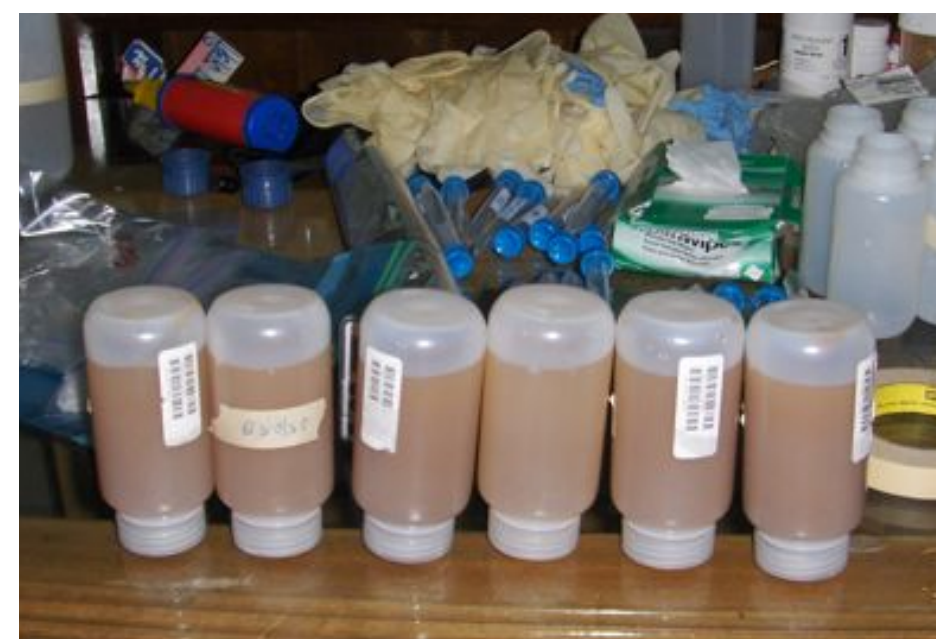

In addition, the filters used in all field experiments have a larger nominal pore size $(11 \mu \mathrm{m})$ than the filters used in the laboratory $(8 \mu \mathrm{m})$. Therefore, final arsenic concentrations are likely higher in the field in part because some ARUBA, to which arsenic is bound, is allowed to pass through the filter paper. Again, this results in an under-estimation of ARUBA's arsenic removal capacity in the field.

\subsubsection{Methods and Results from Bangladesh Trip 1}

To assess ARUBA's ability to remove arsenic from Bangladesh groundwater we traveled to Bangladesh in the spring of 2007. Villages containing tubewells with high levels of arsenic were identified by BRAC using the final report of their 1999-2000 arsenic study (18). BRAC employees, community leaders, and local villagers also helped us identify households with contaminated tubewells.

Tubewells thought to be contaminated with arsenic were tested with QuickTest. Parameters of all tubewells tested including our initial measurement of arsenic concentration are reported in Table 15. If arsenic levels were sufficiently high (in most cases, greater than $200 \mathrm{ppb}$ ), we collected one liter of water in a storage bottle after pumping the tubewell for five minutes in order to ensure that the sample would be free from biological contamination and oxygenated water in the tubewell column. Samples were not collected from tubewells 2, 5, 9 or 13 as arsenic concentrations were below our target, though a sample was collected from tubewell 6 in order to determine if low arsenic water behaves significantly different than high arsenic water.

Groundwater samples from tubewells $1,3,4,6,7,8,10$, and 11 were treated using the protocol outlined in the previous section. Samples were initially treated with $1 \mathrm{~g}$ of ARUBA per $250 \mathrm{ml}$ (single dose) the same evening of sample collection, or early the following morning. Treatment of water from each tubewell was undertaken at least twice to ensure repeatability and accuracy. One ARUBA batch (100 g Batch 3) was used for all the testing conducted throughout the course of this first trip to Bangladesh. Batch 3's laboratory arsenic removal capacity is reported in Section 4.2.2.

If after single dose treatment the arsenic level did not go below $50 \mathrm{ppb}$ (as measured by QuickTest), we repeated the treatment using a fresh water sample and twice as much ARUBA (2.0 g ARUBA per $250 \mathrm{ml}$, double dose). In three cases, we treated groundwater with $4.0 \mathrm{~g}$ ARUBA per $250 \mathrm{ml}$ (quadruple dose). Note that quadruple doses were always given as two consecutive double doses, meaning that after initial treatment with a double dose (including filtration of the ARUBA from the treated water), we added another double dose to the water, as opposed to adding all $4 \mathrm{~g}$ at once.

Directly before each ARUBA treatment, ten milliliter 'initial concentration' samples were taken from the storage bottles. These samples were later analyzed for arsenic by ICP-MS. In retrospect, it would have 
Table 15: Bangladesh Tubewells Sampled March 28, 2007 - April 5, 2007 (QuickTest)

\begin{tabular}{|c|c|c|c|c|c|c|c|c|c|}
\hline $\begin{array}{c}\text { Tubewell } \\
\text { Number }\end{array}$ & $\begin{array}{c}\text { Date Sampled } \\
\mathrm{m} / \mathrm{dd} / \mathrm{yy}\end{array}$ & District & Upazila & Union & Village & $\begin{array}{c}\text { As Conc } \\
\mathrm{ppb}\end{array}$ & $\begin{array}{c}\mathrm{pH} \\
\mathrm{DO} \\
\mathrm{mg} / \mathrm{L}\end{array}$ & $\begin{array}{c}\text { Temp } \\
{ }^{\circ} \mathrm{C}\end{array}$ \\
\hline \hline 1 & $3 / 28 / 07$ & Jessore & Jhikargachha & Godkhali & Kamalpoura & 300 & 6.99 & 1.75 & 26.4 \\
\hline 2 & $3 / 28 / 07$ & Jessore & Jhikargachha & Godkhali & Jafornagar & 30 & 7.04 & 2.67 & $\mathrm{n} / \mathrm{a}$ \\
\hline 3 & $3 / 28 / 07$ & Jessore & Jhikargachha & Godkhali & Jafornagar & 200 & 7.10 & 2.69 & 27.0 \\
\hline 4 & $3 / 28 / 07$ & Jessore & Jhikargachha & Godkhali & Yousufpur & 100 & 7.14 & 1.42 & 28.1 \\
\hline 5 & $3 / 28 / 07$ & Jessore & Jhikargachha & Godkhali & Patuapara & 10 & 7.35 & 1.25 & 28.1 \\
\hline 6 & $3 / 28 / 07$ & Jessore & Jhikargachha & Godkhali & Patuapara & 50 & 7.34 & 1.36 & 27.2 \\
\hline 7 & $3 / 29 / 07$ & Jessore & Avaynagar & Prembug & Prembug & 200 & 7.26 & 1.34 & 26.6 \\
\hline 8 & $3 / 29 / 07$ & Jessore & Avaynagar & Prembug & Prembug & 350 & 7.35 & 1.53 & 26.7 \\
\hline 9 & $3 / 29 / 07$ & Jessore & Avaynagar & Prembug & Prembug & 50 & 7.23 & 1.42 & $\mathrm{n} / \mathrm{a}$ \\
\hline 10 & $3 / 29 / 07$ & Jessore & Avaynagar & Prembug & Prembug & 250 & 7.25 & 1.36 & 26.6 \\
\hline 11 & $3 / 29 / 07$ & Jessore & Avaynagar & Prembug & Prembug & 200 & 7.16 & 1.30 & 26.8 \\
\hline 12 & $4 / 5 / 07$ & Narayanganj & Sonargaon & Aminpur & Bugmusha & 600 & 6.93 & 1.78 & 26.7 \\
\hline 13 & $4 / 5 / 07$ & Narayanganj & Sonargaon & Aminpur & Bugmusha & 5 & 6.95 & 2.36 & 27.9 \\
\hline
\end{tabular}

been best to take these samples directly from the well head since, in almost all cases, the lag time between collection and treatment was long enough so that precipitates had already begun to form in the one liter bottles. In fact, it was noted that the water began to change color only 30 minutes after collection. The precipitates were reddish-orange in color indicating high levels of iron, to which arsenic binds. Though we shook most one liter samples before sampling for ICP-MS it was impossible to ensure that a representative amount of precipitate ended up in the ICP-MS sample vial, which would be necessary in order to get a sense of the actual arsenic concentration of the sample. Alternatively we could have pre-filtered both the ICP-MS samples and the samples that were to be treated with ARUBA to get a sense for how much dissolved arsenic ARUBA removes during the treatment process. This was not done.

Samples of treated water were also collected for ICP-MS. In general, QuickTest results taken over the course of the trip showed poor correlation to ICP-MS results obtained upon return to Berkeley. In fact, QuickTest results were generally significantly lower than ICP-MS results. Therefore, QuickTest results of post-treatment arsenic concentration have not been reported in this document. However, in the field QuickTest results were helpful in getting a general sense for ARUBA's performance in removing arsenic.

\section{Single Dose (1 g per $250 \mathrm{ml})$ Results}

Results of the single dose $(1 \mathrm{~g}$ per $250 \mathrm{ml})$ treatment are given in Figure 10. Results show that $1 \mathrm{~g}$ of ARUBA is able to remove arsenic to below the Bangladesh MCL (50 ppb) in two of the tubewells tested (4 and 6). ARUBA achieved significant arsenic reduction in all of the wells.

\section{Double Dose $(2 \mathrm{~g}$ per $250 \mathrm{ml})$ Results}

Water from five of the wells $(1,3,7,8$, and 10) was treated with a double dose of ARUBA and results are reported in Figure 11. A double dose of ARUBA was able to lower arsenic concentrations to below the Bangladesh MCL in three more wells (1, 7, and 10).

A second set of 'initial concentration' ICP-MS samples were taken from each one liter storage bottle before double dose treatment. Those values have been reported here, though as explained above, it is likely that they are inaccurate because of the formation of precipitates in the one liter water samples. In fact, these are less likely to be accurate than the samples taken before the single dose treatment, because even more time had passed between sample collection and treatment. On average these values are lower than those presented above because these samples were often taken from the top of the container (without sufficient mixing) and therefore the sample vial did not capture many precipitates. 
Figure 10: Single Dose ARUBA Treatment in Bangladesh: $1 \mathrm{~g}$ per $250 \mathrm{ml}$ (ICP-MS)

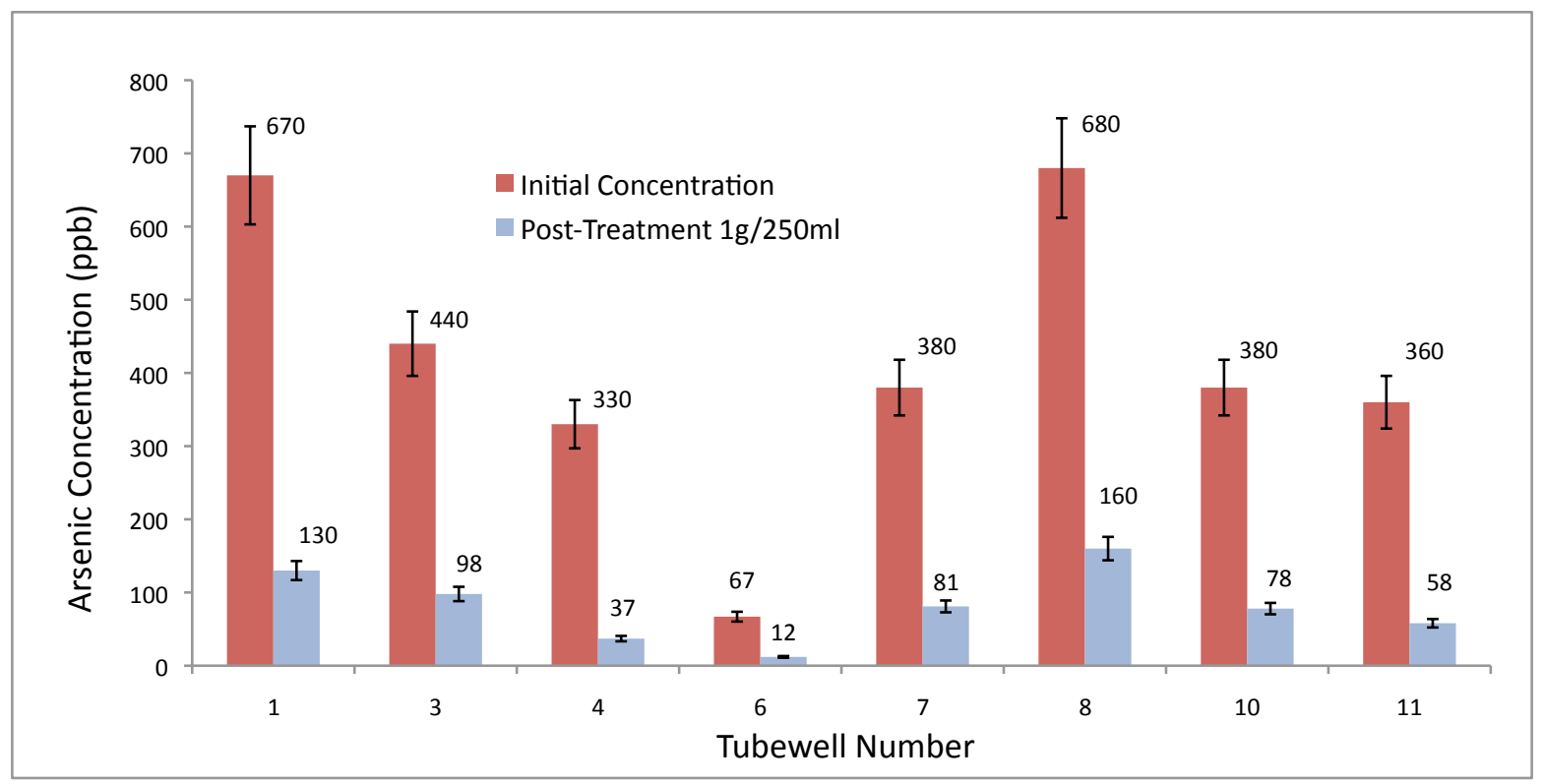

Data Table for Single Dose ARUBA Treatment: $1 \mathrm{~g}$ per $250 \mathrm{ml}$ (ICP-MS)

\begin{tabular}{|c|c|c|c|}
\hline $\begin{array}{c}\text { Tubewell } \\
\text { Number }\end{array}$ & $\begin{array}{c}\text { Initial Concentration } \\
\mathrm{ppb}\end{array}$ & $\begin{array}{c}\text { Final Concentration } \\
\mathrm{ppb}\end{array}$ & $\begin{array}{c}\text { Treatment Delay } \\
\text { hh:mm }\end{array}$ \\
\hline \hline 1 & 670 & 130 & $9: 00$ \\
\hline 3 & 440 & 98 & $7: 30$ \\
\hline 4 & 330 & 37 & $6: 30$ \\
\hline 6 & 67 & 12 & $4: 00$ \\
\hline 7 & 380 & 81 & $0: 45$ \\
\hline 8 & 680 & 160 & $6: 00$ \\
\hline 10 & 380 & 78 & $2: 45$ \\
\hline 11 & 360 & 58 & $2: 00$ \\
\hline
\end{tabular}


Figure 11: Double Dose ARUBA Treatment in Bangladesh: $2 \mathrm{~g}$ per $250 \mathrm{ml}$ (ICP-MS)

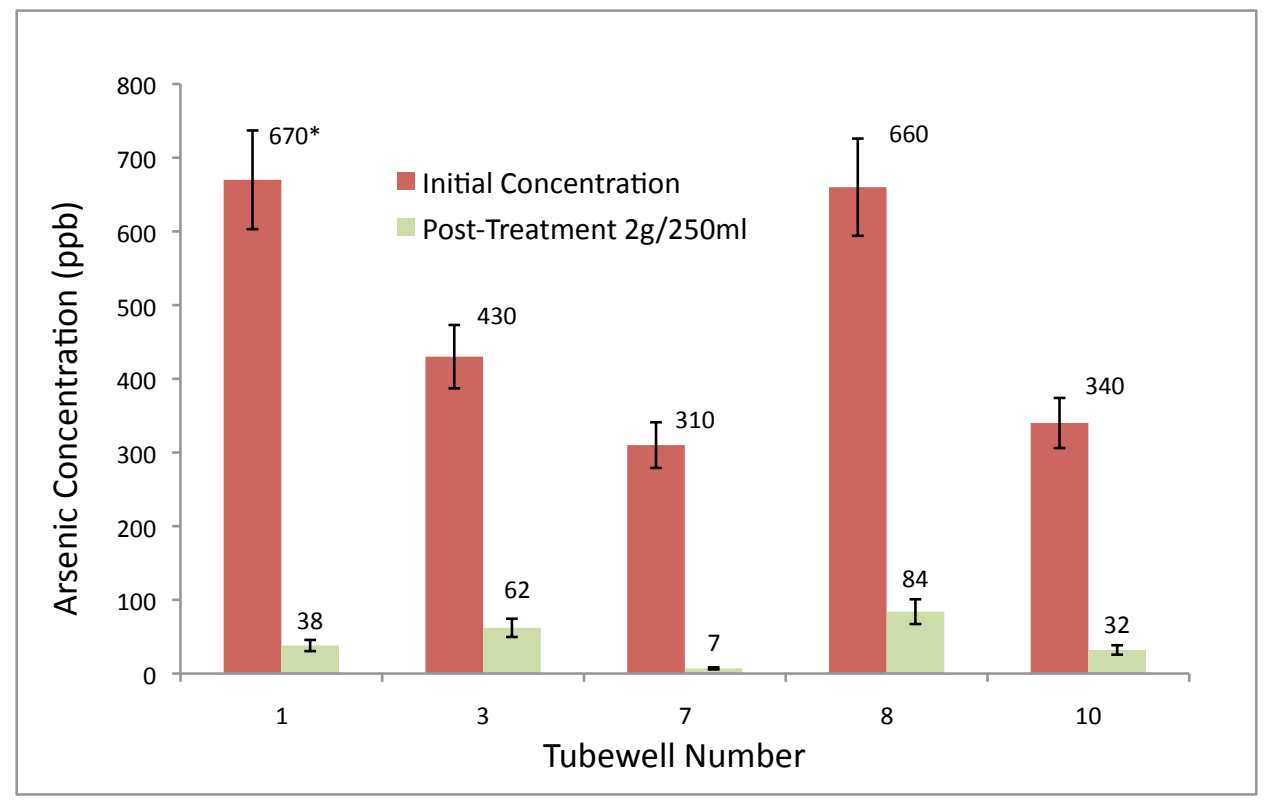

Data Table for Double Dose ARUBA Treatment: 2 g per 250 ml (ICP-MS)

\begin{tabular}{|c|c|c|c|}
\hline $\begin{array}{c}\text { Tubewell } \\
\text { Number }\end{array}$ & $\begin{array}{c}\text { Initial Concentration } \\
\mathrm{ppb}\end{array}$ & $\begin{array}{c}\text { Final Concentration } \\
\mathrm{ppb}\end{array}$ & $\begin{array}{c}\text { Treatment Delay } \\
\text { hh:mm }\end{array}$ \\
\hline 1 & $670^{*}$ & 38 & $30: 00$ \\
\hline 3 & 430 & 62 & $43: 30$ \\
\hline 7 & 310 & 7 & $21: 15$ \\
\hline 8 & 660 & 84 & $21: 45$ \\
\hline 10 & 340 & 32 & $18: 30$ \\
\hline
\end{tabular}

* The sample taken for the initial arsenic concentration of tubewell 1 directly before double dose treatment was lost and therefore the initial arsenic concentration of tubewell 1 directly before single dose treatment has been reported. 
Figure 12: Quadruple Dose ARUBA Treatment in Bangladesh: $2 \mathrm{~g}$ per $250 \mathrm{ml} \& 4 \mathrm{~g}$ per $250 \mathrm{ml}$ (ICP-MS)

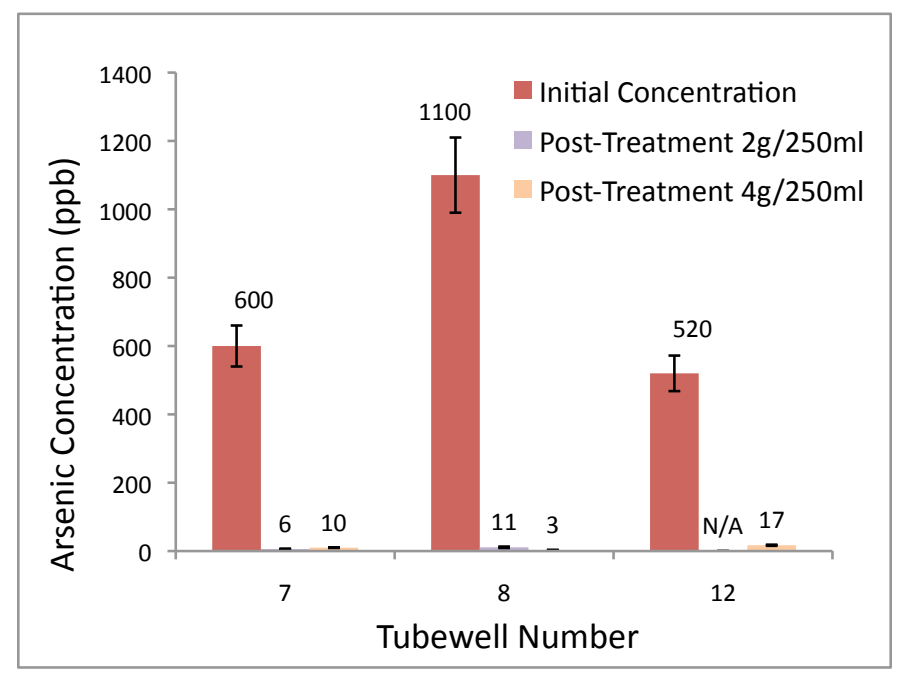

Data Table for Quadruple Dose ARUBA Treatment: $2 \mathrm{~g}$ per $250 \mathrm{ml} \& 4 \mathrm{~g}$ per $250 \mathrm{ml}$ (ICP-MS)

\begin{tabular}{|c|c|c|c|c|}
\hline $\begin{array}{l}\text { Tubewell } \\
\text { Number }\end{array}$ & $\begin{array}{c}\text { Initial Concentration } \\
\text { ppb }\end{array}$ & $\begin{array}{l}\text { Mid Concentration } \\
(2 \mathrm{~g} \text { per } 250 \mathrm{ml}) \\
\text { ppb }\end{array}$ & $\begin{array}{l}\text { Final Concentration } \\
(4 \mathrm{~g} \text { per } 250 \mathrm{ml}) \\
\text { ppb }\end{array}$ & $\begin{array}{c}\text { Treatment Delay } \\
\text { hh:mm }\end{array}$ \\
\hline 7 & 600 & 6 & 10 & (2 days) \\
\hline 8 & 1100 & 11 & 3 & (2 days) \\
\hline 12 & 520 & $\mathrm{~N} / \mathrm{A}$ & 17 & $5: 00$ \\
\hline
\end{tabular}

Despite the fact that water from tubewell 11 that had been treated with a single dose of ARUBA was not below the MCL it was not treated with a double dose. This is because at the point at which the decision was made to re-treat water from certain tubewells we only had QuickTest results from the single dose treatment. Those results indicated that the treated water from tubewell 11 was below $50 \mathrm{ppb}$ arsenic. Similarly, QuickTest results showed a final arsenic concentration of less than $50 \mathrm{ppb}$ for tubewell 3 after double dose treatment. Therefore, water from tubewell 3 was not re-treated with a quadruple dose.

\section{Quadruple Dose (4 g per $250 \mathrm{ml}$ ) Results}

Water samples from tubewell 7 and 8 were treated with a quadruple dose of ARUBA. Results are shown in Figure 12. Though double dose treatment of water from tubewell 7 showed arsenic removal to below the MCL, it was decided that water from tubewell 7 should also be treated with a quadruple dose so that results could be compared directly to that of tubewell 8 . There was some concern that modifying the treatment protocol to add only $2 \mathrm{~g}$ of ARUBA at a time (with filtration in between ARUBA additions) would affect the results unpredictably.

Again, 'initial concentration' ICP-MS samples were taken from the storage bottles directly before treatment. The initial arsenic concentration for tubewell 8 was measured to be much higher than previous measurements. A high concentration of precipitates were noted in the remaining tubewell 8 water and it is likely that many of these ended up in the ICP-MS sample vial. Again, initial arsenic concentrations for tubewells 7 and 8 as shown in Figure 12 should be trusted less than those shown above in the single dose experiment (Figure 10).

Interestingly, treatment with $2 \mathrm{~g}$ of ARUBA per $250 \mathrm{ml}$ produces post-treatment arsenic concentrations comparable to treatment with $4 \mathrm{~g}$ of ARUBA per $250 \mathrm{ml}$. Moreover, water from tubewell 8 performed much 
Figure 13: All Bangladesh Trip 1 ARUBA Treatment Experiments (ICP-MS)

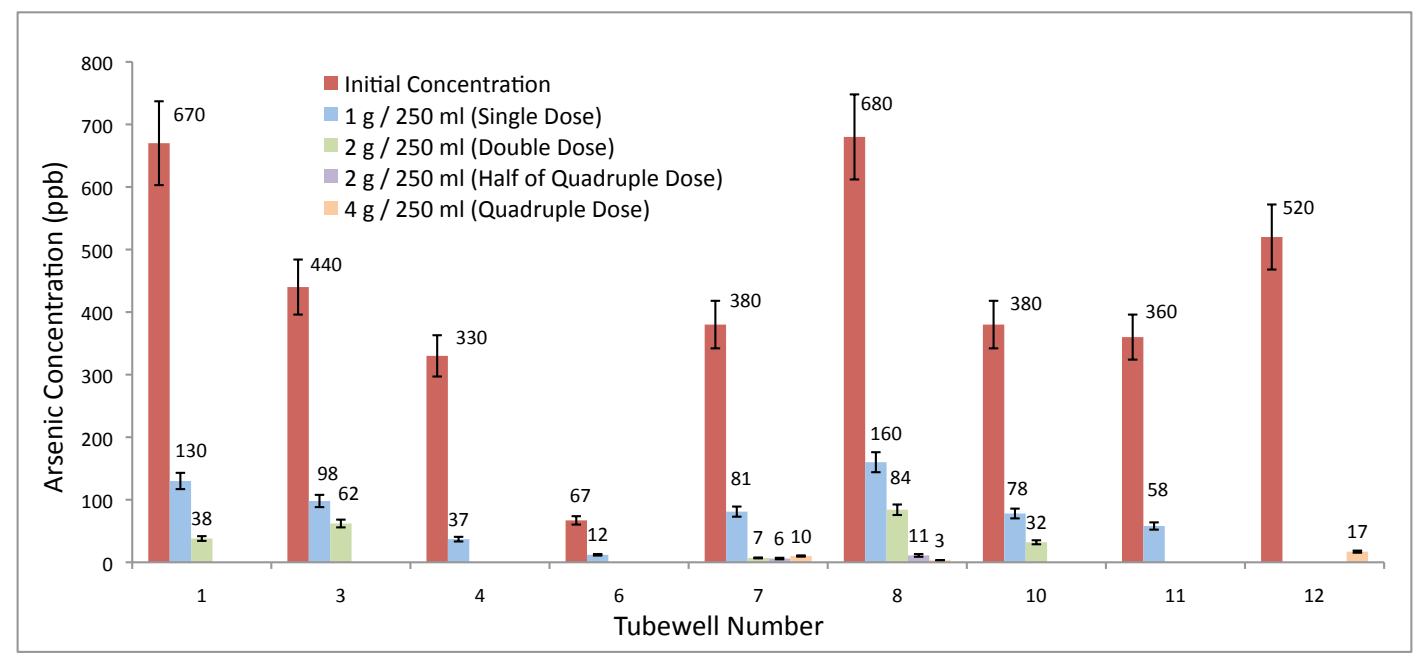

better with $2 \mathrm{~g}$ of ARUBA per $250 \mathrm{ml}$ in the quadruple dose experiment than it had with the same amount of ARUBA in the double dose experiment. Instead of a final arsenic concentration of $84 \mathrm{ppb}$ it achieved a final arsenic concentration of only $11 \mathrm{ppb}$. This is likely because the sample drawn from tubewell 8 had been stored an additional day before the quadruple dose experiment. As will be explained in Section 5.2.5, this time delay likely allowed $\mathrm{As}(\mathrm{III})$ to oxidize to $\mathrm{As}(\mathrm{V})$, which could be removed by ARUBA. In addition, an extra day of coagulation and co-precipitation with naturally-occurring iron could have helped to lower final arsenic concentrations. Therefore, for both tubewell 7 and 8 , the second $2 \mathrm{~g}$ dose of ARUBA in the quadruple dose experiment did little-to-nothing to further diminish arsenic concentrations.

Tubewell 12 was only treated with a quadruple dose because, based on measurement (by QuickTest) of the arsenic concentration in the sampled tubewell water and our experience with treating water from tubewells 1 through 11, we believed that only a quadruple dose of ARUBA would sufficiently lower arsenic concentrations to below the Bangladesh MCL. Results are also presented in Figure 12 and Table ??. A sample was not taken after treatment with $2 \mathrm{~g}$ of ARUBA. Given that water from Tubewell 12 had only been stored for five hours it is possible that after treatment with only $2 \mathrm{~g}$ the arsenic concentration was much higher than the $17 \mathrm{ppb}$ measured after treatment with $4 \mathrm{~g}$. However, it is also likely that if the water had been stored for longer than two days $2 \mathrm{~g}$ of ARUBA would have been sufficient to reduce arsenic concentrations to below the Bangladesh MCL.

\section{Comprehensive Arsenic Removal Capacity Results from Bangladesh Trip 1}

A summary of the results presented in the previous three sections is shown in Figure 13. The initial arsenic concentrations are taken from the single dose experiment, as these measurements are likely to be the most accurate. The amount of ARUBA required to treat contaminated groundwater is related to the amount of arsenic in the water. ARUBA was able to achieve arsenic removal to below the Bangladesh MCL in water from seven of the nine tubewells tested. Adding more ARUBA to water from tubewells 3 and 11 would have likely produced final arsenic concentrations below the Bangladesh MCL as well. This was not done because QuickTest measurements underestimated the amount of arsenic left in the water.

\section{Ionic Analysis of Selected Tubewells}

Analysis was conducted on water from tubewells 1, 7, and 12 to determine concentrations of relevant elements and compounds. Samples were brought back to Berkeley and analyzed by Curtis \& Tompkins within three weeks of collection in Bangladesh. Results are presented in Table 16. Average concentrations 
Table 16: Analysis of Tubewells 1, 7, \& 12

\begin{tabular}{|c||c|c|c|c|c|c|c|c|c|c|}
\hline & $\begin{array}{c}\mathrm{Ca} \\
\mathrm{mg} / \mathrm{L}\end{array}$ & $\begin{array}{c}\mathrm{Cl} \\
\mathrm{mg} / \mathrm{L}\end{array}$ & $\begin{array}{c}\mathrm{Fe} \\
\mathrm{mg} / \mathrm{L}\end{array}$ & $\begin{array}{c}\mathrm{K} \\
\mathrm{mg} / \mathrm{L}\end{array}$ & $\begin{array}{c}\mathrm{Mg} \\
\mathrm{mg} / \mathrm{L}\end{array}$ & $\begin{array}{c}\mathrm{Mn} \\
\mathrm{mg} / \mathrm{L}\end{array}$ & $\begin{array}{c}\mathrm{Na} \\
\mathrm{mg} / \mathrm{L}\end{array}$ & $\begin{array}{c}\mathrm{P} \\
\mathrm{mg} / \mathrm{L}\end{array}$ & $\begin{array}{c}\mathrm{SO}_{4} \\
\mathrm{mg} / \mathrm{L}\end{array}$ & $\begin{array}{c}\mathrm{NO}_{3}, \mathrm{~N} \\
\mathrm{mg} / \mathrm{L}\end{array}$ \\
\hline \hline Tubewell 1 & 120 & 28 & 1.2 & 1.9 & 24 & 0.030 & 17 & 0.18 & 0 & 0.0 \\
\hline Tubewell 7 & 81 & 7.6 & 0.87 & 2.2 & 29 & 1.6 & 26 & 0.11 & 0 & 0.19 \\
\hline Tubewell 12 & 52 & 14 & 0.14 & 4.0 & 14 & 1.4 & 21 & 0.49 & 0 & 0.0 \\
\hline \hline BGS Average & 66 & 81 & 5.6 & 6.0 & 27 & 0.61 & 94 & 1.3 & 4.6 & 0.56 \\
\hline
\end{tabular}

Table 17: Bangladesh Tubewells Sampled July 2, 2007 - July 5, 2008 (ICP-MS)

\begin{tabular}{|c|c|c|c|c|c|c|c|c|}
\hline Tubewell ID & $\begin{array}{c}\text { Date(s) Sampled } \\
\text { m/dd } / y y\end{array}$ & District & Upazila & Union & Village & $\begin{array}{c}\text { As Conc } \\
\text { ppb }\end{array}$ & $\mathrm{pH}$ & $\begin{array}{c}\text { Temp } \\
{ }^{\circ} \mathrm{C}\end{array}$ \\
\hline TW2.1 & $7 / 02 / 07-7 / 05 / 07$ & Narayanganj & Sonargaon & Aminpur & Neel Kanda & 200 & 6.92 & 27.4 \\
\hline TW2.2 & $7 / 02 / 07$ & Narayanganj & Sonargaon & Aminpur & Neel Kanda & $\mathrm{N} / \mathrm{A}$ & $\mathrm{N} / \mathrm{A}$ & $\mathrm{N} / \mathrm{A}$ \\
\hline TW2.3 & $7 / 02 / 07-7 / 05 / 07$ & Narayanganj & Sonargaon & Aminpur & Neel Kanda & 180 & 6.96 & 28.4 \\
\hline
\end{tabular}

of the various elements in Bangladesh groundwater contaminated with greater than $10 \mathrm{ppb}$ arsenic, as determined from British Geologic Survey (BGS) data (11), are also noted.

\subsubsection{Results from Bangladesh Trip 2}

On the second and third trips to Bangladesh, ARUBA treatment, as described in the previous section, was performed on samples from several more tubewells in order to compare results to those obtained during the first trip to Bangladesh. In all cases, 'initial concentration' samples were taken directly from the tubewell.

During the second trip to Bangladesh only three tubewells were tested and two were picked for experiments (TW2.1 and TW2.3) since TW2.2 had a low arsenic concentration ( 60 ppb by QuickTest). Table 17 lists each well and relevant parameters.

Water from each well was treated with both $1 \mathrm{~g}$ and $2 \mathrm{~g}$ of ARUBA per $250 \mathrm{ml}$, within one hour of sample collection. One ARUBA batch (100 g Batch 4) was used for all the testing conducted throughout the course of the second trip to Bangladesh. Batch 4's laboratory arsenic removal capacity is reported in Section 4.2.2. Results of the capacity tests on water from TW2.1 and TW2.3 are shown in Figure 14.

Water from TW2.1 and TW2.3 was also tested for relevant elements and compounds. Samples were brought back to Berkeley and analyzed by Curtis \& Tompkins approximately two months after collection in Bangladesh. Results are presented in Table 18. Alkalinity results are likely not particularly accurate since the water had been stored for so long. Again, average concentrations, computed from BGS data (11), are noted.

\subsubsection{Results from Bangladesh Trip 3}

During the third trip to Bangladesh water from six tubewells (TW3.1-TW3.6) was sampled. Table 19 lists each well and relevant parameters. Hardness (in mg per liter as $\mathrm{CaCO}_{3}$ ) was measured through titration with EDTA, while alkalinity (also in mg per liter as $\mathrm{CaCO}_{3}$ ) was measured through titration with a phenolphthalein indicator, $\mathrm{H}_{2} \mathrm{SO}_{4}$, and a methyl orange indicator.

As(III) concentrations were measured for TW3.1-TW3.4. Figure 15 shows the break-down between the two arsenic species. Since samples were speciated directly after extraction from the well, as opposed to after precipitates had formed, these results are reasonably accurate. 
Figure 14: Bangladesh Trip 2 ARUBA Treatment Experiment (ICP-MS)

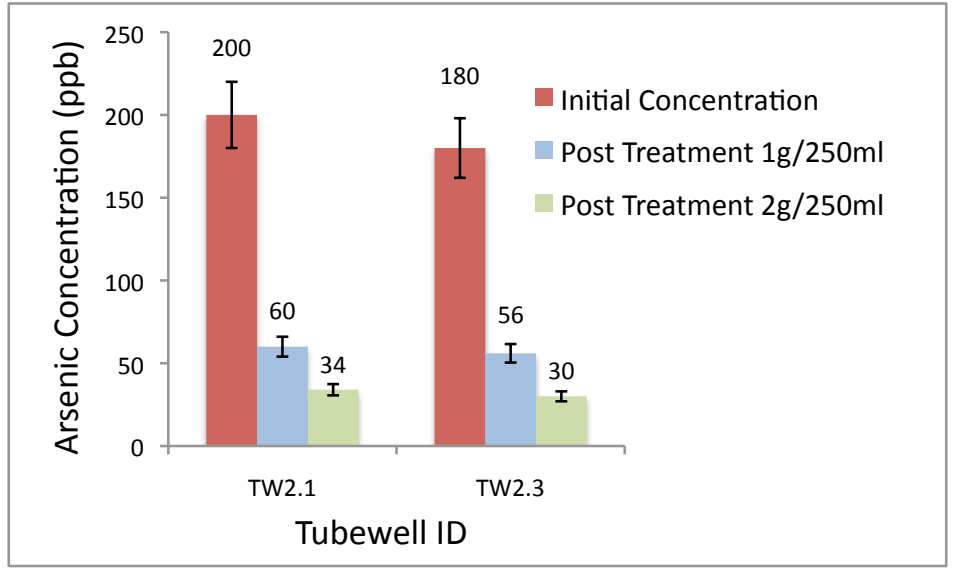

Table 18: Analysis of Tubewells TW2.1 and TW2.3

\begin{tabular}{|c|c|c|c|c|c|c|c|c|c|c|}
\hline Tubewell ID & $\begin{array}{c}\mathrm{Ca} \\
\mathrm{mg} / \mathrm{L}\end{array}$ & $\begin{array}{c}\mathrm{Cl} \\
\mathrm{mg} / \mathrm{L}\end{array}$ & $\begin{array}{c}\mathrm{Fe} \\
\mathrm{mg} / \mathrm{L}\end{array}$ & $\begin{array}{c}\mathrm{K} \\
\mathrm{mg} / \mathrm{L} \\
\end{array}$ & $\begin{array}{c}\mathrm{Mg} \\
\mathrm{mg} / \mathrm{L}\end{array}$ & $\begin{array}{c}\mathrm{Mn} \\
\mathrm{mg} / \mathrm{L}\end{array}$ & $\begin{array}{c}\mathrm{Na} \\
\mathrm{mg} / \mathrm{L}\end{array}$ & $\begin{array}{c}\mathrm{P} \\
\mathrm{mg} / \mathrm{L}\end{array}$ & $\begin{array}{c}\mathrm{SO}_{4} \\
\mathrm{mg} / \mathrm{L}\end{array}$ & $\begin{array}{c}\mathrm{NO}_{3}, \mathrm{~N} \\
\mathrm{mg} / \mathrm{L}\end{array}$ \\
\hline TW2.1 & 110 & 9.3 & 2.6 & 3.6 & 21 & 1.4 & 42 & 1.4 & 0 & 0.63 \\
\hline TW2.3 & 81 & 9.7 & 0.79 & 3.4 & 22 & 1.4 & 57 & 1.2 & 0 & 0.40 \\
\hline BGS Average & 66 & 81 & 5.6 & 6.0 & 27 & 0.61 & 94 & 1.3 & 4.6 & 0.56 \\
\hline & & & \multicolumn{2}{|c|}{ Tubewell ID } & $\begin{array}{r}\text { Alkalini } \\
\mathrm{mg} / \mathrm{L}\end{array}$ & \multicolumn{2}{|c|}{$\begin{array}{l}\text { Silica } \\
\mathrm{mg} / \mathrm{L}\end{array}$} & & & \\
\hline & & & \multicolumn{2}{|c|}{ TW2.1 } & 420 & \multicolumn{2}{|c|}{37} & & & \\
\hline & & & \multicolumn{2}{|c|}{ TW2.3 } & 420 & \multicolumn{2}{|c|}{36} & & & \\
\hline & & & \multicolumn{2}{|c|}{ BGS Average } & 500 & 20 & & & & \\
\hline
\end{tabular}

Table 19: Bangladesh Tubewells Sampled June 1, 2008 - June 27, 2008 (GF-AAS)

\begin{tabular}{|c|c|c|c|c|c|c|c|c|}
\hline Tubewell ID & $\begin{array}{c}\text { Date(s) Sampled } \\
\mathrm{m} / \mathrm{dd} / \mathrm{yy}\end{array}$ & District & Upazila & Village & $\begin{array}{c}\text { As Conc } \\
\text { ppb }\end{array}$ & $\mathrm{pH}$ & $\begin{array}{c}\text { Hardness } \\
\mathrm{mg} / \mathrm{l}\end{array}$ & $\begin{array}{c}\text { Alkalinity } \\
\mathrm{mg} / \mathrm{l}\end{array}$ \\
\hline TW3.1 & $6 / 01,17,27 / 08$ & Munshiganj & Sreenagar & Besgao & 260 & 6.820 & 272 & 384 \\
\hline TW3.2 & $6 / 01,17,27 / 08$ & Munshiganj & Sreenagar & Besgao & 561 & 6.922 & 310 & 409 \\
\hline TW3.3 & $6 / 01 / 08$ & Munshiganj & Sreenagar & Besgao & 249 & 6.849 & 382 & 466 \\
\hline TW3.4 & $6 / 01 / 08$ & Munshiganj & Sreenagar & Besgao & 129 & 6.934 & 328 & 465 \\
\hline TW3.5 & $6 / 13 / 08$ & Chandpur & Matlab & North Nolua & 400 & 7.029 & 218 & 255 \\
\hline TW3.6 & $6 / 13 / 08$ & Chandpur & Matlab & North Nolua & 2 & 7.018 & 454 & 206 \\
\hline
\end{tabular}


Figure 15: Arsenic(III) and Arsenic(V) Concentrations of TW3.1 - TW3.4 (GF-AAS)

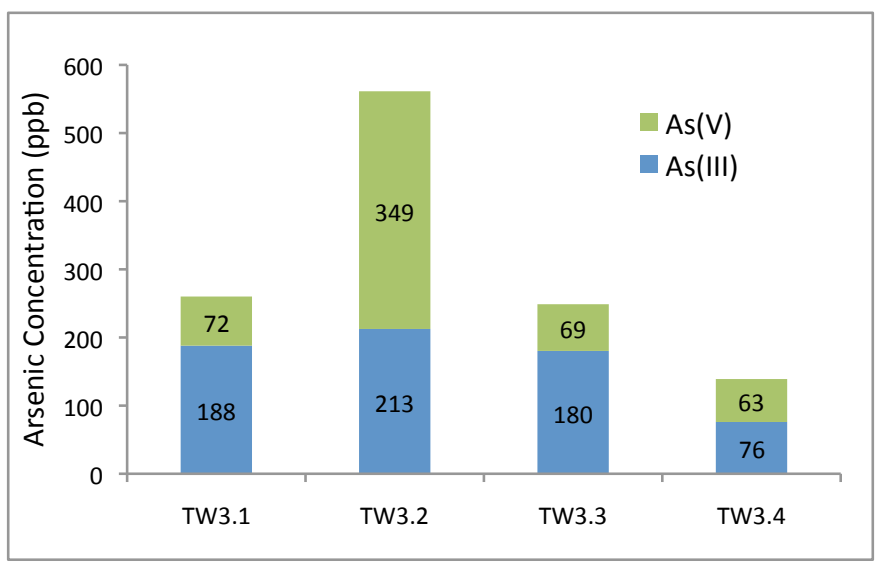

Figure 16: Bangladesh Trip 3 ARUBA Treatment Experiment (GF-AAS)

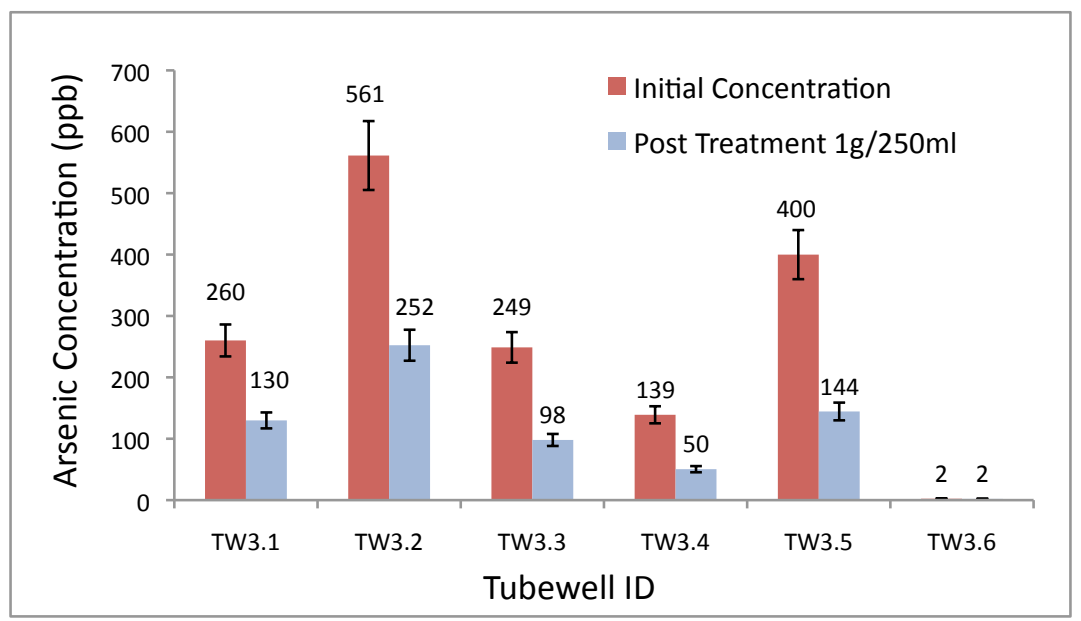

Water from each well was treated with $1 \mathrm{~g}$ of ARUBA per $250 \mathrm{ml}$. ARUBA used for each test was from a combined batch. The combined batch had been tested in the laboratory and shown to have an arsenic removal capacity of $1.06 \mathrm{mg}$ As per gram ARUBA in $2200 \mathrm{ppb} \mathrm{As}(\mathrm{V})$ spiked de-ionized water. For TW3.1 - TW 3.4, treatment was performed 10 to 13 hours after collection of samples. For TW3.5 and TW3.6, treatment was performed 18 to 20 hours after collection of samples. Results, as measured by GF-AAS, are presented in Figure 16. Note that initial arsenic concentrations of water taken from Besgao Village may low since ICP-MS measurements of the same tubewell water were much higher. See section 5.2.5 for details.

Water from TW3.1 and TW3.2 was tested at BUET for several elements and compounds, using colorimetric methods. Iron was measured by mixing a water sample with $\mathrm{HCl}$, potassium permanganate, and potassium thiocyanate solution. The color of the resulting solution was matched with that of a standard iron solution. Manganese was measured by mixing a water sample with 1-(2-pyridylazo)-2-naphthol(PAN) method to form an orange complex. Phosphate was measured by mixing a water sample with ammonium molybdate. Phosphate was then reduced by stannous chloride to form a blue complex. Chloride was measured by mixing a water sample with $\mathrm{AgNO}_{3}, \mathrm{Cl}_{2}$, and potassium chromate to produce silver chromate, a red complex. Sulfate was measured by mixing a sample with barium chloride to produce a barium sulphate suspension. Finally, silica was measured by mixing a water sample with ammonium molybdate to produce blue heteropolyacids. 
Table 20: Analysis of Tubewells TW3.1 and TW3.2

\begin{tabular}{|c|c|c|c|c|c|c|}
\hline & $\begin{array}{c}\mathrm{Cl} \\
\mathrm{mg} / \mathrm{L}\end{array}$ & $\begin{array}{c}\mathrm{Fe} \\
\mathrm{mg} / \mathrm{L}\end{array}$ & $\begin{array}{c}\mathrm{Mn} \\
\mathrm{mg} / \mathrm{L}\end{array}$ & $\begin{array}{c}\mathrm{PO}_{4} \\
\mathrm{mg} / \mathrm{L}\end{array}$ & $\begin{array}{c}\mathrm{SO}_{4} \\
\mathrm{mg} / \mathrm{L}\end{array}$ & $\begin{array}{c}\text { Silica } \\
\mathrm{mg} / \mathrm{L}\end{array}$ \\
\hline \hline TW3.1 & 105.1 & 2.72 & 0.07 & 1.468 & 0 & 36.5 \\
\hline TW3.2 & 75.1 & 1.52 & 0.13 & 1.585 & 0 & 32.1 \\
\hline \hline BGS Average & 81 & 5.6 & 0.61 & 4.015 & 4.6 & 20 \\
\hline
\end{tabular}

Table 21: Cambodia Tubewells Sampled July 2, 2008 - July 11, 2008 (ICP-MS)

\begin{tabular}{|c|c|c|c|c|c|c|c|c|c|}
\hline Tubewell ID & $\begin{array}{c}\text { Date Sampled } \\
\mathrm{m} / \mathrm{dd} / \mathrm{yy}\end{array}$ & Village & Sub-District & District & Province & $\begin{array}{c}\text { As Conc } \\
\mathrm{ppb}\end{array}$ & $\begin{array}{c}\text { Temp } \\
{ }^{\circ} \mathrm{C}\end{array}$ & $\begin{array}{c}\mathrm{pH} \\
\mathrm{DO} \\
\mathrm{mg} / \mathrm{l}\end{array}$ \\
\hline \hline TWC1 & $7 / 02 / 08$ & Preak Russei & Leuk Daek & Kaoh Thum & Kandal & 1300 & 29.97 & 7.62 & 1.83 \\
\hline TWC2 & $7 / 02 / 08$ & Preak Russei & Leuk Daek & Kaoh Thum & Kandal & 1100 & 30.72 & N/A & N/A \\
\hline TWC3 & $7 / 02 / 08$ & Preak Russei & Leuk Daek & Kaoh Thum & Kandal & 1200 & 29.56 & 7.91 & 3.00 \\
\hline TWC4 & $7 / 04 / 08$ & Po Peal Khel & Dei Edth & Kien Svey & Kandal & 420 & 29.54 & N/A & N/A \\
\hline TWC5 & $7 / 04 / 08$ & Dei Edth & Dei Edth & Kien Svey & Kandal & 1600 & 31.3 & N/A & N/A \\
\hline TWC6 & $7 / 04 / 08$ & Po Peal Khel & Dei Edth & Kien Svey & Kandal & 1300 & 29.68 & N/A & N/A \\
\hline TWC7 & $7 / 11 / 08$ & Mittapheap & Preak Aeng & Kien Svey & Kandal & 380 & 28.38 & N/A & N/A \\
\hline TWC8 & $7 / 11 / 08$ & Toul Tachan & Preak Aeng & Kien Svey & Kandal & 770 & 30.23 & N/A & N/A \\
\hline TWC9 & $7 / 11 / 08$ & Toul Tachan & Preak Aeng & Kien Svey & Kandal & 820 & 29.38 & 7.29 & 2.50 \\
\hline
\end{tabular}

Results are presented in Table 20. As before, average concentrations, computed from BGS data, are noted.

\subsubsection{Results from Cambodia}

Between July 2 and July 11, 2008 members of the BEAR team visited nine tubewells in Cambodia and tested ARUBA's performance. A list of the tubewells visited and relevant parameters in Table 21.

The team used the same field protocol as used in Bangladesh with the exception that contact time between the contaminated water and the ARUBA was 3 hours for TWC7 and 2.5 hours for TWC9, instead of the normal 30 minutes. Samples were treated immediately after they were pumped from the tubewell. Some wells were treated with $1 \mathrm{~g}$ ARUBA per $250 \mathrm{ml}$ and some wells were treated with $2 \mathrm{~g}$ ARUBA per $250 \mathrm{ml}$. Results, as measured by ICP-MS, are shown in Figure 17. Many of the tubewells had extremely high initial arsenic levels, resulting in ARUBA's inability to lower arsenic levels to the MCL. However, it is likely that higher ARUBA concentrations could further lower arsenic concentrations.

\subsubsection{Arsenic Removal Capacity Versus Initial Arsenic Concentration in the Field}

Arsenic removal capacity as computed from the Bangladesh and Cambodia data presented above can be plotted versus initial arsenic concentration as in Figure 18. For this plot, only data from single dose ARUBA treatments that were performed within one day of sample collection (ensuring that most of the As(III) had not yet converted to $\mathrm{As}(\mathrm{V})$ ) were used. A linear regression was fit to the Bangladesh data and Cambodia data separately; however, equations for both regressions are the same, with the Cambodia regression line fitting slightly better than the Bangladesh regression line.

Adding this data to the graph of arsenic removal capacity versus initial arsenic concentration as measured in the laboratory (Figure 19) the difference in ARUBA's performance in the field and the lab can be seen. 
Figure 17: Cambodia ARUBA Treatment Experiment (ICP-MS)

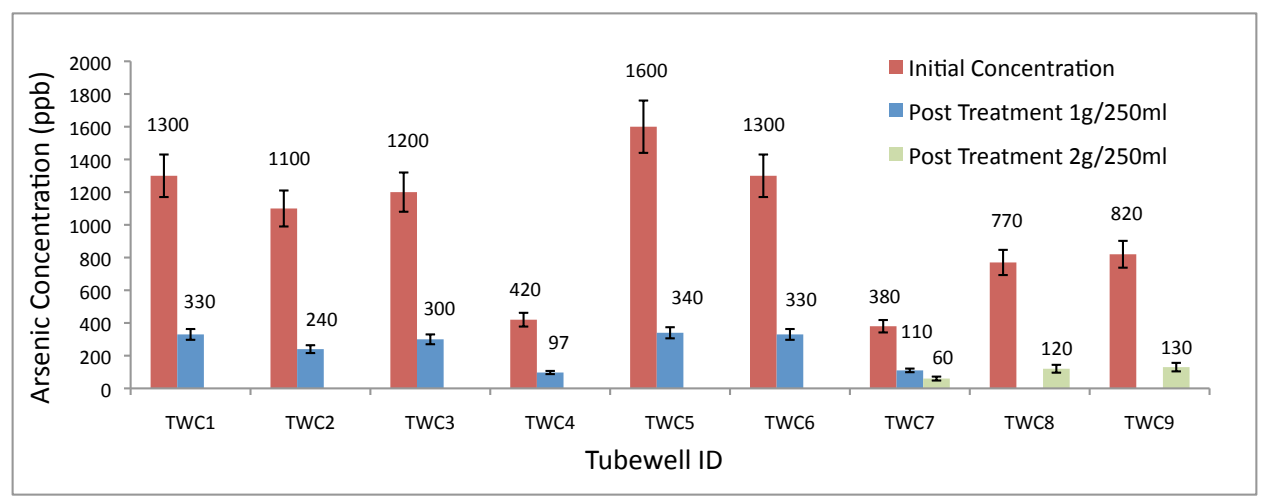

Figure 18: Bangladesh \& Cambodia Arsenic Removal Capacity v. Initial Arsenic Concentration (ICP-MS \& GF-AAS)

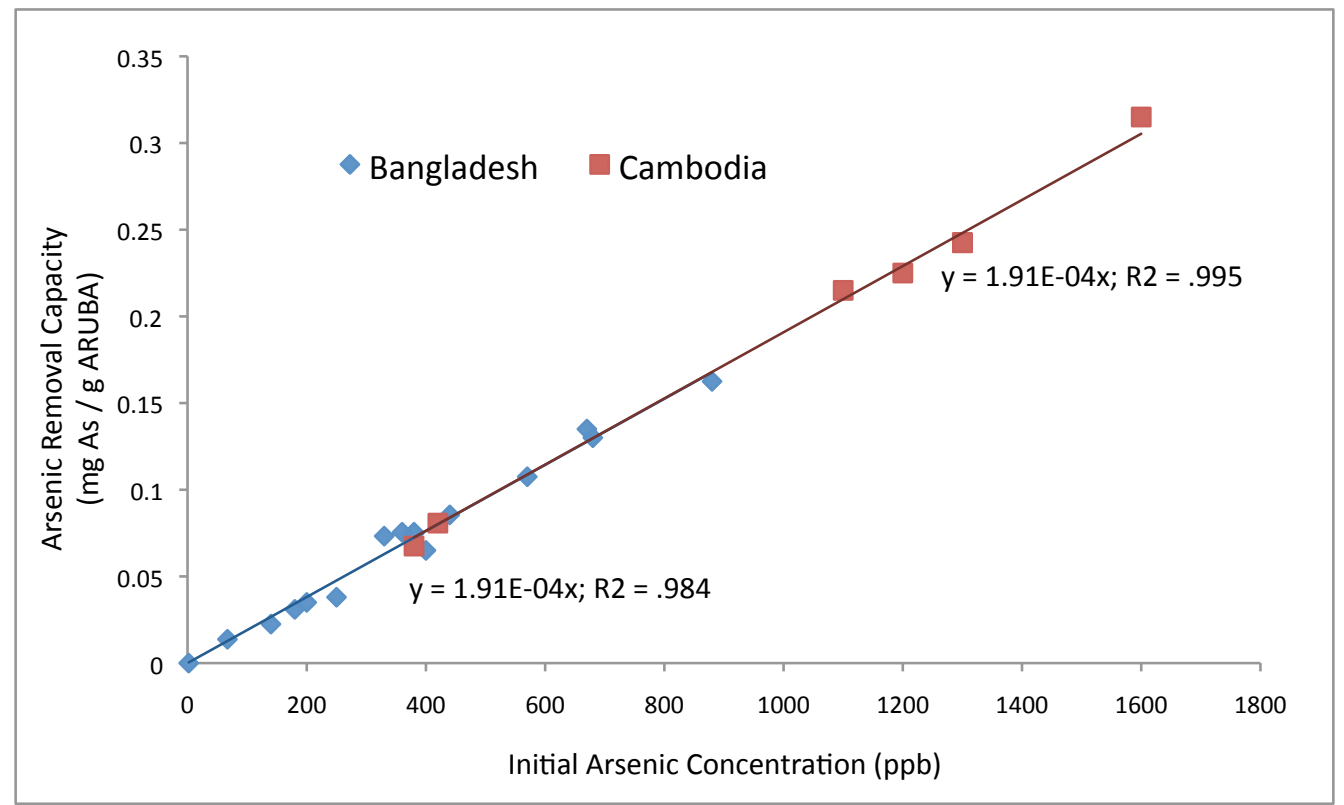


Figure 19: Bangladesh, Cambodia, \& Laboratory Arsenic Removal Capacity v. Initial Arsenic Concentration (ICP-MS \& GF-AAS)

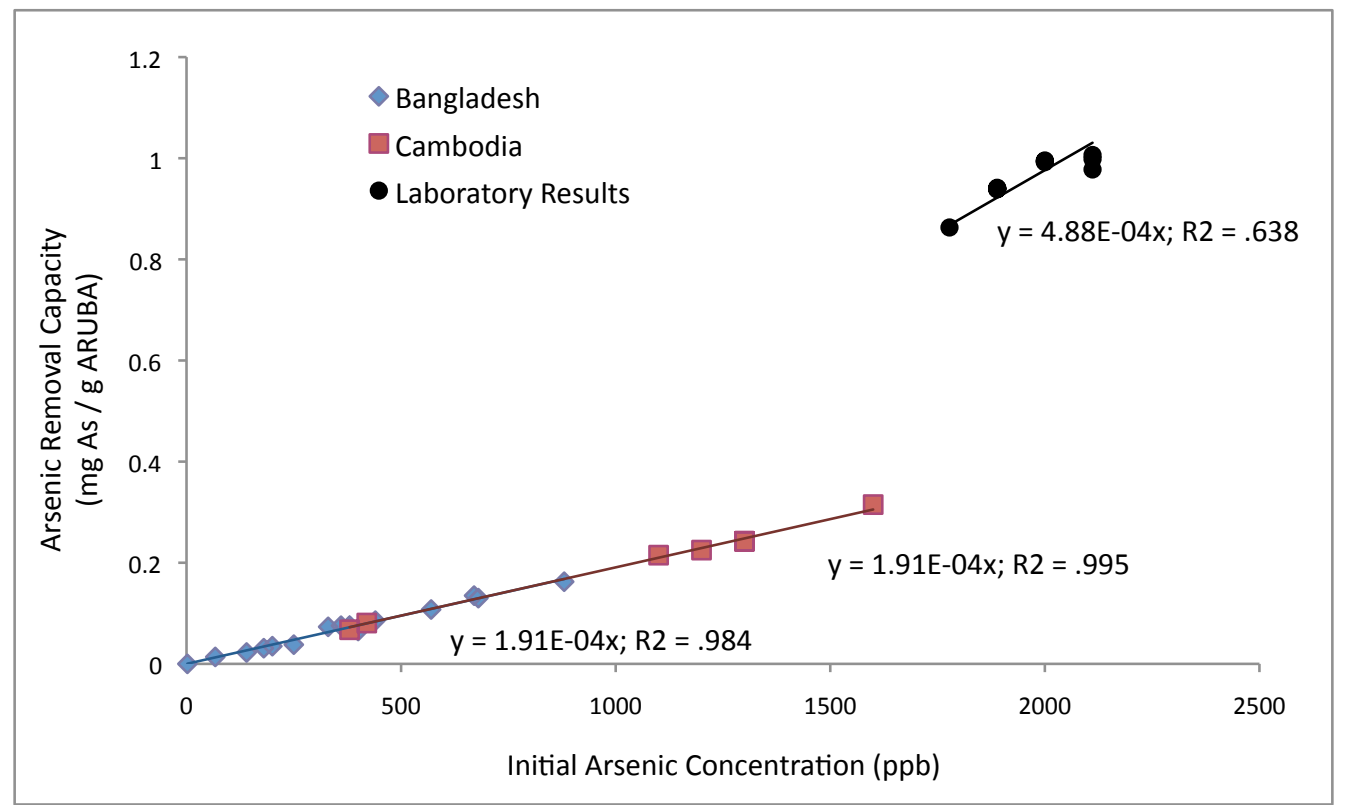

Two likely reasons why field and laboratory results differ include:

1. As(III) in the Bangladesh and Cambodia groundwater were not removed by ARUBA. Water treated in the laboratory did not contain As(III).

2. Groundwater from Cambodia and Bangladesh contains ions which compete with arsenic for adsorption sites on ARUBA particles. Many compounds compete with arsenic for adsorption onto iron including carbonate (6); bicarbonate (62); phosphate $(57,75,62,84,87)$; silicate $(75,62,81,84)$; dissolved organic carbon (32); molybdate (57); calcium (81); and nitrate (87).

\section{$5.2 \quad$ ARUBA Properties}

In addition to arsenic removal capacity, several other properties of ARUBA have been established through field experiments including ARUBA's repeatability in treating arsenic contaminated water, ARUBA's arsenic removal kinetics, the scalability of ARUBA treatment, ARUBA's performance with sequential fractionated dosing, and ARUBA's performance in treating water that has been stored. Each property is discussed below.

\subsubsection{Treatment Repeatability}

During the second trip to Bangladesh, each day for four days, water was taken from TW2.1 and TW2.3 in order to measure the variation in the wells' arsenic concentration over time. Also, water was treated with $1 \mathrm{~g}$ and $2 \mathrm{~g}$ of ARUBA per $250 \mathrm{ml}$ for three days to measure the variation in the treated water's arsenic concentration. Results of the experiment in Table 22 show that ARUBA treatment is very repeatable despite the small variation in arsenic concentration of the well over the sampling period. 
Table 22: Repeatability of ARUBA Treatment (ICP-MS)

\begin{tabular}{|c||c|c|}
\hline & $\begin{array}{c}\text { TW2.1 } \\
\text { ppb }\end{array}$ & $\begin{array}{c}\text { TW2.3 } \\
\text { ppb }\end{array}$ \\
\hline \hline Average Initial Concentration (N=4) & 200 & 180 \\
\hline Max & 210 & 180 \\
\hline Min & 200 & 170 \\
\hline \hline Average Final Concentration, 1 g ARUBA (N=3) & 60 & 56 \\
\hline Max & 61 & 56 \\
\hline Min & 58 & 56 \\
\hline \hline Average Final Concentration, 2 g ARUBA (N=3) & 34 & 30 \\
\hline Max & 36 & 32 \\
\hline Min & 32 & 28 \\
\hline
\end{tabular}

Figure 20: Arsenic Concentration v. Treatment Time for TW2.1 and TW2.3 (ICP-MS)

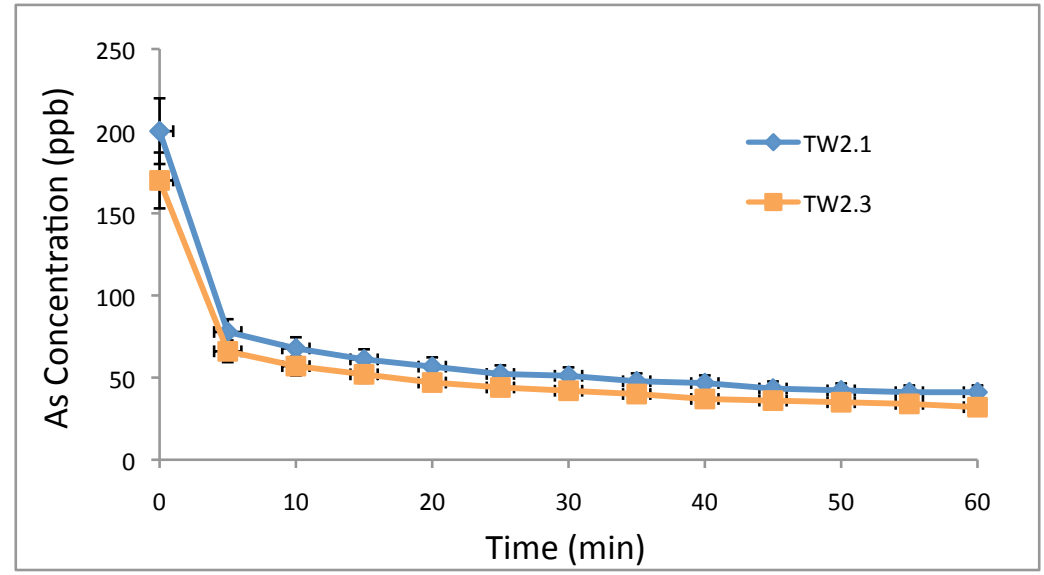

\subsubsection{Arsenic Removal Kinetics}

During the second trip to Bangladesh, water from TW2.1 and TW2.3 was treated with $1 \mathrm{~g}$ of ARUBA in 250 $\mathrm{ml}$ for one hour (flipping the bottles every 30 seconds). During the treatment period samples were filtered and stored at five minute intervals. Figure 20 shows a graphs of arsenic concentration versus treatment time for each well. Over half of the arsenic is removed in the first five minutes. Both curves appear to be decreasing even after sixty minutes of treatment indicating that the arsenic concentration has not reach equilibrium.

A modified version of this experiment was repeated during the third trip to Bangladesh using water from TW3.1 and TW3.2. In this experiment, treatment was not stopped after one hour. Instead, after the first hour which included flipping the bottles every 30 seconds, ARUBA was left to settle and remain in contact with with water for three days. In this experiment, samples were taken less frequently. For the first hour samples were taken ever 15 minutes, and sampling became less and less frequent through out the course of the experiment.

Results from both tubewells are presented in Figure 21. Interestingly, arsenic removal seems to exhibit two modes. Initially, there is an exponential decrease in arsenic concentration until a temporary steady state is reached. However, after about six hours arsenic concentrations again start to decrease exponentially, but at a lower rate. It has been hypothesized that during the first hour of treatment existing $\mathrm{As}(\mathrm{V})$ adsorbs to 
Figure 21: Arsenic Concentration v. Treatment Time for TW3.1 and TW3.2 (GF-AAS)
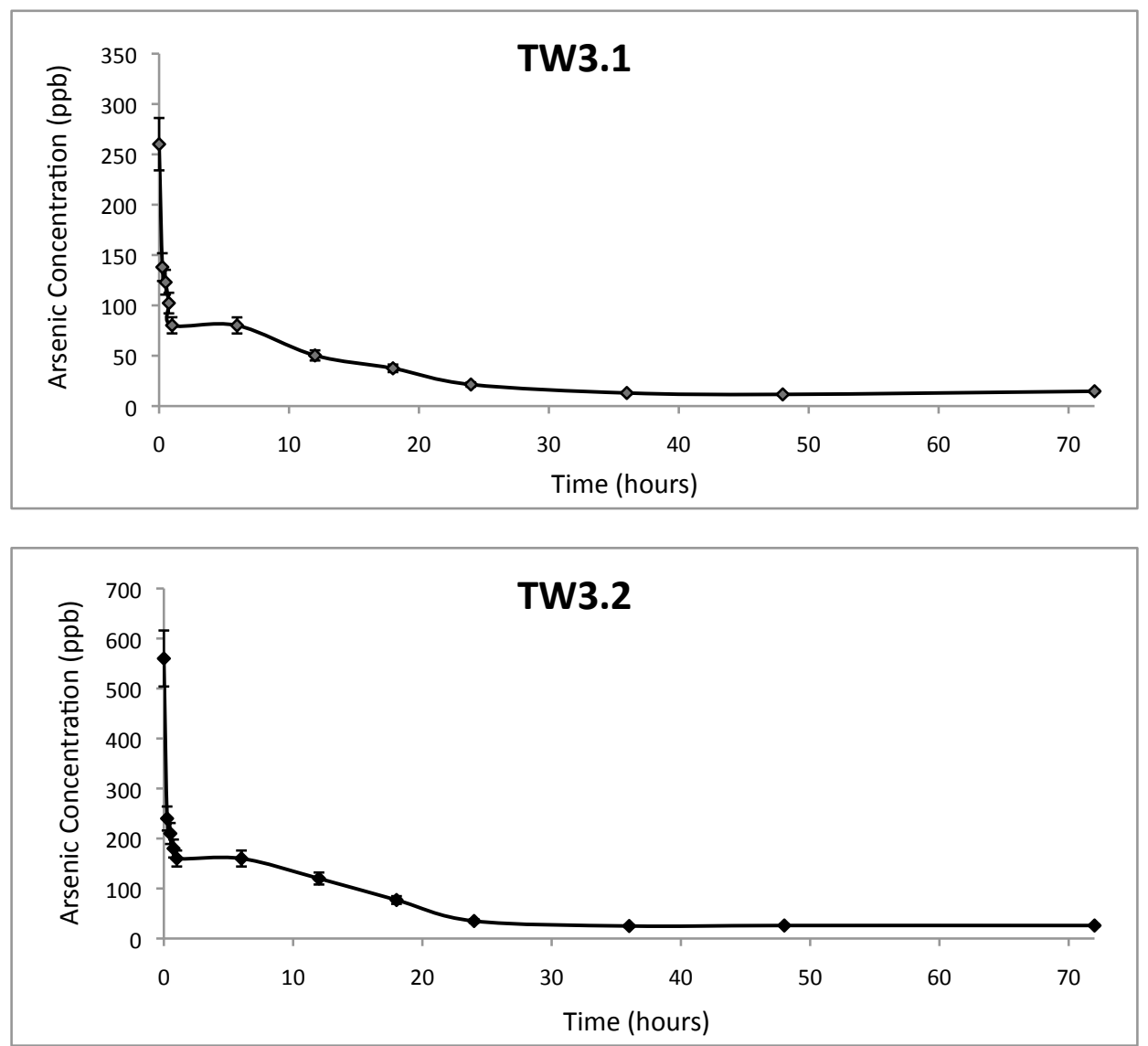

ARUBA. After six hours, As(III) slowly begins to oxidize to As(V), which eventually adsorbs to ARUBA as well. Noteworthy is the fact that adsorption continues despite the fact that the ARUBA is settled at the bottom of the container, not suspended in the solution.

\subsubsection{Treatment Scalability}

During the second trip to Bangladesh, an experiment was performed in which $250 \mathrm{ml}, 500 \mathrm{ml}$, and $1000 \mathrm{ml}$ of water from TW2.1 and TW2.3 was treated with $1 \mathrm{~g}, 2 \mathrm{~g}$, and $4 \mathrm{~g}$ ARUBA per $250 \mathrm{ml}$, respectively, using the standard field treatment protocol in order to assess the scalability of ARUBA treatment. Results are in Table 23 .

Treatment does not seem to be perfectly scalable. However, prototype experiments presented Section 6.2 show that ARUBA treatment is scalable. It is likely that this experiment was not successful in demonstrating scalability because ARUBA was not as effectively mixed in the larger treatment containers (1.5 liter plastic water bottles) that were used for the $500 \mathrm{ml}$ and $1000 \mathrm{ml}$ treatments.

Also, since the standard field treatment protocol was used, treatment was only for 30 minutes, which has shown to be insufficient in the previous section. In fact, water from both $1000 \mathrm{ml}$ treatments, which was left over from this experiment and still contained ARUBA, was left overnight. After 22.5 additional hours of contact time between the water and ARUBA, samples were taken and filtered. Because of the additional contact time the arsenic concentration of TW2.1 was reduced from $69 \mathrm{ppb}$ to $50 \mathrm{ppb}$, and the arsenic 
Table 23: ARUBA Treatment Scalability (ICP-MS)

\begin{tabular}{|c||c|c|}
\hline & $\begin{array}{c}\text { TW2.1 } \\
\text { ppb }\end{array}$ & $\begin{array}{c}\text { TW2.3 } \\
\text { ppb }\end{array}$ \\
\hline \hline $250 \mathrm{ml}$ & 53 & 29 \\
\hline $500 \mathrm{ml}$ & 53 & 46 \\
\hline $1000 \mathrm{ml}$ & 69 & 50 \\
\hline
\end{tabular}

Figure 22: Comparison of the Final Arsenic Concentration of Different Fractionated Dosing Schemes in the Laboratory: $0.5 \mathrm{~g}$ Total Dose (ICP-MS)

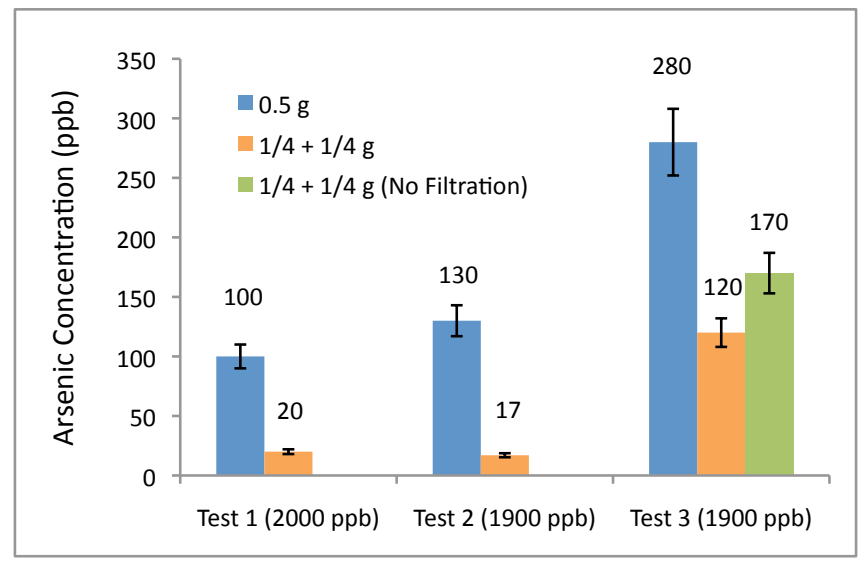

concentration of TW2.3 diminished from $50 \mathrm{ppb}$ to $21 \mathrm{ppb}$ (as measured by ICP-MS). These results are un-surprising given the results presented in the previous section.

\subsubsection{ARUBA Dosing}

Based on results from the first trip to Bangladesh, it was suspected that adding ARUBA in sequential fractionated doses could remove more arsenic than adding a dose of ARUBA all at once (for example, adding $2 \mathrm{~g}$ of ARUBA followed by a second $2 \mathrm{~g}$ of ARUBA, as opposed to adding $4 \mathrm{~g}$ of ARUBA all at once, which was done for the quadruple dose treatments described in Section 5.1.2). This method is known to increase the arsenic removal capacity of iron-based arsenic adsorbents formed through the chemical addition of ferric or ferrous salts (75).

This protocol was tested in the laboratory on $\mathrm{As}(\mathrm{V})$ spiked de-ionized water using the laboratory treatment protocol. Results of treating the water with a total dose of $0.5 \mathrm{~g}$ per $250 \mathrm{ml}$ are presented in Figure 22 and a total dose of $1 \mathrm{~g}$ per $250 \mathrm{ml}$ are presented in Figure 23. For each treatment with fractionated doses, except those labelled 'No Filtration', ARUBA was filtered out of the water between addition of doses. For the 'No Filtration' treatments the second dose of ARUBA was added to treatment containers still containing the first dose of ARUBA.

Because ARUBA's arsenic removal kinetics were not fully understood when these experiments were conducted, the treatment time was not held constant between experiments. For Test 1 (in both the $0.5 \mathrm{~g}$ and $1 \mathrm{~g}$ total dose experiments), the first fractionated dose of ARUBA was left in contact with the water for 35 minutes while the second fractionated dose of ARUBA was left in contact with the water for 20 minutes, for a total contact time of about 55 minutes. The final arsenic concentration of the fractionated dosing treatment is noted by the orange bar. The contact time for the dose that was added all at once was 35 minutes, and 
Figure 23: Comparison of the Final Arsenic Concentration of Different Fractionated Dosing Schemes in the Laboratory: $1 \mathrm{~g}$ Total Dose (ICP-MS)

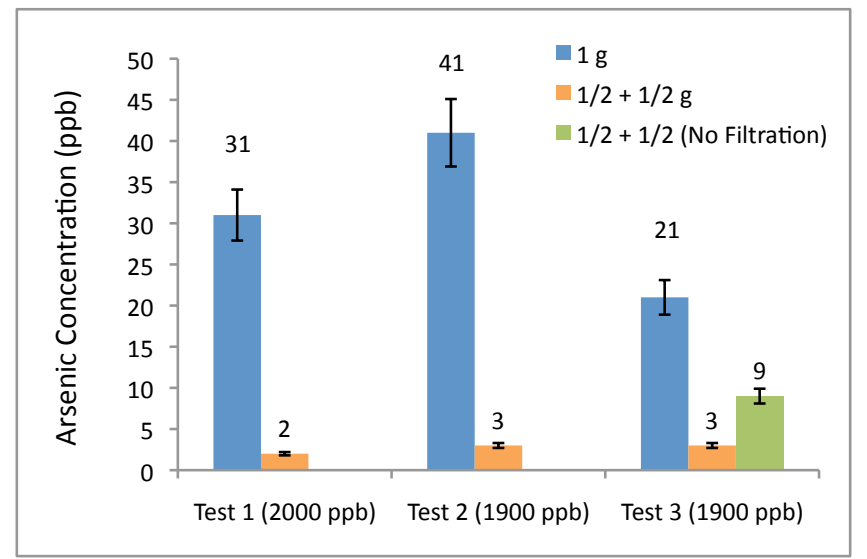

the final arsenic concentration is noted by the blue bar. Therefore, water treated with a dose of ARUBA added all at once was not treated as long as water treated with fractionated doses. However, it is unlikely that kinetics alone accounts for difference in final arsenic concentration between the two methods.

For Test 2, all water was treated for one hour. This means that the contact time for the dose that was added all at once was 60 minutes, while the contact time for each of the two fractionated doses was 30 minutes, for a total contact time of 60 minutes.

For Test 3, each dose was in contact with the water for 30 minutes, including the dose that was added all at once. Therefore, the total contact time for the treatments with fractionated doses was double the that of the treatments with a dose added all at once. Again, it is unlikely that kinetics alone accounts for the difference in final arsenic concentrations between the methods, given the results of Test 2.

It is interesting that the fractionated dosing treatments performed without filtration between the addition of doses performed significantly better than addition of a dose of ARUBA all at once. It is hypothesized that this is because arsenic diffuses to ARUBA particles until equilibrium is reached, and once equilibrium is reached, even if all the possible adsorption sites are not full, adsorption stops. When the first fractionated dose of ARUBA is added diffusion occurs until equilibrium is reached, and then when the second fractionated dose is added, since arsenic already adsorbed to the first fractionated dose of ARUBA does not desorb, a new equilibrium can be reached. Treatment works best when filtration is performed between addition of doses because arsenic bound to ARUBA is removed from solution, and equilibrium is reached at an even lower arsenic concentration.

These experiments were modified and performed in Bangladesh during the second trip. Water from TW2.1 and TW2.3 was treated with ARUBA using the standard field protocol $(1 \mathrm{~g}$ per $250 \mathrm{ml})$, and compared to water treated with five fractionated dosing schemes (Figure 24). For each treatment with fractionated doses, except the one labelled 'No Filtration,' ARUBA was filtered out of the water between addition of doses. Each dose was in contact with the water for 30 minutes, meaning that for water treated with one dose added all at once total contact time was 30 minutes, for water treated with two doses total contact time was 60 minutes, and for water treated with three doses total contact time was 90 minutes. Water from both tubewells was also treated with $2 \mathrm{~g}$ of ARUBA per $250 \mathrm{ml}$, adding all at once and adding in two equal doses (Figure 25).

These results are similar, though less extreme, than the laboratory results. Again, increased arsenic removal capacity of ARUBA added in fractionated doses may be due in part to the increased total contact time with the media; however, given laboratory results this is unlikely to account for the full discrepancy. The diffusion hypothesis as presented above seems to hold in the field as well. Note that water treated with three fractionated doses of ARUBA performed best indicating that increasing the number of doses increases 
Figure 24: Comparison of the Final Arsenic Concentration of Different Dosing Schemes in Bangladesh: $1 \mathrm{~g}$ Total Dose (ICP-MS)

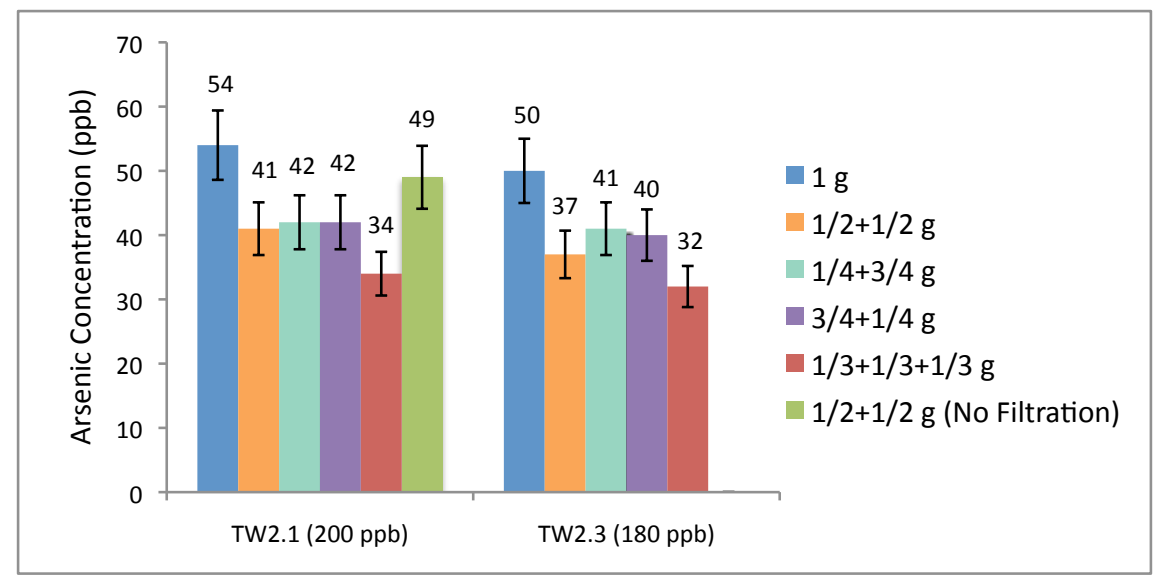

Figure 25: Comparison of the Final Arsenic Concentration of Different Dosing Schemes in Bangladesh: $2 \mathrm{~g}$ Total Dose (ICP-MS)

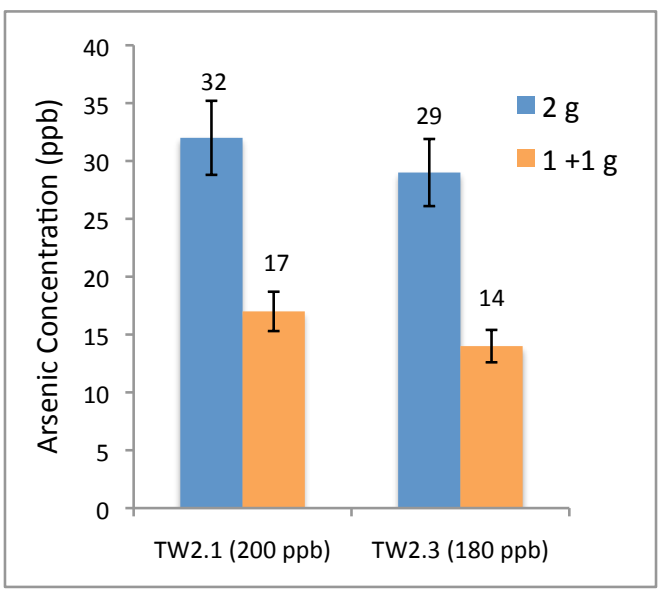


Figure 26: Final Arsenic Concentrations of TW2.1 \& TW2.3 Water Stored Before Treatment (ICP-MS)
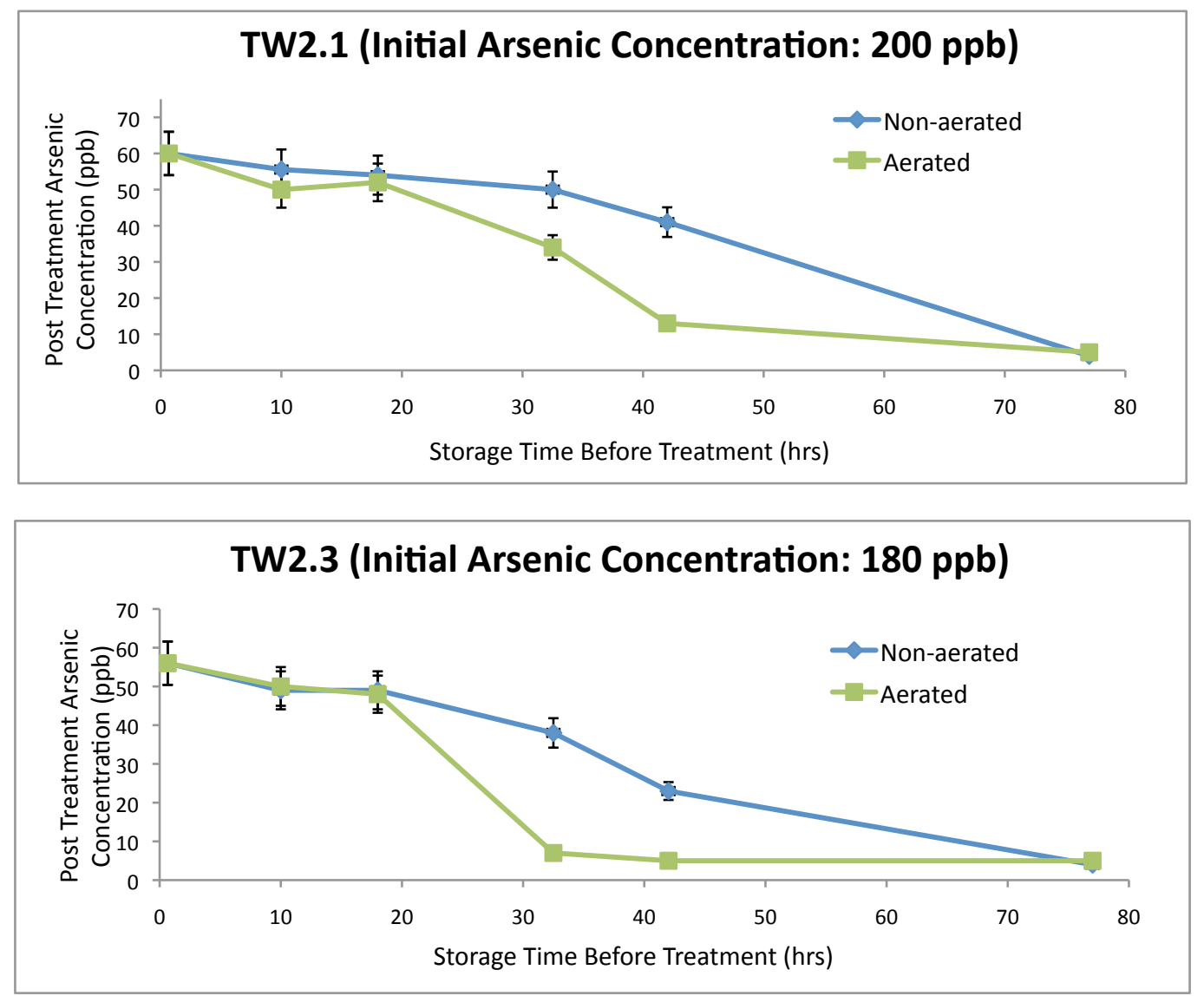

ARUBA's arsenic removal efficiency, but the choice of fractionation (e.g., $\frac{1}{2} g+\frac{1}{2} g$ versus $\frac{3}{4} g+\frac{1}{4} g$ of ARUBA) does not seem to have a significant affect on the final arsenic level.

\subsubsection{Water Storage before Treatment}

As a result of work conducted during the first trip to Bangladesh, we learned that storing water for some time before treatment could effectively increase the arsenic removal capacity of ARUBA. Therefore, during the second trip to ARUBA we quantified how arsenic removal capacity changes with increased water storage time. We also determined the difference in ARUBA's arsenic removal capacity in treating water that had been stored open to the atmosphere, and water that had been stored sealed shut.

Three liters of water were collected from TW2.1 and TW2.3. Half of the water was stored in six $250 \mathrm{ml}$ bottles, which were overfilled and sealed in an attempt to minimize the amount of air in the container. The remaining portion of water was stored in open one liter bottles. Air was pumped into the open containers approximately every 12 hours throughout the course of the experiment. At intervals, water from one 250 $\mathrm{ml}$ non-aerated bottle and a $250 \mathrm{ml}$ aliquot of water from the aerated containers was each treated ARUBA using the standard field protocol. Post-treatment arsenic concentrations as a function of water storage time are plotted in Figure 26. ARUBA's arsenic removal capacity increases as the samples are stored for longer periods of time, presumably because more of the As(III) has oxidized to As(V), which ARUBA is able to remove.

In order to correlate As(III) concentrations to ARUBA's arsenic removal capacity, this experiment was 
repeated during the third trip to Bangladesh. We also aimed to determine how much arsenic is settled through co-precipitation with naturally-occurring iron in the water sample. Water was taken from TW3.1 and TW3.2 and stored in uncapped bottles for one week. At intervals, samples of the water were:

1. tested for As(III) concentration,

2. filtered with Whatman Grade Number 1 filter paper, to remove naturally-occurring iron-arsenic precipitates, and tested for total arsenic concentration, and

3. treated with ARUBA using the standard field protocol and tested for total arsenic concentration.

Figure 27 shows results of the arsenic concentration measurements (by GF-AAS) described above for both tubewells. Figure 28 shows how the dissolved oxygen concentration of the stored water changed over the course of the experiment, while Figure 29 shows how the $\mathrm{pH}$ changed over the course of the experiment.

While general trends seen in Figure 27 seem to correspond to trends seen in Figure 26 and support our hypothesis that as As(III) converts to As(V) ARUBA's arsenic removal capacity increases, data taken over the first day of the experiment are confusing. 'Initial Concentration AAS 1' in purple were measured from samples taken directly from the tubewell the day that we collected the water for the storage experiment. The initial arsenic concentrations make little sense as they are lower than some subsequent arsenic concentrations measured during the experiment. In addition, arsenic concentrations measured for 'Arsenic III' and 'Filtration only' increase before they begin to decrease, which is counter-intuitive.

Approximately a week after taking these water samples we acidified some water that we had drawn from TW3.1 and TW3.2 the same day that water samples were taken for the water storage experiment. Acidification was performed in order to dissolve the precipitates that had formed. Using GF-AAS we measured arsenic concentrations of the acidified samples and adjusted the measurements by the correct dilution factor. Results are plotted in light blue as 'Initial Concentration AAS 2.' These results make more sense, given arsenic concentrations measured throughout the experiment.

We also took the initial samples (from which 'Initial Concentration AAS 1' was measured) to Berkeley for ICP-MS analysis. Results labeled 'Initial Concentration ICP-MS' are plotted in orange. Again, these results make more sense than the original measurement, but do not correspond well to the second AAS measurement.

In order to understand the differences in arsenic concentration measurements we re-analyzed seven samples from TW3.1 water and seven samples from TW3.2 water with ICP-MS. Results are plotted in Figure 30 side-by-side with GF-AAS measurements. 'Initial' samples were taken directly from the tubewell head or on site, while ' $12 \mathrm{Hr}$ ' samples were taken in bottles back to Dhaka and left uncapped for many hours before filtration, ARUBA treatment, and As(III) measurements. Samples for GF-AAS (and later ICP-MS) were stored tightly capped.

Interestingly, the discrepancies between GF-AAS and ICP-MS for all of the '12 Hr' samples and the 'Initial Treatment' are small, while discrepancies between the initial arsenic concentrations, initial As(III) concentrations, and initial filtered arsenic concentrations are enormous.

When samples were taken from both tubewells, bubbles were seen to form in the solution indicating that the samples contained a volatile compound. Our collaborator, Dr. ABM Badruzzaman, mentioned that high levels of methane had been measured in tubewells in this area. Methane is known to complex with arsenic to form organic arsenic molecules (52). Given the results is seems as though methane, or some other volatile compound, is biasing our initial GF-AAS arsenic concentration measurements, with the exception of the initial treatment. This makes sense given that during the initial treatment and during water storage (in uncapped bottles) the volatile compound would have had ample time to escape.

Interestingly, if this theory is true, the volatile compound did not seem to have time to escape when sample vials were opened sporadically by the lab technician who measured their arsenic concentrations with GFAAS. However, repeated GF-AAS measurements of the same samples were, on average, a bit higher than earlier measurements supporting the theory that some volatile compound is slowly escaping from the water. 
Figure 27: Final Arsenic Concentration of TW3.1 \& TW3.2 Water Stored Before Treatment (GF-AAS)
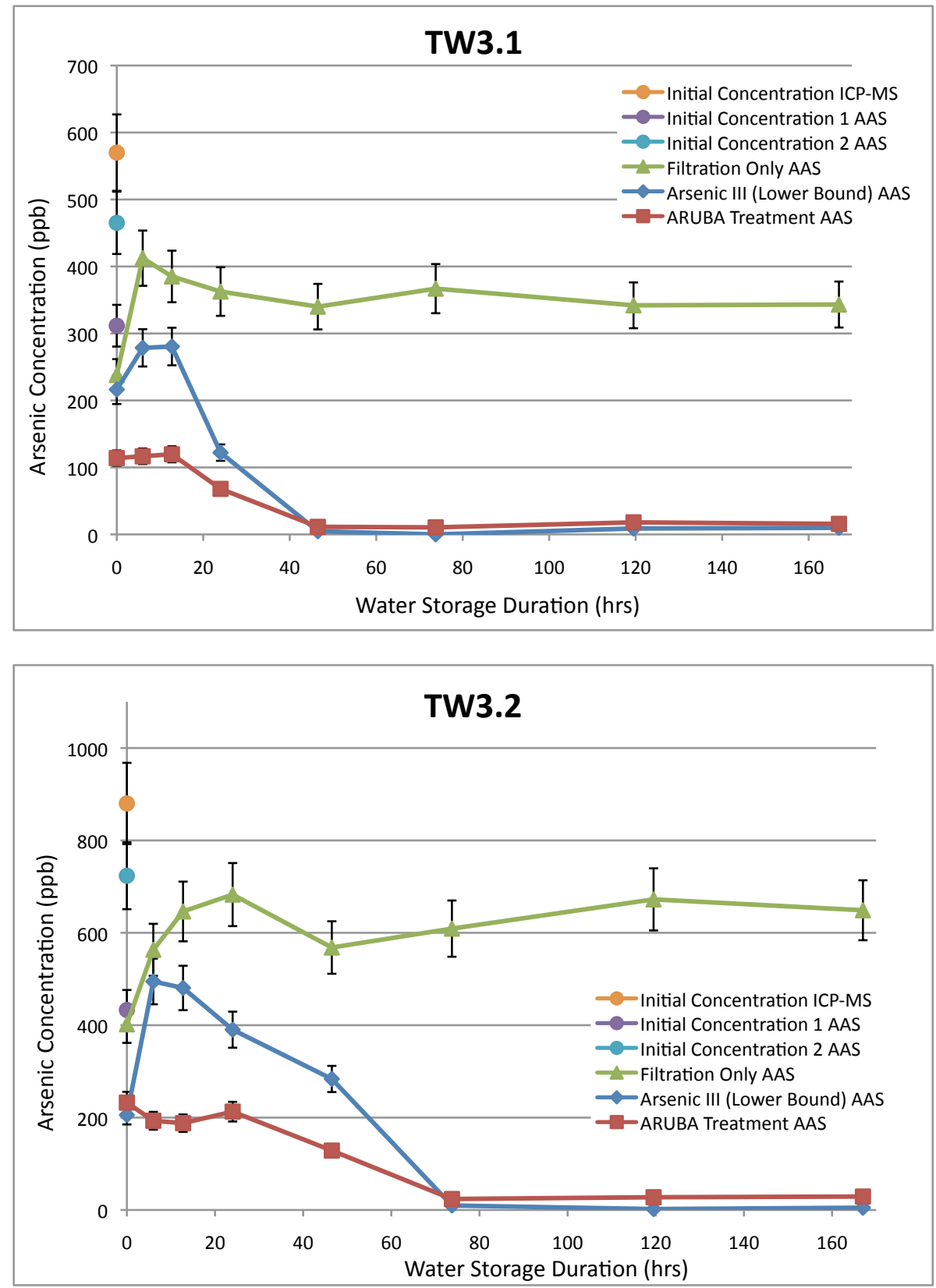
Figure 28: DO Measurements of the Stored Water

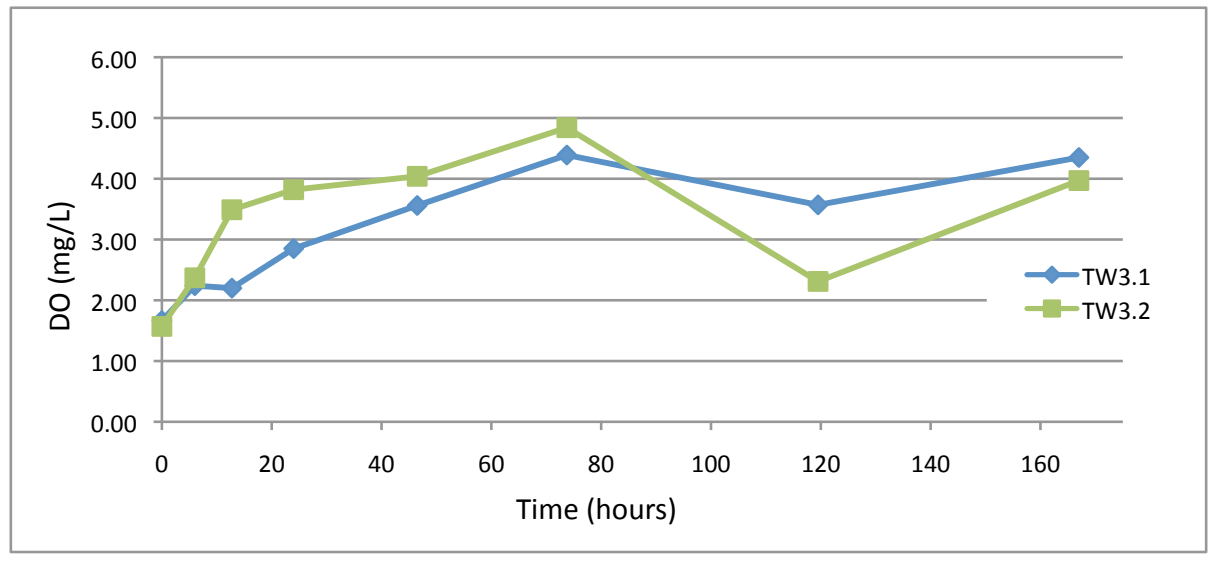

Figure 29: pH Measurements of the Stored Water

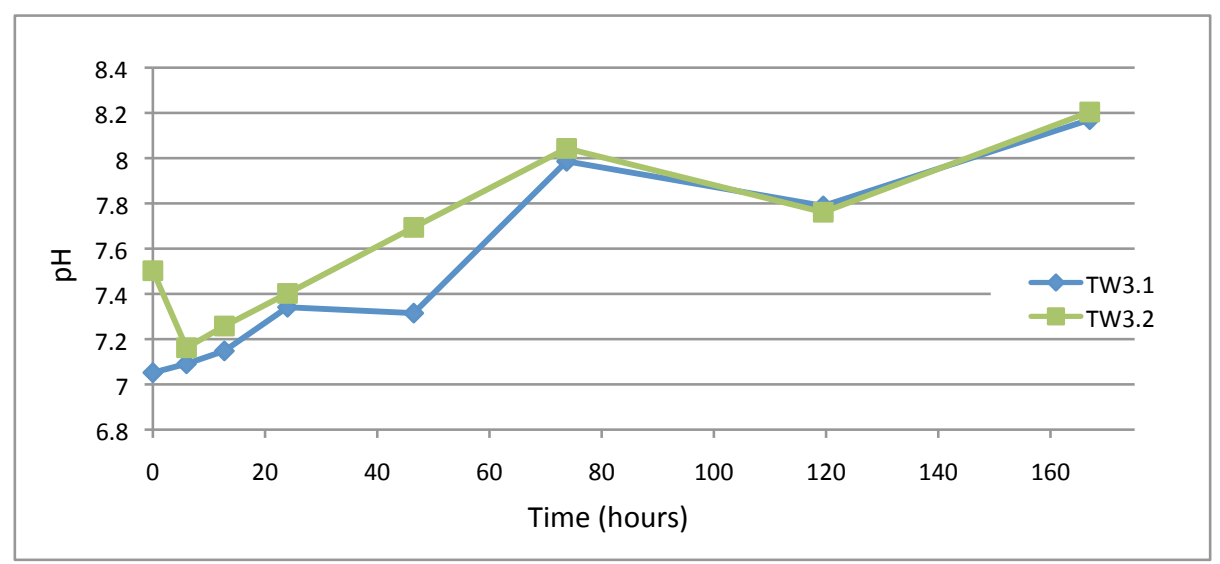


Figure 30: Discrepancies between ICP-MS and GF-AAS Measurements (ICP-MS \& GF-AAS)
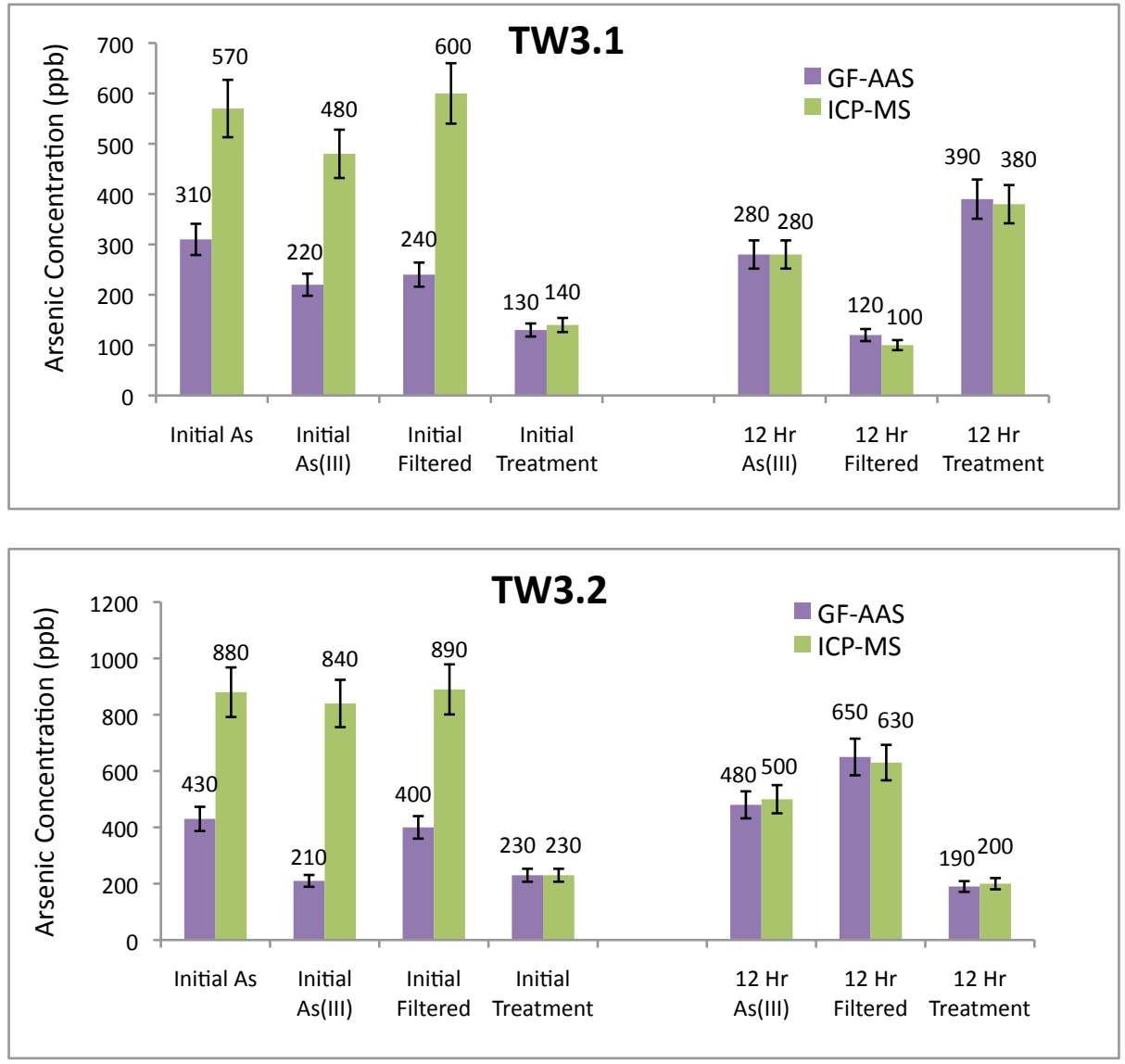
Figure 31: Water Storage (ICP-MS \& GF-AAS)
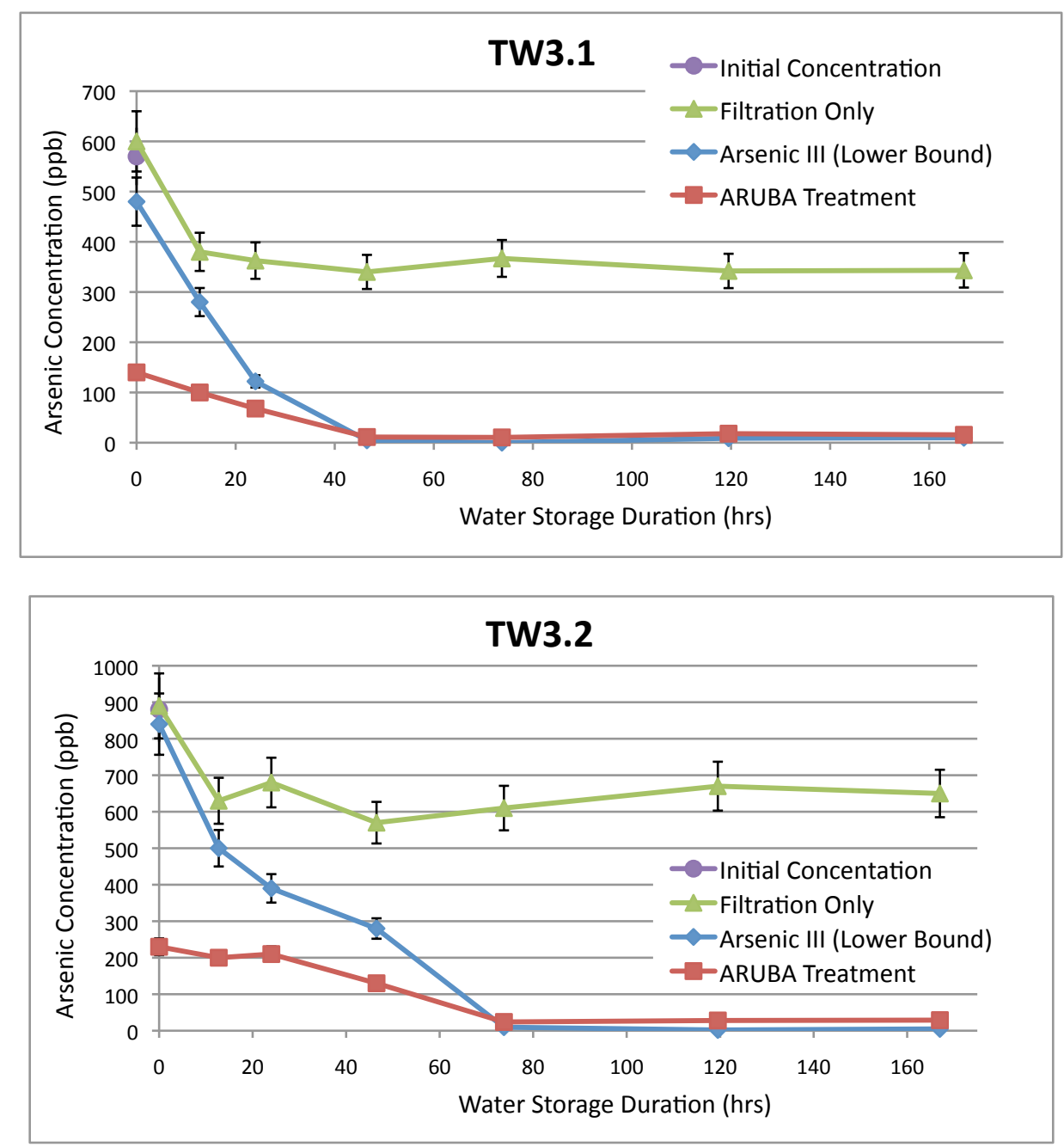

Assuming that ICP-MS results are more accurate for initial arsenic concentrations, and assuming that ICPMS and GF-AAS converge after 12 hours, we can make a composite ICP-MS/GF-AAS plot as seen in Figure 31. This plot uses ICP-MS results for the initial and ' $12 \mathrm{Hr}$ ' arsenic concentrations and GF-AAS measurements for the remaining arsenic concentrations (GF-AAS results for '6 $\mathrm{Hr}$ ' are not included).

From Figure 31 we can see that the concentration of $\mathrm{As}(\mathrm{III})$ decreases overtime as it oxidizes to $\operatorname{As}(\mathrm{V})$, enhancing the performance of ARUBA. In fact, after storing water uncapped for three days, post-treatment arsenic concentrations are ten times lower than those of freshly pumped water. Note that natural coprecipitation followed by filtering removes some arsenic; however, this constitutes a small percentage of the total arsenic removed by ARUBA treatment.

Plotting data from both storage experiments conducted during the second and third trip to Bangladesh on the graph of arsenic removal capacity versus initial arsenic concentrations and fitting that data to a new regression line as in Figure 32, we can see that by storing water for several days ARUBA's arsenic removal capacities increases noticeably. The slope of this regression line is approximately half of that in the laboratory. Since we can assume that the stored water which treated to produce these four data points did not contain any more As(III), the remaining difference between the performance of ARUBA in the laboratory and in the field can be attributed to competing ions. 
Figure 32: Bangladesh, Cambodia, Laboratory, \& Post-Storage Arsenic Removal Capacity v. Initial Arsenic Concentration (ICP-MS \& GF-AAS)

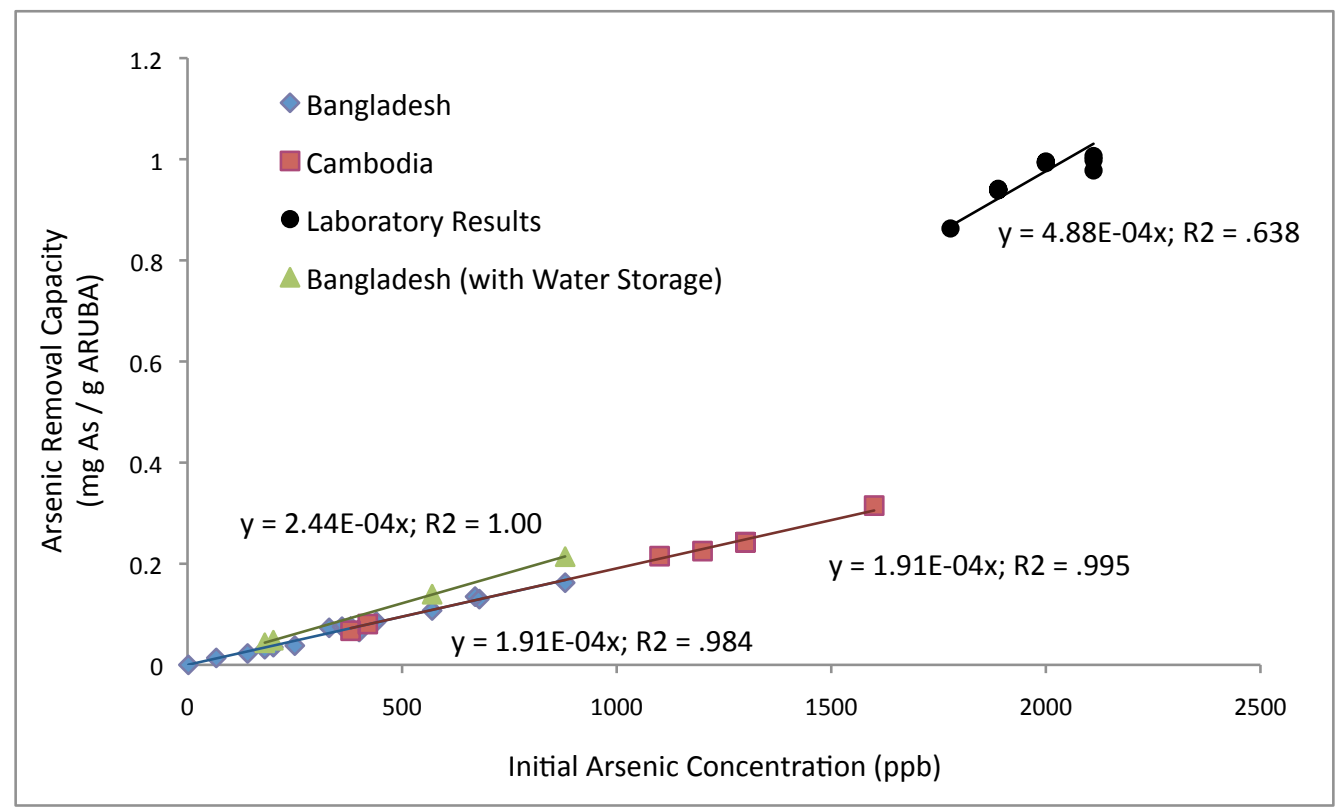

\subsubsection{Removing Manganese with ARUBA}

Recently there have been worries that high levels of manganese $(\mathrm{Mn})$ in drinking water could have adverse health effects. The US EPA suggests reducing manganese content in drinking water to below $50 \mu \mathrm{g}$ per liter (26). Therefore, we tested ARUBA's ability to remove manganese from groundwater, hoping that this could be an added benefit of the technology.

During the third trip to Bangladesh, water samples from TW3.1 and TW3.2 were treated with ARUBA using the standard field protocol. Two treatments were performed for each well for repeatability (A \& B). Initial manganese concentrations were measured using a sample taken directly from the tubewells, and post-treatment manganese concentrations were measured as well. Results are plotted in Figure 33. ARUBA removes a significant amount of manganese from Bangladesh groundwater. In fact, in both cases initial manganese concentrations were above the US EPA recommended limit, and after ARUBA treatment manganese concentrations had decreased to a safe level.

Welch and Stollenwerk (2003) explain that manganese oxides can adsorb to arsenic. Therefore, when arsenic adsorbed to ARUBA, manganese may have adsorbed to the arsenic, instead of to ARUBA directly. We have not explored these mechanisms.

\subsection{Performance of ARUBA made in Bangladesh}

To demonstrate that ARUBA could be manufactured in Bangladesh, four $200 \mathrm{~g}$ batches were made and tested for their ability to remove arsenic. The batches were made at BUET using the standard laboratory protocol with the exception that distilled water was used instead of de-ionized water for three of the batches, and Dhaka tap water was used for one of the batches. Both the sodium hydroxide and the ferrous sulfate were reagent grade chemicals purchased from Merck KGaA, Germany. In each case, $100 \mathrm{~g}$ was spread in each of two Pyrex dishes for drying. Because of Bangladesh's humid climate, ARUBA does not dry overnight without use of a fan, and so a fan was incorporated into the protocol. 
Figure 33: Manganese Removal with ARUBA

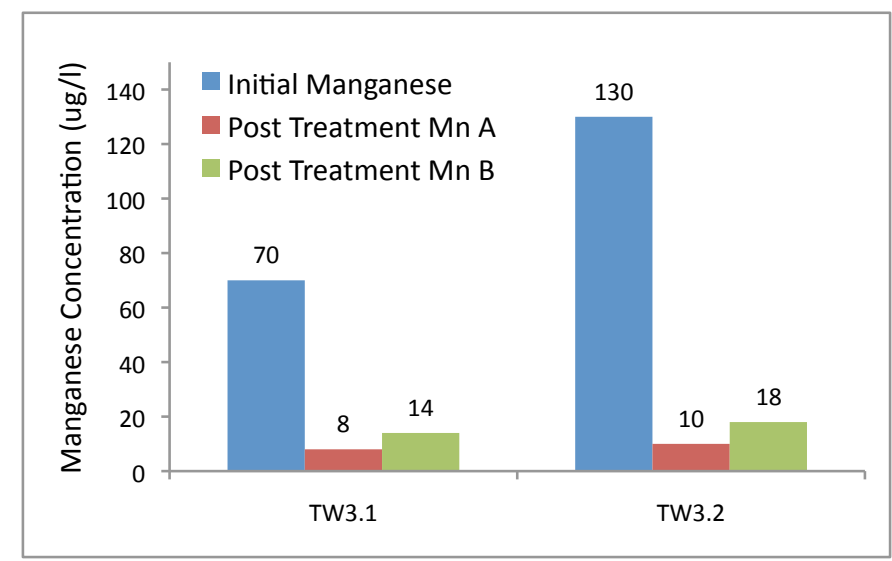

Figure 34: Capacity Test Results of ARUBA Made in Bangladesh, Initial Arsenic Concentration: $1750 \mathrm{ppb}$ (GF-AAS)

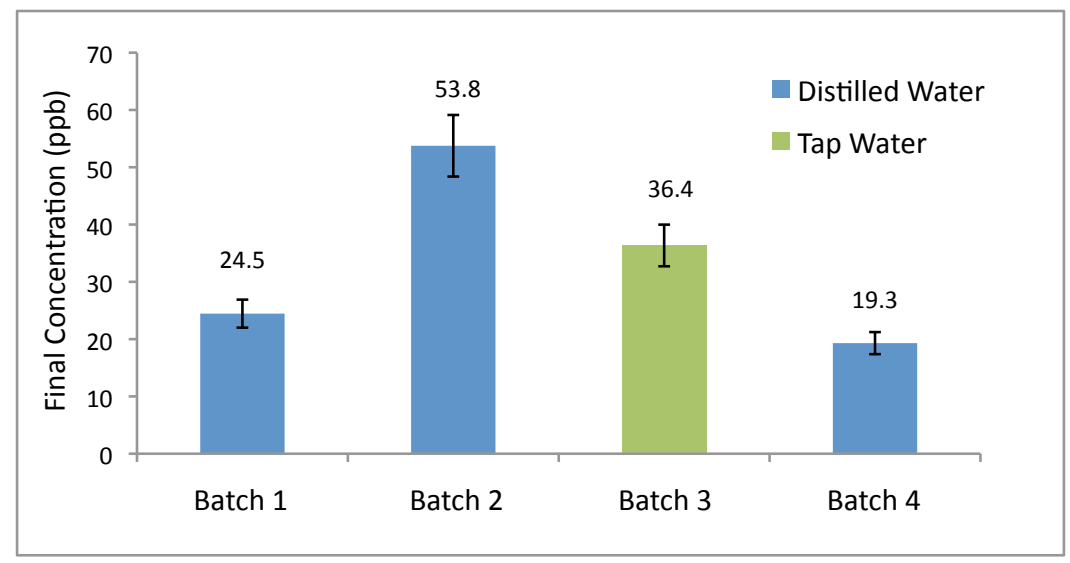

Each batch of ARUBA was tested for its arsenic removal capacity using the standard laboratory protocol, with the exception that $\mathrm{As}(\mathrm{V})$ distilled water was used instead of de-ionized water. Final arsenic concentrations are plotted in Figure 34.

Note that Batch 3 was made with tap water because the lab distiller was broken. Importantly, it performed comparably to the other batches. Using tap water instead of de-ionized or distilled water to manufacture ARUBA will mean significant manufacturing cost savings.

\section{Designing an Arsenic Removal Device}

In designing a water treatment device that uses ARUBA to remove arsenic from drinking water, it was necessary to develop a number of design strategies to ensure that the technology will be accepted by users, long-term sustainable, and meet the policy requirements in Bangladesh. This section discusses each of the eight design strategies we have developed over the course of this project. It also describes the development and analysis of a 10 liter per hour prototype and the design of a 100 liter per hour prototype. It concludes with a discussion of a possible implementation plan, and a cost analysis. 
Table 24: Eight Key Design Strategies for Designing an Arsenic Removal Device

\begin{tabular}{|l|l|}
\hline 1 & Maximize effectiveness of arsenic removal technology \\
\hline 2 & Design community-scale treatment center to minimize perceived inconvenience \\
\hline 3 & Minimize distance between homes and water treatment center, or provide water delivery \\
\hline 4 & Enhance perception of treated water quality \\
\hline 5 & Build trust in technology through continuous water monitoring and guaranteeing technical efficacy \\
\hline 6 & Minimize cost to villagers \\
\hline 7 & Allow for ease of local water management (source monitoring) \\
\hline 8 & Ensure feasibility of arsenic removal waste management \\
\hline
\end{tabular}

\subsection{Design Strategies}

Much of the research on arsenic removal technologies for Bangladesh has focused only on technical solutions. Analysis of user preferences and costs appear as footnotes to technical designs and testing. Plans for largescale implementation and sustainability are often left out completely.

While it has been important for us to develop an effective arsenic removal technology, it has been equally as important to consider how our technology will be incorporated into a system that will be accepted by users and scalable for dissemination throughout rural Bangladesh. Therefore, we have developed eight design strategies through analysis of past studies (primarily in public health \& medicine, policy, and risk analysis), in addition to field observations, informal interviews with Bangladeshi villagers, and discussions with leaders in the Bangladesh's water sector. A summary of our eight design strategies is presented in Table 24.

Several other studies have outlined criteria for evaluation of arsenic removal technologies. Chowdhury et al. (2000) list costs; ease of implementation, running and maintenance; flow rate; arsenic removal capacity; susceptibility to bacteriological contamination; and community acceptability. Ahmed (2001) lists the following major design needs: improve arsenic removal effectiveness, reduce costs, user-friendly designs, overcome maintenance problems of household technologies, and resolve waste management problem. Many of these criteria have been incorporated into our design strategies.

\subsubsection{Strategy 1: Maximize Effectiveness of Technology}

Research presented in Sections 4 and 5 have chronicled our attempt to maximize the effectiveness of ARUBA. Our results imply a number of trade-offs that must be made when designing an arsenic removal system using ARUBA. Storing water before treatment, increasing water treatment time, and/or using fractionated doses drives up treatment costs, while reducing the amount of media needed (though, we expect media costs will not dominate the total system costs). In turn, this decreases the amount of waste produced by the treatment system and, subsequently, the waste management costs (see Section 6.1.8 for more information on waste management). Since clearly strategy 1 and strategy 6 compete the degree to which we would actually maximize the effectiveness of ARUBA (measured as its arsenic removal capacity) is still unclear.

\subsubsection{Strategy 2: Community-Scale Treatment}

Our second design strategy addresses the appropriate scale of the technology. Many technical studies have proposed household-based filters; however, in an extensive study for the World Bank, Ahmad et al. (2003) found that $72 \%$ of villagers surveyed would choose a community-based technology (specifically, deep tubewells) over a household filter. This may result from other preferences held by villagers. Several studies have found that villagers listed convenience as the most important attribute of a water treatment system $(2,14,45)$. 
Community-scale systems, especially those maintained by a trained technician, are more convenient than household filters in terms of individual time spent using and maintaining the system. Several studies report household filters are often abandoned because they required too much attention and maintenance $(38,2)$.

It is important to note that the literature is not consistent on whether a household or community-scale device would be most appropriate. For example, Hussam and Munir (2007) claim that household filters are more appropriate than community arsenic removal systems or switching to deep tubewells because women should not be expected to travel far to fetch water, as traveling to fetch water is inconvenient. This point is discussed in the next subsection.

\subsubsection{Strategy 3: Minimize Distance to Safe Water}

Villagers have reported a preference for fetching water from deep tubewells over using and maintaining a household-based filter to remove arsenic, but their most common complaint is the distance to the deep tubewell (2). Most villagers have shallow (and inexpensive ${ }^{5}$ ) tubewells in their yard. In several villages in Jessore District, we spoke with villagers who had to walk $200-500 \mathrm{~m}$ to fetch water from community-owned deep tubewells. These distances were considered far. While people reported that they generally fetched drinking water from the deep tubewell, most also admitted that they would drink water out of contaminated tubewells when they did not want to make the trip to the arsenic-free source.

In North Nolua (Matlab District), where families were not using a community source, men reported that it would put women and their children in danger if the women had to walk far from their family's compound to collect water. Caldwell et al. (2003) state that both fetching water from outside family compounds and maintaining a household water treatment unit, "reverses the process of relieving Bangladeshi women of some of their onerous workload." Therefore, minimizing the distance to safe water sources and/or providing water delivery is important for the success of a community water treatment center.

\subsubsection{Strategy 4: Enhance Perception of Treated Water}

In designing an arsenic removal unit, it is necessary to ensure that villagers have a positive perception of the treated water's quality. In North Nolua, all of the villagers we spoke to associated water quality with the look and taste of the water. For example, TW3.5 and TW3.6 are approximately ten meters apart and villagers reported that they drank water from TW3.5 (containing more than $400 \mathrm{ppb}$ arsenic) because the water looked cleaner and tasted better than water from TW3.6 (containing 2 ppb arsenic and high levels of iron, which precipitates out of solution). See Figure 35.

Hoque et al. (2004) found that villagers complained about poor water quality from household filters, while Adeel and Ali (2002) explained that the primary reason for user adoption of an iron-coated sand filter was the villagers liked the clarity of the water. Clearly, a water treatment system will not succeed if the treated water is perceived to be of a quality lower than that of the source.

\subsubsection{Strategy 5: Build Trust in Technology}

Villagers must trust that the water treatment system is working to remove arsenic, and not introducing biological or other chemical contaminants. Hymowitz et al. (2006) found that that the perception of efficacy of surface water treatment units was one of the main factors that dictated adoption. Chemical packets (containing ferric chloride) that remove arsenic from drinking water have not succeeded in Bangladesh because villagers could not tell if they were working, and were sceptical of a technology that was not explained to them (37).

Effective implementation of a community-scale systems must include community education about the devastating effects of arsenic and the method of arsenic removal, and must build a level of trust in an arsenic removal technology. Importantly, villagers also must trust the organization or program providing arsenic-free

\footnotetext{
${ }^{5}$ Caldwell et al. (2003) report that installation of a shallow tubewell takes less than 2 days and under $\$ 40$.
} 
Figure 35: Water from TW3.5 (right) and TW3.6 (left)

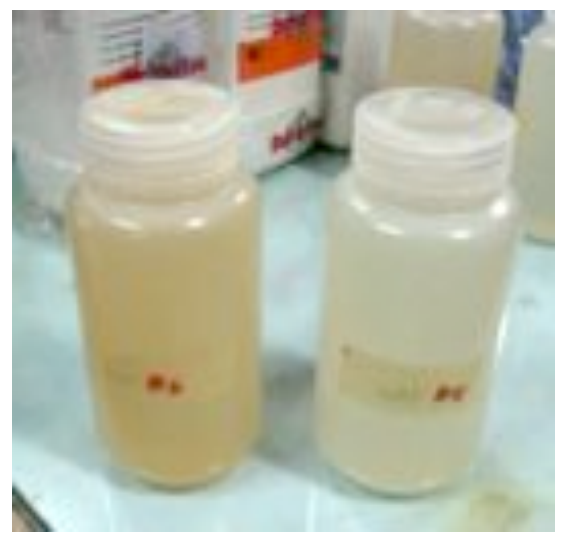

water or an arsenic removal technology. Jakariya (2000) explains that lack of villager trust has been a barrier for technology adoption. Some villagers believed that the intent of one arsenic remediation program was to financially benefit local pipe manufacturers (46).

Importantly, with community-scale treatment, trust can be built through water quality monitoring (including daily measurements of the treated water's arsenic concentrations and biological contaminant levels). At the household-scale users do not generally get feedback about their system. A major conclusion of a study by Chowdhury et al. (2000) is that all arsenic removal systems should be continuously monitored for arsenic and bacteriological contamination. Especially at the household level, improper use and maintenance of arsenic removal systems can easily lead to inadequate performance.

\subsubsection{Strategy 6: Minimize Cost to the Consumer}

For an arsenic removal technology to succeed, treatment costs must be minimized. In Jafornagar, we visited a community-scale arsenic-treatment unit that had been donated to a village. Unfortunately, villagers explained that they were unable to afford the annual filter cartridge replacement cost, reported to be $\$ 60$ - $\$ 75$, so the treatment unit had sat unused for more than three years. Similarly, many household filters (e.g., the SONO filter) have only been adopted with significant subsidies or donations because of large initial costs: $\$ 40-\$ 50$ for a filter with a lifetime of five years, a huge sum of money for risk-averse villagers living on less than $\$ 2$ per day and generally exhibiting very high discount rates. Moreover, it is difficult for villagers to secure micro-finance loans for household-based water treatment when such systems have little to no possibility of income generation. A community-scale system operating with a pay-as-you-go model does not require individual villagers to make large capital investments, instead villagers can purchase the amount of treated water that they need on a day-to-day basis. The system requires the village council, or some other entity to finance the project. Fortunately, it is much easier for a village council to take out a loan.

\subsubsection{Strategy 7: Ease of Local Water Management}

From a policy standpoint, water treatment systems should allow for ease in local water management, and, if possible, increase the effectiveness of local and national water policies. Fortunately, this is simpler with community-scale treatment since water quality can be monitored and guaranteed, something that has been lacking in the ad-hock development of rural clean water systems in Bangladesh (2). 


\subsubsection{Strategy 8: Feasibility of Waste Management}

An important logistical consideration is that all arsenic removal systems produce waste. On our most recent trip to Bangladesh we learned that Bangladesh policies classify spent arsenic removal media as radioactive waste and require it to be buried in concrete pits lined with thick plastic-membranes located far away from human habitation (Rick Johnston, personal communication, June 2008). Therefore, in a 2000 BRAC project people were asked to deposit arsenic removal waste at the nearest BRAC office for appropriate disposal (18). Unfortunately, this would is impractical.

A water treatment system should maximize the feasibility of waste management. Again, community-scale technologies make this possible. The same vehicle that delivers ARUBA to a community treatment center could also take the spent media away for burial or reprocessing, if the latter proves affordable.

It is important to note that the disposal costs in Bangladesh could be substantial. Approximately 14 grams of ARUBA are required to treat three liters of water (assuming that the water contains $400 \mathrm{ppb}$ arsenic and is stored for three days to allow $\mathrm{As}(\mathrm{III})$ to oxidize to $\mathrm{As}(\mathrm{V})$ ), which is enough for one person for one day according to the National Academy of Sciences Dietary Reference Intake (DRI) chart (28). Given that the average Bangladeshi village has approximately 2,000 people, over 10 metric tons of ARUBA would needed to provide arsenic-free water in each village each year. After use, all of this material would be waste.

\subsection{Prototype Development}

To fulfil the design strategies presented above we propose the design of a community-scale water treatment system. This decision directly addresses strategy 2, and enhances our ability to address strategies 4, 5, 7, and 8. More details are presented in Section 6.3. Note that strategy 6 (minimizing cost) was considered in every technical design decision.

Conveniently, designing a community-scale water treatment system, as opposed to household scale treatment units, allows us to consider the use of a wider array of technologies in the arsenic removal process. We assume that a trained technician instead of an untrained user would maintain the treatment system. We also assume access to electricity or, because of the size of the system, that it would be appropriate and affordable to incorporate a power source into the system design. Note that ARUBA treatment does not require electricity; however, hand-pumping enough water for an entire community would be impractical.

Since the average Bangladeshi village has approximately 2,000 people a community-scale treatment center would have to provide around 4,000 liters per day to meet the drinking water needs of the entire village. While ARUBA treatment has been standardized at a testing scale, several technical issues were solved to bring ARUBA treatment to a community-scale:

1. an effective way to mix ARUBA into large volumes of contaminated water, and

2. a low-cost method to remove the spent ARUBA from treated water.

\subsubsection{Mixing ARUBA into Water}

Working at BUET, we investigated two ways to mix ARUBA into arsenic-contaminated water: using small aeration pumps and using a mechanical mixer.

\section{Aeration Pumps}

Forty grams of ARUBA were mixed into 20 liters of $2000 \mathrm{ppb} A s(\mathrm{~V})$ spiked distilled water with two small aquarium pumps, each with two hoses resting on the bottom of the treatment bucket, vigorously bubbling water through the bucket (Figure 36). Unfortunately, during the experiment it was visually apparent that the aeration pumps were ineffective at maintaining complete ARUBA particle suspension. It was suspected 
Figure 36: Aeration Pumps Mixing ARUBA into 20 Liters of Contaminated Water

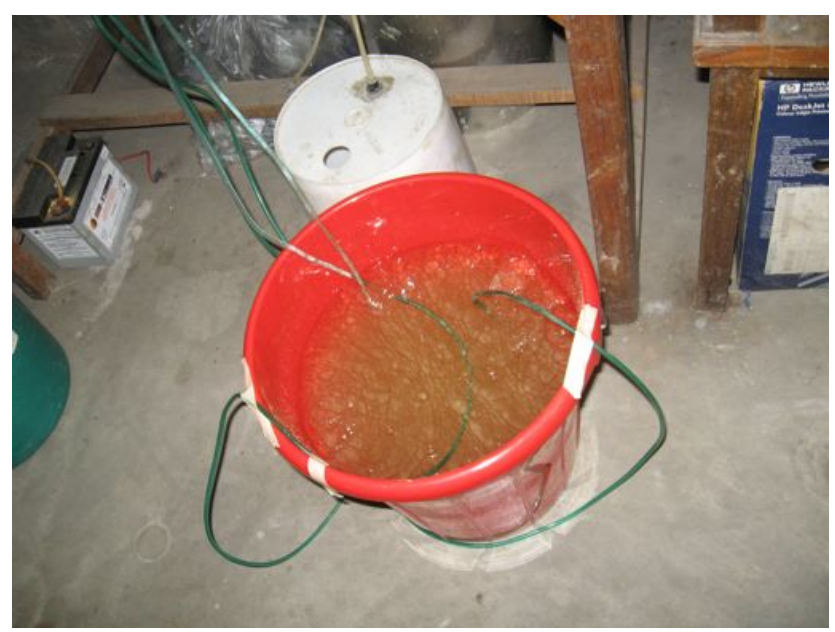

Figure 37: Treating 20 Liters of Water Using Aeration Pumps for Mixing (QuickTest)

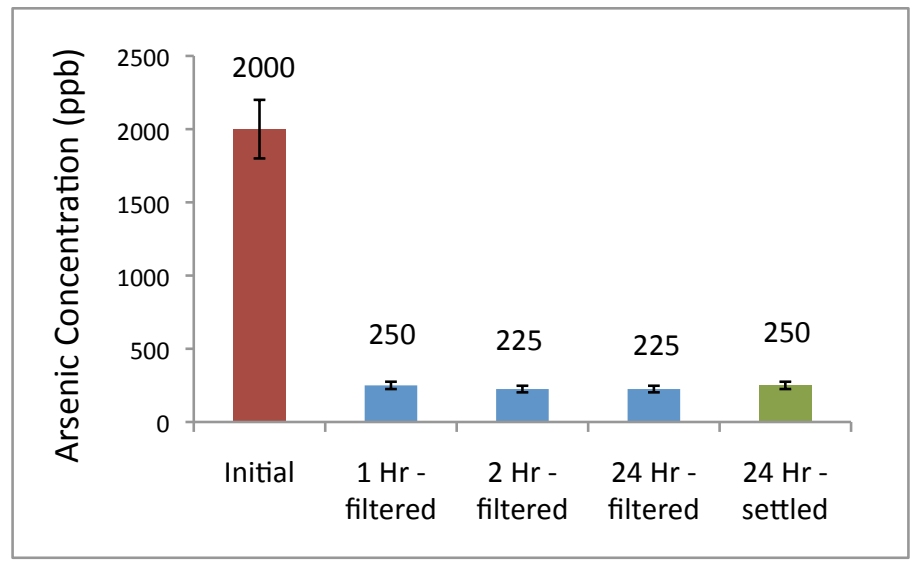

that stronger, more expensive pumps would be needed to ensure particle suspension at required ARUBA concentrations.

After one hour of treatment samples were taken and filtered (using Whatman Grade No 1 Qualitative Filter Paper). The arsenic concentration of the filtrate was measured and found to be $250 \mathrm{ppb}$ (as measured by QuickTest). An additional hour of treatment did not reduce the final arsenic concentration significantly. Hoping that additional contact time with ARUBA could reduce arsenic concentrations, ARUBA was left in contact with the water for 24 hours (the pumps were turned off during this period). Two samples were taken; one sample was filtered and tested for total arsenic while the second sample was simply tested for total arsenic (ARUBA had settled to the bottom of the treatment container and so there was no visible ARUBA in the sample). Arsenic concentrations were not lower than those measured the previous day. Results are summarized in Figure 37. Note that because the experiment was unsuccessful, samples were not saved for ICP-MS or GF-AAS. 
Figure 38: Electric Kitchen Mixer Mixing ARUBA into 20 Liters of Contaminated Water

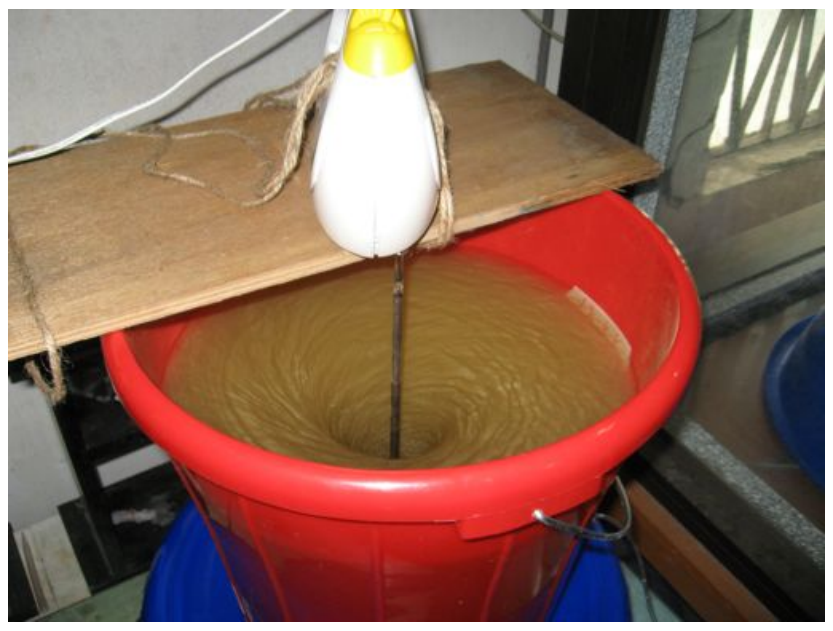

\section{Mechanical Mixer}

An electric kitchen mixer was used for mixing 40 grams of ARUBA into 20 liters of $2000 \mathrm{ppb}$ As(V) spiked water after lengthening one of the mixing shafts by welding an additional length of shaft on to the original. See Figure 38. Small plastic spoons were attached to the bottom of the shaft with rubber bands to serve as mixing blades. Eventually the cups of the spoons were cut off because the device, even on the lowest speed, produced too much turbulence and water over-spilt the treatment bucket.

After one hour of mixing with the mechanical mixer a water sample was taken and filtered. The final arsenic concentration was measured to be $57 \mathrm{ppb}$ (by GF-AAS), comparable to that which would be seen on the $250 \mathrm{ml}$ scale, indicating that the mechanical mixing method works well in maintaining ARUBA particle suspension.

The mixer was stopped and ARUBA was left to remain in contact with the water for six hours. A sample was taken off of the top (again, ARUBA had settled to the bottom of the treatment container and so there was no visible ARUBA in the sample), resulting in an even lower arsenic concentration. This indicated that treatment had not been concluded after 1 hour, and even through mixing had stopped.

Given these results, summarized in Figure 39, we used the electric kitchen mixer for the remainder of our experiments, and a mechanical mixer was been proposed for our larger scale prototype.

\subsubsection{Removing Spent ARUBA From Treated Water}

We also investigated two ways to remove spent ARUBA from treated water: a sand filtration system tested in Berkeley and an up-flow clarifier tested at BUET. Results of experiments used to test each method are presented below.

Other methods could be employed to remove ARUBA from water, though these methods have not yet been investigated. ARUBA particles are attracted to magnets; however, a simple experiment showed that the attraction did not seem strong enough to make particle removal by magnets practical. Further investigation is needed. Alternatively, Seo et al. (2007) present a method for removing small particles from water with a device that creates asymmetric curvilinear laminar flow. This device allows particle-laden water to separate from particle-free water without the use of membranes, and it has been proposed for use in water treatment systems $(78,79,53)$. It would be worthwhile to determine if ARUBA particles could be removed from treated water with this device. 
Figure 39: Treating 20 Liters of Water Using a Mechanical Mixer for Mixing (GF-AAS)

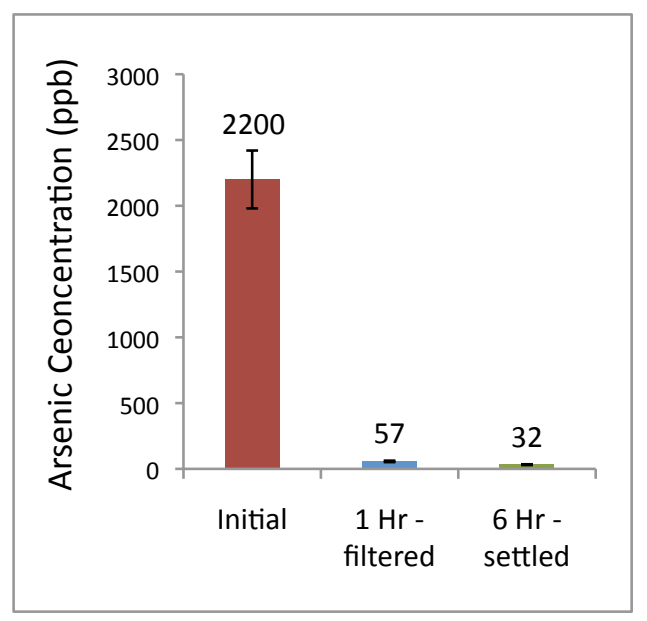

\section{Filtration System}

For community-scale treatment, we initially considered commercial water filtration systems such as GE's Homespring and Dow Chemical's OMEXEL, which are gravity-fed and therefore do not require pumps to operate. However, both of these system are expensive and would likely clog quickly given the high concentration of ARUBA needed to treat arsenic-contaminated water. Also, filtration membranes, capable of filtering 1 to $10 \mu \mathrm{m}$ particles, are very expensive for community-scale water treatment. In addition, they require high pressure pumps to push water through the membranes. Therefore, we did not consider the use of a membrane to remove ARUBA particles.

At LBNL we explored the use of a commercially available pool sand filter (Hayward S166T90 16 inch Pro Series High-Rate Sand Filtration System including a $1 \mathrm{hp}$ Power-Flo Matrix Pump) to remove ARUBA particles from treated water. The first task was to determine if the sand filter was able to remove ARUBA particles. We tested two filtration media: Grade \#20 silica sand $(450-550 \mu \mathrm{m})$ and ZeoSand ${ }^{T M}$ (by Zeo, Inc. PO Box 2353, McKinney, TX 75070. www.zeoinc.com), a natural zeolite marketed as a pool filter media that claims to have 100 times the surface area of pool filter sand.

Both filtration media proved ineffective at removing both un-coated bottom ash (which was tested first so as not to waste ARUBA) and ARUBA (which tested once it was shown that un-coated bottom ash passed through the filter) from the treated water, even when the ARUBA-laden water was re-circulated through the filter several times. We had intended to measure the effluent with an NTU meter in order to indirectly assess particulate concentrations; however, that proved unnecessary when the effluent came out of the filter heavily laden with particles. It was unsurprising that the sand was unable to remove ARUBA particles since grade \#20 sand should only be capable of filtering 20-100 $\mu \mathrm{m}$ particles. However, the results of testing the zeolite were disappointing. A diatomaceous earth (DE) pool filter, capable of filtering 3-5 $\mu \mathrm{m}$ particles, may be able to remove ARUBA particles from treated water. However, DE filters need high pressures necessitating a stronger, more expensive pump and/or resulting in lower flow-rates and lower efficiency. We have not attempted filtration with such a filter.

Experiments were conducted in Berkeley to determine if a coagulant could be used in order to increase particle sizes before filtration. Alum (hydrated potassium aluminium sulphate) was the first coagulant tried. An experiment was performed in which two beakers of $250 \mathrm{ml}$ of $2700 \mathrm{ppb} \mathrm{As}(\mathrm{V})$ spiked de-ionized water were each treated with $0.5 \mathrm{~g}$ of ARUBA using a modified version of the standard laboratory protocol. After one hour of mixing, one beaker was left to settle for a total of 60 minutes, and $0.06 \mathrm{~g}$ of alum was added to the other beaker. The water containing both ARUBA and the coagulant was mixed for 10 minutes, and then left to settle for 50 minutes, for a total alum contact time of 60 minutes. Alum seemed to successfully coagulate ARUBA particles, causing them to settle faster than in the beaker without alum. However, alum 
Figure 40: Particle Coagulation with Alum (ICP-MS)

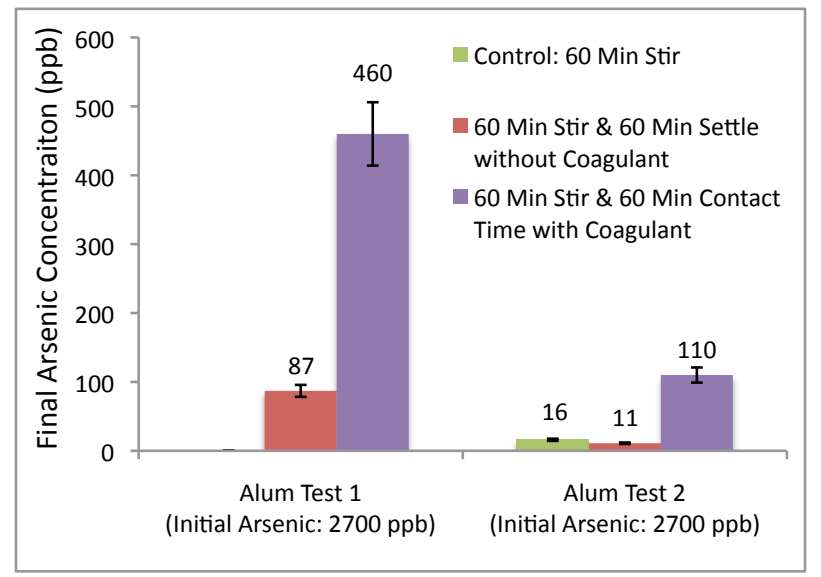

Figure 41: Particle Coagulation with Polyacrylamide (ICP-MS)

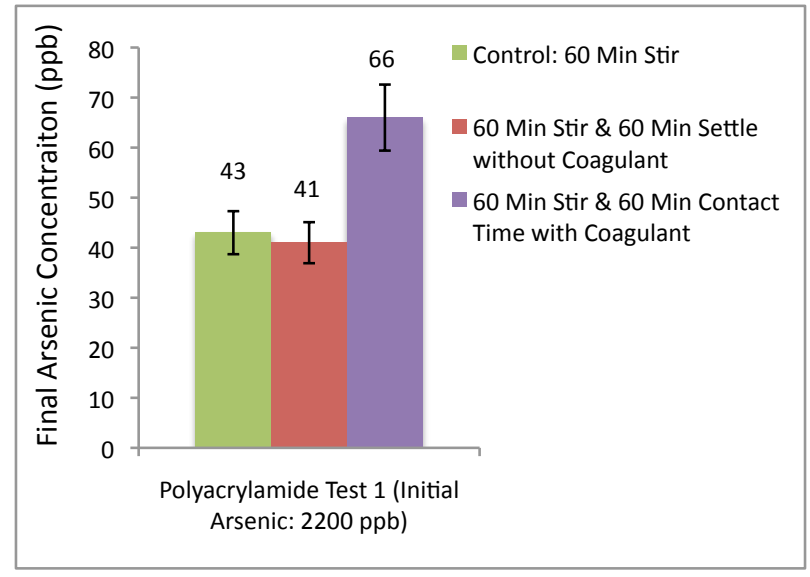

was found to interfere with ARUBA's ability to remove arsenic. See Figure 40 for results. The experiment was repeated using a different batch of ARUBA and a control (normal laboratory capacity test). Results are less extreme though the water treated with alum still performs the worst.

Polyacrylamide, a polyelectrolytic coagulant commonly used in water treatment, was also tried. The experimental protocol used to test the effectiveness of alum was repeated; however, only $0.05 \mathrm{~g}$ of polyacrylamide were used. Results, presented in Figure 41, show that the water treated with the coagulant performs worse, though not significantly worse than the water that was not treated with the coagulant. Unfortunately, during this experiment polyacrylamide did not successfully coagulate ARUBA particles. In fact, it appeared as though the polyacrylamide stayed on the water surface instead of interacting with the particles.

The polyacrylamide experiment was repeated, with the exception that the water was only treated with ARUBA for 20 minutes instead of the normal 60 minutes. Results were inconsistent. After five minutes of interaction with polyacrylamide the water looked clear because all of the ARUBA had settled on the bottom, whereas the water that was not treated with the coagulant still appeared cloudy with ARUBA. A different ARUBA batch was used for this experiment possibly indicating that some ARUBA parameter might affect its ability to be coagulated with polyacrylamide. Given the inconsistent results coagulation with polyacrylamide was abandoned. Further tests would be necessary to determine the cause of the inconsistency 
Figure 42: Diagram of Prototype Clarifier

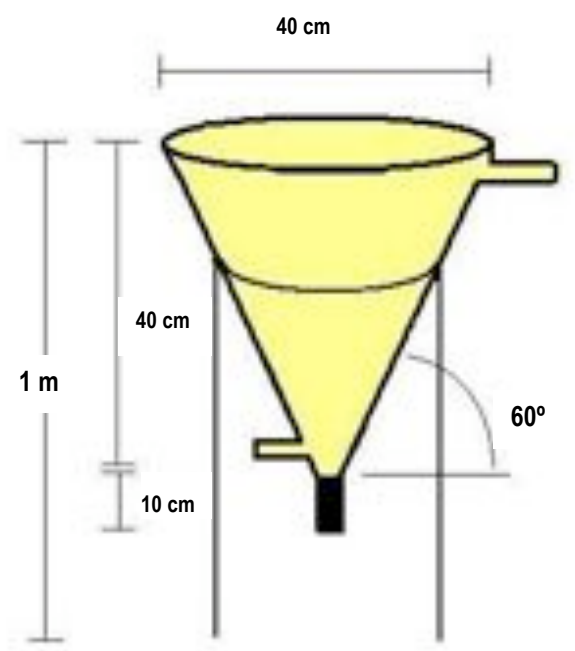

and if polyacrylamide could be made to consistently coagulate ARUBA.

Importantly, the ARUBA-polyacrylamide mixture was difficult to filter from the treated water. The filter paper became clogged very quickly and needed to be changed several times to allow all of the water to be filtered. Given these results we abandoned filtration and focused our efforts on removing ARUBA from treated water with a clarifier.

\section{Clarification System}

Since the sand filter was unsuccessful in removing spent ARUBA particles we designed and tested a prototype up-flow clarifier. Water enters a the clarifier from the bottom of the cone and flows upward, eventually spilling over the top edge, or through an outlet pipe. Placing the bottom of the water tank that feeds the clarifier higher than the top of the clarifier ensures that the system can be gravity-fed. Due to laminar flow, particles settle to the bottom of the clarifier and can be removed through a sludge outlet pipe.

Through experiments, ARUBA's settling rate was approximated to be $0.13 \mathrm{~mm}$ per second; however, this value is not very precise because we were forced to do this experiment by making qualitative observations over the course of 12 hours. Using this together with the clarifier design rule that the particle settling rate must be greater than the flow-rate divided by the cross-sectional area $\left(v_{t}>\frac{Q}{A}\right.$, where $v_{t}$ is the particle settling velocity, $Q$ is the flow rate through the clarifier, and $A$ is the cross sectional area halfway up the cone), we designed and built a clarifier capable of processing 10 liters per hour. We chose the angle of the cone to be 60 degrees, after surveying existing products to get a sense for the range of angles generally used to minimize particle accumulation on the wall. A diagram of the prototype (capable of holding about 16 liters) is in Figure 42, and a picture of the prototype is in Figure 43.

The flow rate was controlled with a valve, obtained at a local market, that is usually used in hospitals to control the rate of fluid release from a drip bag. Unfortunately, it was difficult to control the flow rate accurately and we often found the device filling faster or slower than we expected. We were told that obtaining precision valves in Bangladesh is not generally possible.

After experimenting with $\mathrm{As}(\mathrm{V})$ spiked DI water we tested the clarifier with 20 liters of water from several different wells in Sreenagar (a hybrid water sample). See Figure 44. We mixed $80 \mathrm{~g}$ of ARUBA into the water and after one hour we filtered a small sample for testing. Unfortunately, we were unable to complete the experiment that same day and had to leave the water to settle for three days. After three days we took 
Figure 43: Ten Liter per Hour Prototype Clarifier

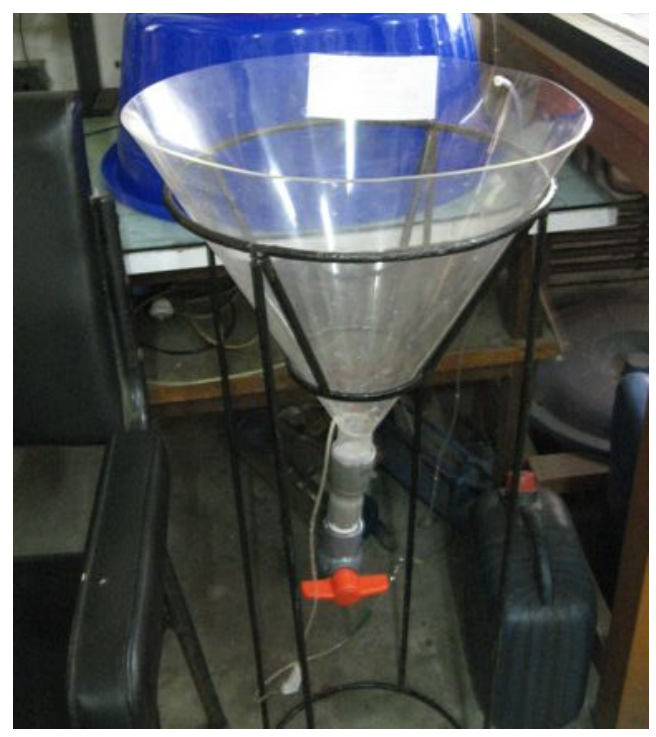

a sample off the top of the 20 liter container. We then stirred the ARUBA back into the water and then ran it through the clarifier, in order to test the effectiveness of the clarifier. The clarifier effluent looked tinged with yellow indicating that some iron or ARUBA had escape from the clarifier, resulting in the higher arsenic concentration than both the filtered sample and the sample taken from the top of the bucket after 3 days of settling. A summary of results are presented in Figure 45.

\section{Clarification with Particle Coagulation}

In general, even when the clarifier control valve was adjusted so that the water passed through the clarifier slower than 10 liter per hour the water was tinged with yellow. This yellow tinge was reminiscent of the tinge seen in all Bangladeshi groundwater samples containing high levels of iron that have been allowed to sit for several days. Therefore, we guessed that the tinge was mostly a result of precipitated iron rather than ARUBA. However, concerned that ARUBA was passing through the clarifier, we again sought a coagulant.

Song et al. (2006) claim good results in removing arsenic by coagulation with ferric ions and coarse calcite $(38-74 \mu \mathrm{m})$. Therefore, we obtained calcium carbonate and tried to use it as a coagulant; however, calcium carbonate powder does not have the same surface properties as coarse calcite (crushed mineral) and so coagulation was ineffective.

A polyelectrolyte commonly used in local water treatment systems was purchased in Dhaka for Tk 400 (approximately \$6) per kg. Though we are unaware of its chemical composition we were told that it is commonly used in water treatment applications and it is the 'high end' of the two polyelectrolytes available on the market. The polyelectrolyte was very successful at coagulating ARUBA. Figure 46 shows coagulated ARUBA particles, ten minutes after the addition of the polyelectrolyte.

In two separate tests, we treated 20 liters of groundwater from TW3.2 with $80 \mathrm{~g}$ of ARUBA and compared final arsenic concentrations in water that had been filtered versus water that had been treated with the polyelectrolyte (1.241 g in 20 liters) and passed through the clarifier, which took about two hours. Note that the water was stored for several days and so the As(III) content had diminished (and is less in the second experiment, which was conducted several days after the first). The results in Figure 47 show that both methods produced similar results. The effluent of the clarifier still had a slight yellowish tinge and so for aesthetic reasons it may be necessary to incorporate a post-clarification filter into the treatment process. Importantly, this filter would not need frequent maintenance since the clarifier precedes it. 
Figure 44: Shefah Qazi Tests the 10 liter per hour Prototype Clarifier

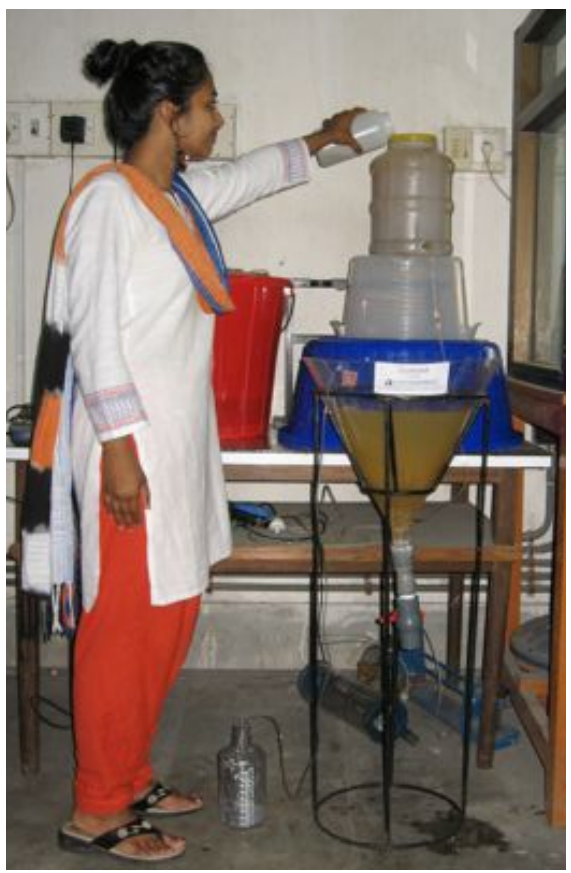

Figure 45: Comparison of Three Spent ARUBA Removal Methods (ICP-MS)

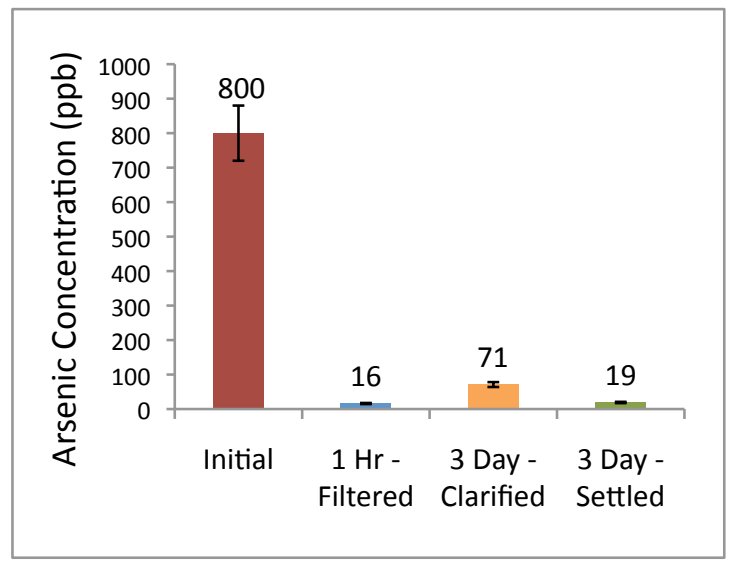


Figure 46: Coagulated ARUBA Particles, Ten Minutes after Addition of the Polyelectrolyte

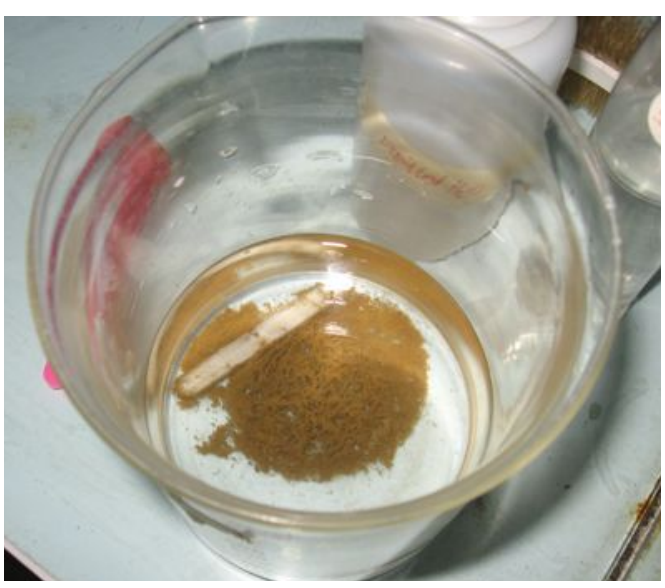

Figure 47: Removing Spent ARUBA with a Filter v. a Clarifier and Coagulant (ICP-MS)

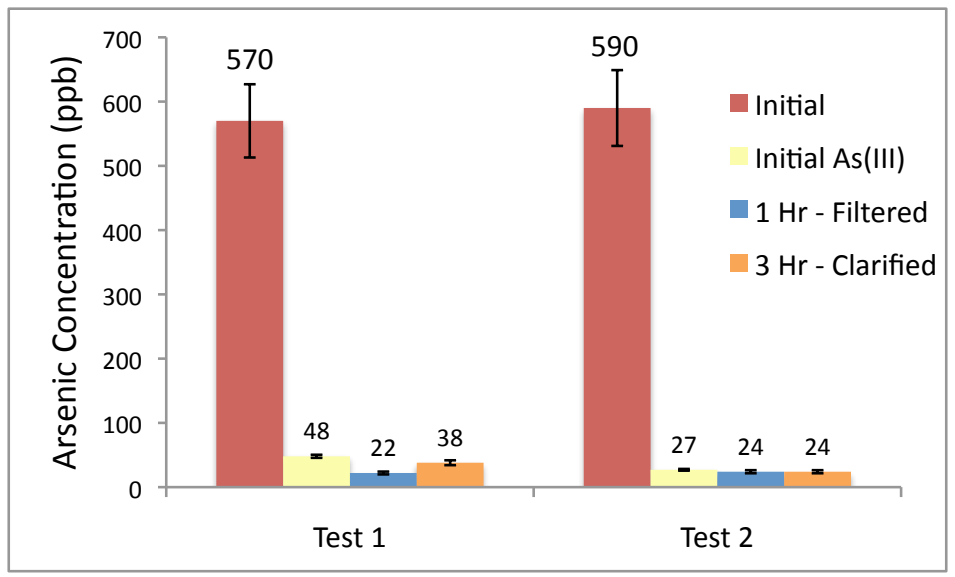


Figure 48: Water Treatment Center Design

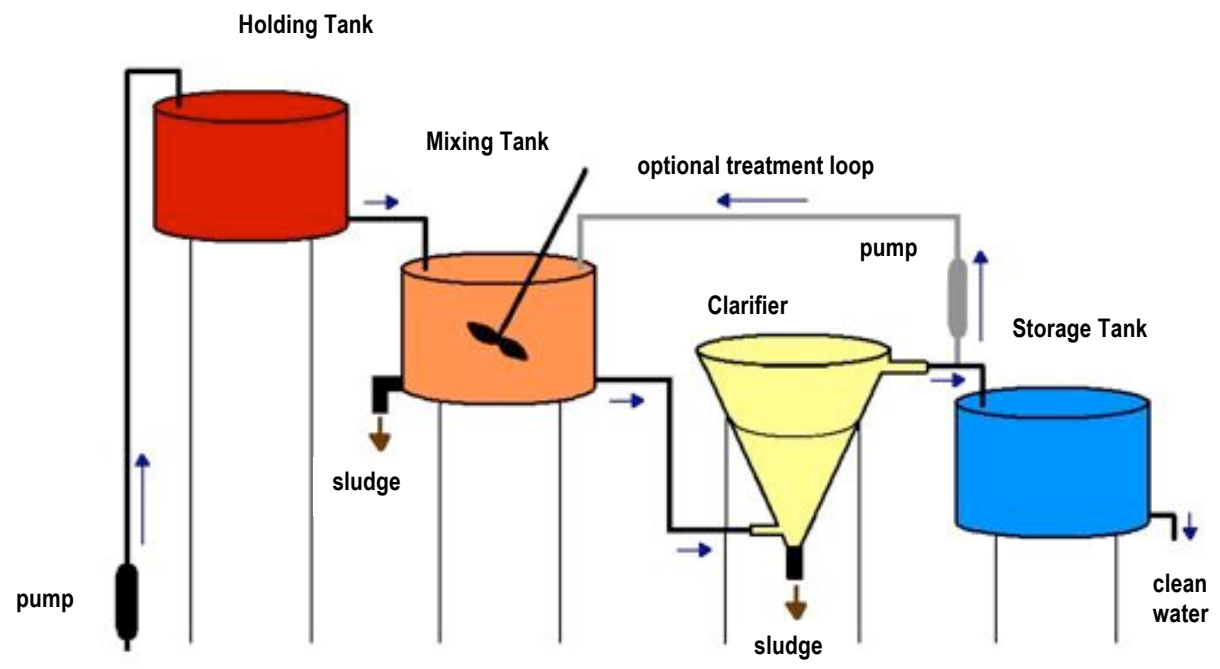

The polyelectrolyte concentration used in the experiment was not optimized. A reasonable coagulant dose is 0.05-0.10 g per liter (Vikas Garud, personal communication, June 2008), and our dose was well within that range. However, further experiments showed that only a very small concentration of polyelectrolyte, 0.012 g per liter, is needed to coagulated ARUBA. Therefore, this polyelectrolyte could be incorporated into the treatment process without adding significant cost. It is possible that this coagulant could also be used in conjunction with the sand filter; however, this has not yet been attempted.

\subsubsection{Conceptual Water Treatment Center Design}

Based on our results, we have designed a water treatment center that uses ARUBA to remove arsenic from contaminated groundwater. A schematic of the treatment center is in Figure 48. Water is pumped into a holding tank, where it can be stored to allow $\mathrm{As}(\mathrm{III})$ to oxidize to $\mathrm{As}(\mathrm{V})$. It is then sent to a mixing tank where ARUBA, and later a coagulant, are added and mixed. After a brief settling period, the water is sent through a clarifier and can be pumped back to the mixing tank for additional ARUBA doses, or pumped directly into the clean water storage tank. Outlets take sludge out of the mixing tank and the clarifier.

\subsubsection{One Hundred Liter per Hour Prototype System}

We have constructed a 100 liter per hour prototype water treatment system based on a simplified version of the conceptual water treatment system design presented in the previous section. The prototype combines the holding tank and the mixing tank, and does not include the optional loop for treating water with multiple doses of ARUBA. See Figure 49.

To remove arsenic, water is pumped into a 500 liter tank where ARUBA is added and mixed for one hour with a propeller attached to a $1.5 \mathrm{hp}$ motor. ${ }^{6}$ Polyelectrolyte is added and mixed for 15 minutes. The valve connecting the tank to a large custom-made clarifier (a direct scale-up of the clarifier in Figure 42, with a 1 meter diameter and a 1 meter cone height) is opened, and, due to gravity and manual valve adjustments, the water passes through the clarifier. Instead of an outlet tube, our collaborators recommended that we

\footnotetext{
${ }^{6}$ In the future this could be replaced by a submersible mixer such as those sold by PAX Water Technologies, www.paxwater.com.
} 
Figure 49: One Hundred Liter per Hour Prototype System

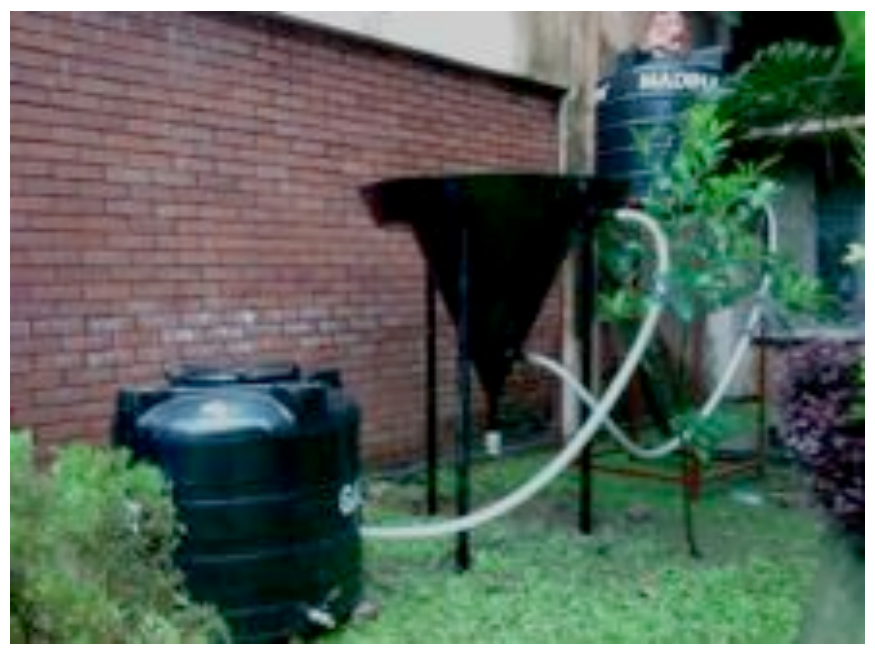

Table 25: 100 Liter per Hour Prototype Costs

\begin{tabular}{|l|c|c|}
\hline Item & Total $($ tk $)$ & Total $(\$)$ \\
\hline \hline Mixing Tank (500 liter PVC tank, 1.5 hp motor, stainless steel shaft/blade) & 30,000 & $\$ 441$ \\
\hline Stand for Mixing Tank (1.5 meter tall, 3 feet by 3 feet base) & 10,000 & $\$ 147$ \\
\hline Clarifier (1 meter cone height, 1 meter diameter) & 40,000 & $\$ 588$ \\
\hline Clean water holding tank (500 liter PVC tank) & 5,000 & $\$ 74$ \\
\hline \hline Total & $\mathbf{8 5 , 0 0 0}$ & $\$ 1250$ \\
\hline
\end{tabular}

allow the water to spill over the top of the clarifier into a catchment channel. The channel drains into the piping connecting the clarifier to the clean water storage tank. This design insures laminar flow at the outlet. Clean water is stored in a 500 liter holding tank. Costs of each system component (as purchased in Dhaka in June 2008) are listed in Table 25. The system is currently undergoing preliminary testing at BUET before field-testing in two Bangladeshi villages.

\subsection{Possible Implementation Model}

One possible implementation model is a public-private partnership similar to that developed by WaterHealth International, ${ }^{7}$ which provides clean drinking water to more than a million people in rural India through publicly owned, privately managed village-scale water treatment centres. Through a three-way partnership between a local financial institution, a local NGO, and a company responsible for constructing and maintaining the water treatment centres (all working together with the local village governments), community-scale water treatment plants could be constructed in rural Bangladeshi villages. Figure 50 shows the structure of the public-private partnership.

At the treatment center, the water would not only be treated for arsenic, but also pathogens and other chemical contaminants, enhancing the perception of treated water quality (addressing design strategy 4). Users would pay a small fee for the safe drinking water that they collect from the treatment centre, but due to the low-cost of ARUBA the fee would remain affordable to those living on less than $\$ 2$ a day and

\footnotetext{
${ }^{7}$ www.waterhealth.com
} 


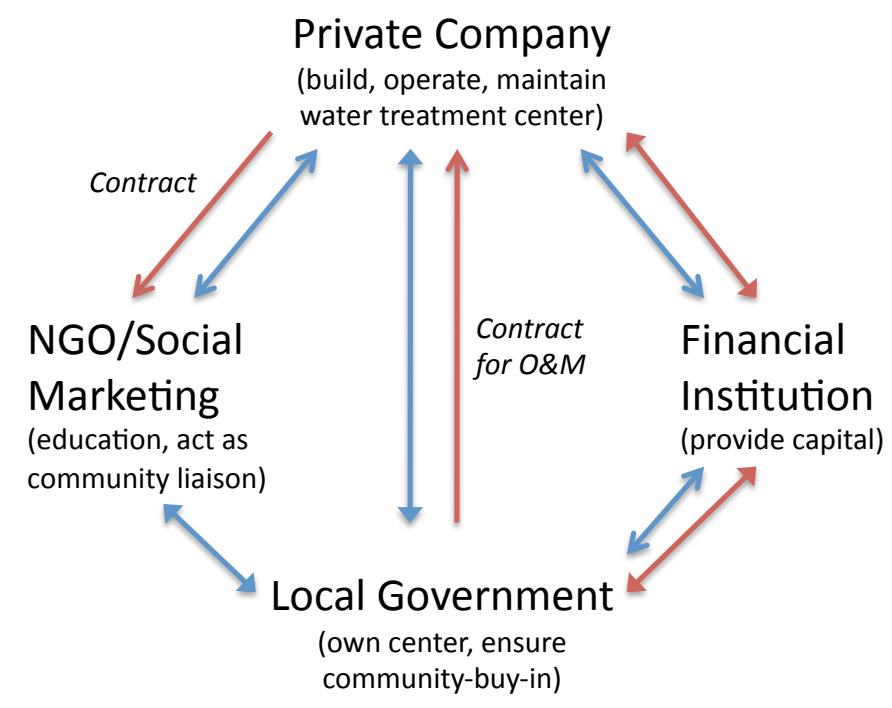

would be enough to cover both the capital and operating costs of the treatment centre. For the example of WaterHealth, the water treatment centers are completely paid off after 8 years.

This implementation plan meets the design strategies listed above. In addition to being effective and lowcost, community-scale treatment using ARUBA leads to ease in water quality monitoring (strategy 5), local water management (strategy 7 ), and waste management (strategy 8). Villagers would not be required to maintain their own water treatment system, meaning that the system would be convenient to users. However, water delivery (strategy 3 ) would be essential for the success of the water treatment system. We believe this feature could be built in at a low-cost.

\subsection{Projected Costs}

From the field data presented above it is possible to estimate the cost of ARUBA. Bottom ash from coal fire power plants can be purchased for approximately $\$ 4$ per ton (Firas Ahmad, personal communication, February 2007). Assuming a bulk cost of $\$ 175$ per ton of ferrous sulfate $\left(\mathrm{FeSO}_{4}\right)^{8}$ and $\$ 250$ per ton of sodium hydroxide $(\mathrm{NaOH}),{ }^{9}$ and given the proportions needed to manufacture ARUBA, as detailed in Section 4.1 (100 g bottom ash : $\left.157 \mathrm{~g} \mathrm{FeSO}_{4}: 2 \mathrm{~g} \mathrm{NaOH}\right)$, the cost per kilogram of ARUBA is calculated to be 31 cents $(\$ 0.31$ per $\mathrm{kg})$. Note that $100 \mathrm{~g}$ of bottom ash is needed to make $\sim 100 \mathrm{~g}$ of ARUBA since the ferric hydr(oxide) coating adds only a very small amount of mass, and some media is lost in the manufacturing process.

\footnotetext{
8"Ferrous Sulfate producers price capacity market demand consumption production growth uses outlook" by The Innovation Group: Chemical Market \& Technology Consulting, 2002, http://www.the-innovationgroup.com/ChemProfiles/Ferrous\%20Sulfate.htm

9"Long-term market reactions to changes in demand for NaOH" by Marianne Wesnæs and Bo Weidema of 2.-0 LCA Consultants, Oct 19, 2006, http://www.lca-net.com/files/naoh.pdf
} 
Figure 51: ARUBA Cost (per household per year) v. Arsenic Concentration of Water Supply

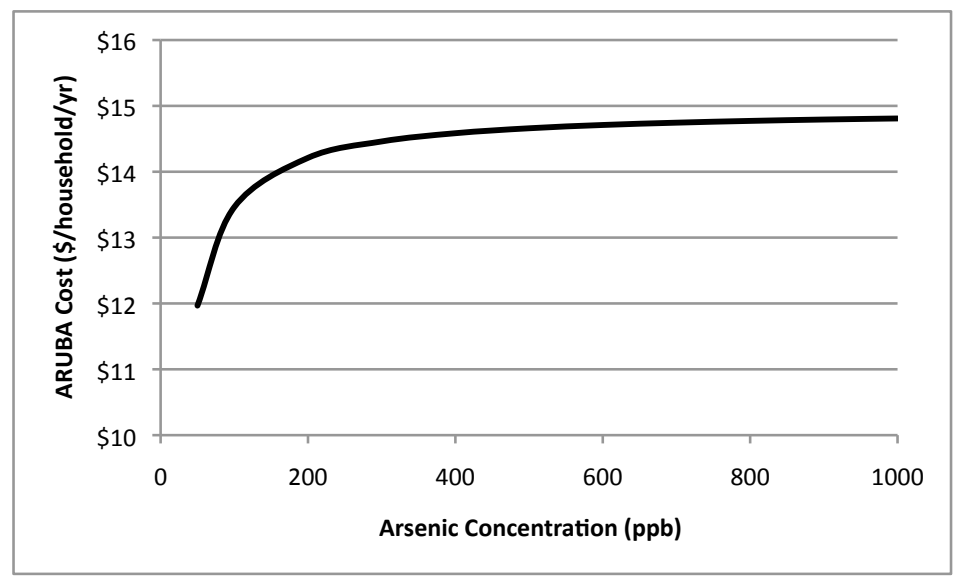

Both the the ferrous sulfate and sodium hydroxide solutions decanted during the manufacturing process could be reused in the manufacture of subsequent ARUBA batches. To get a sense for exactly how much ferrous sulfate and sodium hydroxide are needed to manufacture $100 \mathrm{~g}$ of ARUBA we can approximate the arsenic-rust reaction with the stochiometric equation:

$$
\mathrm{Fe}(\mathrm{OH})_{3}+\mathrm{As}^{+5}+\mathrm{H}_{2} \mathrm{O} \Rightarrow \mathrm{FeAsO}_{4}+5 \mathrm{H}^{+}
$$

Using an average arsenic removal capacity (from Bangladesh data) of $0.09 \mathrm{mg}$ As per g ARUBA, we find that the proportion listed above changes to $100 \mathrm{~g}$ bottom ash : $0.03 \mathrm{~g} \mathrm{FeSO}_{4}: 0.01 \mathrm{~g} \mathrm{NaOH}$. This leads to a cost per kilogram of ARUBA of 0.45 cents $(\$ 0.0045$ per $\mathrm{kg}$ ). This tells us our current manufacturing protocol uses excessive amounts of both ferrous sulfate and sodium hydroxide. However, in practice it would be impossible to actually achieve a cost this low because it would be impractical to recover all of the unused solution and the stochiometric equation above only accounts for one of many potential reactions that could describe how arsenic binds to ARUBA. A more realistic cost would be on the order of 2 U.S. cent per $\mathrm{kg}$ $(\$ 0.02$ per $\mathrm{kg}$ ). This value for raw material costs has been used in the cost calculations in this document.

ARUBA handling, transport, storage, delivery, and margins for distribution and retailing are expected to be on the order of $\$ 0.08$ per $\mathrm{kg}$, raising the cost to $\$ 0.10$ per $\mathrm{kg}$. This is based on the assumption that these costs would be comparable to those associated with ground, iodized table salt in India which is sold at $\sim \$ 0.17$ per $\mathrm{kg}$, as compared to raw rock salt which is sold at $\sim \$ 0.09$ per $\mathrm{kg}$.

Costs associated with the centralized ARUBA manufacturing are still a subject of research but are expected to be low due to the simple processes involved. Generously assuming that the manufactured cost would raise the total cost from $\$ 0.10$ per $\mathrm{kg}$ to $\$ 0.20$ per $\mathrm{kg}$, the cost of treating arsenic-contaminated water for per household (five people) per year can be determined as a function of the arsenic concentration of the water supply (which dictates the arsenic removal capacity). We assume each person purchases ten liters of drinking water per day and the arsenic concentration is lowered to the WHO limit of $10 \mathrm{ppb}$. Note that our cost estimate does not include the capital cost of the treatment center, as that would be heavily dependant on the implementation plan and financing. It also does not include the cost of waste disposal. Figure 51 shows a plot of the cost of arsenic removal to the household based on a price of $\$ 0.20$ per $\mathrm{kg}$ ARUBA. The shape of the curve is a result of the linear relation between initial arsenic concentration and arsenic removal capacity.

For the range of arsenic concentrations commonly seen in Bangladesh $(0-1000 \mathrm{ppb})$ this implies that the cost of ARUBA arsenic removal would not go above $\$ 15$ per household per year. In fact, it is unlikely that households would purchase ten liters of drinking water per person per day. A more realistic number would 
Figure 52: Benefits and Costs of Arsenic Remediation v. Arsenic Concentration of Water Supply

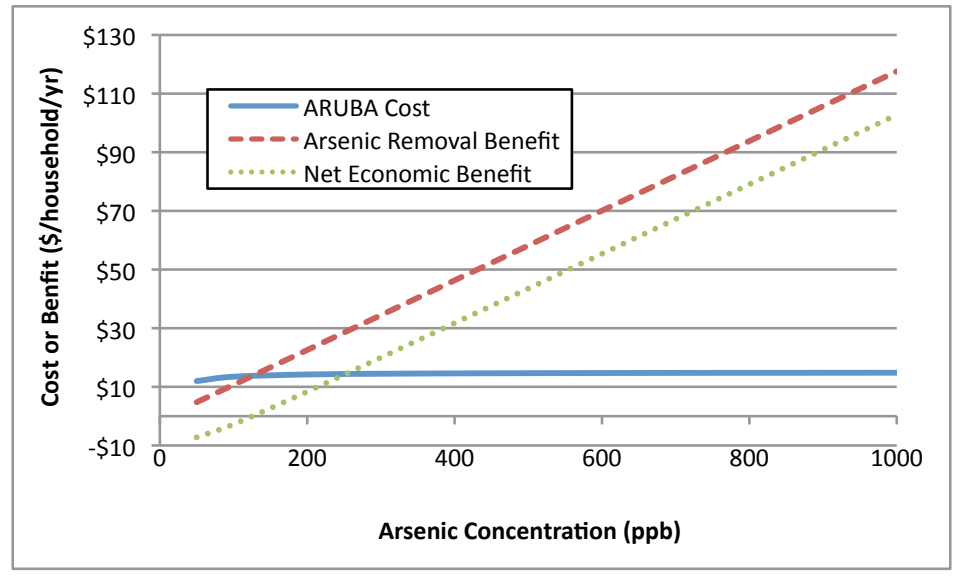

be 3 liters per person per day, which is the National Academy of Sciences' recommended DRI for drinking water (28). Using this figure lowers the upper bound of the cost of ARUBA arsenic removal to $\$ 4.50$ per household per year.

Depending upon the assumptions made, the cost of ARUBA arsenic removal is less than or comparable to that of household arsenic removal filters on the market ( $\$ 40-\$ 50$ for a filter rated for 5 years).

Using data for West Bengal from Roy (2008) as presented in Section 2.2 (INR 0.49 of welfare benefit per ppb arsenic per household per month), we can calculate that the total welfare benefit of eliminating exposure to arsenic in drinking water as a function of the arsenic concentration in the water supply. Note that in actuality the relation is probably nonlinear, and so the implications of these results are limited. Figure 52 shows the result of superimposing this data on the data presented in figure 51. The net economic benefit is also calculated and plotted. At arsenic concentrations greater than $\sim 100 \mathrm{ppb}$ the benefit attributed to drinking clean water is greater than the cost of removing arsenic.

According to Ahmad et al. (2003) villagers' mean willingness to pay for recurring costs associated with an arsenic-free stand-post is approximately $\$ 9$ per year (2).

\section{Waste Disposal and Reuse}

All arsenic removal systems produce waste, and ARUBA arsenic remediation is no exception. This section presents key results of leachate testing to determine if the bottom ash itself could contaminate water and TCLP testing of spent media.

\subsection{Leachate Testing}

An important issue in using coal ash as a substrate is the possibility that the ash itself might contaminate the treated water with other leachates such as heavy metals (such as aluminum, antimony, barium, beryllium, cadmium, calcium, chromium, cobalt, copper, iron, lead, magnesium, manganese, nickel, potassium, selenium, silicon, titanium, and zinc). In fact, coal ash has been shown to contain trace levels of arsenic itself. Arsenic concentrations in fly ash have been measured to be 100-800 $\mu \mathrm{g}$ per g where concentrations decrease with increased particle size (22). Bottom ash particles are smaller than fly ash particles and so we would expect arsenic concentrations in bottom ash to be lower. Also, presumably, leached arsenic could be adsorbed by ARUBA's ferric hydr(oxide) coating. 
Table 26: MCL Standards and Un-Coated Coal Ash Leachate Results (ppb)

\begin{tabular}{|c||c|c|c||c|c|c||c|}
\hline & EPA MCL & WHO MCL & NSF MCL & $\mathrm{pH} 3$ & $\mathrm{pH} 6$ & $\mathrm{pH} 10$ & De-ionized water \\
\hline \hline Arsenic & 10 & 10 & 10 & 88 & 17 & 33 & 1 \\
\hline Beryllium & 4 & - & - & 1 & $<1$ & $<1$ & $<1$ \\
\hline Cadmium & 5 & 3 & 5 & 13 & 39 & $<1$ & 1 \\
\hline Chromium & 100 & 50 & 100 & 18 & 2 & 90 & 2 \\
\hline Copper & 1300 & 2000 & 1300 & 17 & 30 & 16 & 9 \\
\hline Lead & 15 & 10 & 15 & $<10$ & $<10$ & $<10$ & $<10$ \\
\hline Selenium & 50 & 10 & 50 & 17 & 6 & 8 & $<1$ \\
\hline
\end{tabular}

Table 27: MCL Standards and ARUBA Leachate Results (ppb)

\begin{tabular}{|c||c|c|c||c|c|c|}
\hline & EPA MCL & WHO MCL & NSF MCL & pH 3 & pH 6 & pH 10 \\
\hline \hline Aluminum & & & & 13000 & 12000 & 13000 \\
\hline Barium & 2000 & 700 & 2000 & 70 & 67 & 66 \\
\hline Beryllium & 4 & & & ND & ND & ND \\
\hline Calcium & & & & 310000 & 280000 & 330000 \\
\hline Cadmium & 5 & 3 & 5 & ND & ND & ND \\
\hline Chromium & 100 & 50 & 100 & 3 & 3.9 & 4.5 \\
\hline Cobalt & & & & ND & ND & 11 \\
\hline Copper & 1300 & 2000 & 1300 & 15 & 9.4 & 13 \\
\hline Iron & & & 300 & 6200 & 4800 & 12000 \\
\hline Lead & 15 & 10 & 15 & 1.1 & ND & 1.3 \\
\hline Magnesium & & & & 22000 & 18000 & 22000 \\
\hline Manganese & & 400 & 50 & 8.3 & 9.2 & 15 \\
\hline Molybdenum & & & & 1.6 & 1.9 & 1.6 \\
\hline Nickel & & & & 3.8 & 2.7 & 9.6 \\
\hline Potassium & & & & 2500 & 800 & 2000 \\
\hline Selenium & 50 & 10 & 50 & ND & ND & ND \\
\hline Sodium & & & & 7200 & 6000 & 60000 \\
\hline Zinc & & & 5,000 & 130 & 90 & 120 \\
\hline
\end{tabular}

Leachates were extracted at $\mathrm{pH} 3,6$, and 10 from un-coated Indian bottom ash by mixing the bottom ash with solution equal to ten times the weight of the ash, sonicating for one hour at $30^{\circ} \mathrm{C}$, followed by filtration through ash-less paper. Acetic acid and sodium carbonate were used to make the acidic and basic conditions, respectively. Results, adapted from Gadgil et al. (2008), are presented below in Table 26. Full methods and results are presented in Gadgil et al. (2008).

Note that the arsenic and cadmium concentrations of the leachates were above the EPA MCL. However, it is important to note that bottom ash would never be directly mixed into contaminated water. It would be coated with ferric hydroxide. In addition, it would be mixed with water at far higher dilution.

Leachates were also extracted from ARUBA (coated Indian bottom ash) at $\mathrm{pH} 3,6$, and 10. Results are presented in Table 27.

In this case, concentrations of all heavy metals are not only below the EPA MCL, but also below the more stringent WHO MCLs. The ferric hydr(oxide) coating seems to act as a shield, preventing the release of heavy metals present in the bottom ash into the water. 


\subsection{TCLP \& EPA Approvals}

We tested the toxic chemical leaching from spent media prepared with US Fly Ash, not Indian bottom ash. The leachates from spent media were tested using EPA Method 1311 (Toxicity Characteristics Leaching Procedure, TCLP). The spent media is not toxic, based on the results of the TCLP. Details are included in Gadgil et al. (2008). Assuming ARUBA behaves the same way as US Fly Ash, it is harmless enough for disposal in a landfill U.S. municipal landfill. Unfortunately, as noted in Section 6.1.8 arsenic removal waste in Bangladesh can not be disposed in landfills.

It is important to note that several studies have questioned the appropriateness of TCLP for assessing the leaching potential of arsenic removal wastes. Ali et al. (2003) and Badruzzaman (2003) note that TCLP does not address leaching over time. Instead, Badruzzaman (2003) recommends that the testing should imitate the actual sludge disposal conditions in order to assess leaching in the environment. MacPhee et al. (2003) explain that reducing conditions could result in the leaching of arsenic which TCLP could not predict. Also, arsenic solubility increases with increased alkalinity.

In addition to TCLP, California WET (Ca WET) is used to characterize arsenic removal waste. Generally, Ca WET produces might higher arsenic leaching concentrations than TCLP (56). ARUBA has not gone through Ca WET testing.

\subsection{Spent ARUBA Processing \& Reuse}

Arsenic waste remediation could be enhanced by allowing it to undergo biochemical processes, such as through mixing with cow dung (5) or mixing with mud and domestic sewage (8), since toxic arsenic species are lost though biomethylation (52).

ARUBA could be incorporated into concrete used in road construction with a layer of asphalt added over the top to ensure that the concrete will not crumble and turn into dust that people could inhale. The Chinese already incorporate arsenic removal waste into concrete (Guy Howard, personal communication, November 2008). Moreover, researchers have recently developed a new building material out of coal ash (60).

Some have suggested using arsenic removal waste in bricks; however, spent ARUBA should not be incorporated into brick building materials since they are baked at high temperatures, at which arsenic can volatilize.

\section{Potential Future Research}

While this research has advanced our knowledge about ARUBA a number of questions are still unanswered. Many of these are listed below, and could be the subject of future research.

1. For how long is the arsenic-ARUBA bond stable? What environmental conditions affect the strength of the bond?

2. What industrial processes could be used to manufacture ARUBA in large quantities? How much would it cost to manufacture a kilogram of ARUBA?

3. How does the manufacturing process affect the ARUBA's chemical properties?

4. What is the chemical structure of ARUBA? What are the actual chemical processes that are responsible for removing arsenic?

5. Does ARUBA remove other contaminants? To what extent?

6. How would a public-private partnership modelled after that of WaterHealth International be accepted in Bangladesh villages? 
7. How far are villagers willing to walk for arsenic-free water? Would water delivery be feasible and affordable in rural Bangladesh?

8. What methods could be used to process spent ARUBA? How much would it cost to process spent ARUBA?

9. Besides combining spent ARUBA into concrete, what other uses could the material have?

\section{Conclusions}

This report has presented an overview of the ARUBA arsenic project goals and results over the past several years. Laboratory and field results from three trips to Bangladesh and one trip to Cambodia have been presented. Also detailed was the design and analysis of a low-cost, community-scale water treatment plant that uses ARUBA to remove arsenic from contaminated groundwater in Bangladesh, and a possible implementation plan. The design was informed by existing studies, observations, discussions, and informal interviews that have lead to the development of eight design strategies. These design strategies ensure that our design and implementation plan meet not only technical goals, but also address user preferences and policy constraints.

Considering both scalability and long-term sustainability early on is essential for the success of technologyrelated projects in the developing world. The strategies and learning points developed as a result of this research could be generalized to other technology implementation projects in the developing world.

\section{Acknowledgements}

Thank you to the National Defense Science and Engineering Graduate (NDSEG) Fellowship Program for funding the first three years of my graduate studies. Thanks to all of the institutions that have been involved in this research Lawrence Berkeley National Laboratory, the UC Berkeley Department of Mechanical Engineering, the Bangladesh University of Engineering and Technology, BRAC, and BRAC University. Thanks to the many people who have contributed to this project over the past eight years: Susan Amrose, William Babbitt, Yola Bayram, Ebere Chukwueke, Raymond Dod, Meghana Gadgil, Christie Galitsky, Lara Gundel, Kosar Jahani, Tasnuva Khan, Mathew Jeung, Nadia Madden, Melissa Quemada, Heena Patel, Clete Reader, Mehmet Seflek, Mark Sippola, and Duo Wang. Iqbal and Kamal Quadir provided us funds and support for our first trip to Bangladesh and the Khan family greatly supported our second trip. Thanks to our Bangladeshi collaborators Dr. A.B.M. Badruzzaman and Mahbuba Iasmin Ahmed at BUET for their exceptional advice and support during our third visit to Bangladesh. Also, thank you to the Berkeley Electrocoagulation Arsenic Remediation (BEAR) Team for testing ARUBA in Cambodia in July 2008: Debbie Cheng, Jessica Huang, Michèle Itten, Marianna Kowalczyk, Marc Muller, and John Wang. Finally, the biggest thanks goes to my research advisers, Dr. Ashok Gagil and Dr. Alice Agogino, for all of their advice and support. 


\section{References}

[1] Adeel Z., and M.A. Ali, 2002. "A comparative evaluation and field implementation of treatment technologies for arsenic removal from groundwater." In Proceedings of International Workshop on Arsenic Mitigation in Bangladesh, 14-16 January 2002, Ministry of Local Government, Rural Development and Cooperative, Government of Bangladesh, Dhaka, Bangladesh.

[2] Ahmad, J., B.N. Goldar, S. Misra, and M. Jakariya, 2003, "Willingness to Pay for Arsenic-Free, Safe Drinking Water in Bangladesh." World Bank Water and Sanitation Program- South Asia.

[3] Ahmed, M.F., 2001. "An overview of arsenic removal technologies in Bangladesh and India." In Proceedings of BUET-UNU International Workshop on Technologies for Arsenic Removal from Drinking Water, Dhaka, 5-7 May 2001 Bangladesh University of Engineering and Technology and United Nations University, Bangladesh. p 251-269.

[4] Ahsan, H., Y. Chen, F. Parvez, M. Argos, A.I. Hussain, H. Momotaj, D. Levy, A. van Geen, G. Howe, and J. Graziano, 2006. "Health effects of arsenic longitudinal study (HEALS): Description multidisciplinary epidemiological investigation." Journal of Exposure Science and Environmental Epidemiology. Vol 16, p 191-205.

[5] Ali, M.A., A.B.M. Badruzzaman, M.A. Jalil, M. Feroze Ahmed, Md. Kamruzzaman, M. Azizur Rahman, and A. Al Masud, 2003. "Fate of arsenic wastes generated from arsenic removal units." In Proceedings of BUET-UNU Symposium on Fate of Arsenic in the Environment, Dhaka, 5-6 February 2003 Bangladesh University of Engineering and Technology and United Nations University, Bangladesh. p 147-159.

[6] Arai, Y., D.L. Sparks and J.A. Davis, 2004. "Effects of dissolved carbonate on arsenate adsorption and surface speciation at the hematite-water interface." Environmental Science and Technology. Vol 38, p. 817-824.

[7] Asadullah, M.N. and N. Chaudhury, 2008. "Poisoning the Mind: Arsenic contamination and the cognitive achievement of children." World Bank: South Asia Region, Human Development Unit.

[8] Badruzzaman, A.B.M., 2003. "Leaching of arsenic from wastes of arsenic removal systems." In Proceedings of BUET-UNU Symposium on Fate of Arsenic in the Environment, Dhaka, 5-6 February 2003 Bangladesh University of Engineering and Technology and United Nations University, Bangladesh. p 161-179.

[9] Badruzzaman, M., P. Westerhoff, D.R.U. Knappe, 2004. "Intraparticle diffusion and adsorption of arsenate onto granular ferric hydroxide (GFH)." Water Research. Vol 38, Issue 18, p 4002-4012.

[10] Bang, S., M. Patel, L. Lippincott, and X. Meng, 2005. "Removal of arsenic from groundwater by granular titanium dioxide adsorbent." Chemosphere. Vol 60, p 389-397.

[11] BGS, 2001. "Arsenic contamination of groundwater in Bangladesh." WC/00/19, British Geological Survey, Keyworth. http://www.bgs.ac.uk/arsenic/bphase2/Data/NationalSurveyData.csv

[12] Biswas, B.K., R.K. Dhar, G. Samanta, B.K. Mandal, D. Chakraborti, I. Faruk, K.S. Islam, M. Chowdhury, A. Islam, S. Roy, 1998. "Detailed study report of Samta, one of he arsenic-affected villages of Jessore District, Bangladesh." Current Science. Vol 74, No 2, p 134-145.

[13] Boyd, A., E. Chukwueke, A. Gadgil, C. Galitsky, L. Gundel, Y. Pang, H. Patel, M. Sippola, and D. Wang, 2005. "Powerpoint Presentation: Arsenic Filters." Summer 2005.

[14] Caldwell, B.K., J.C. Caldwell, S.N. Mittra, and W. Smith, 2003. "Searching for an optimum solution to the Bangladesh arsenic crisis." Social Science \& Medicine. Vol 56, p 2089-2096.

[15] Campos, V. and P.M. Buchler, 2007. "Anionic sorption onto modified natural zeolites using chemical activation." Environmental Geology. Vol 52, No 6, p 1187-1192. 
[16] Chen Y. and Ahsan H, 2004. "Cancer burden from arsenic in drinking water in Bangladesh." American Journal of Public Health. Vol 94, No 5, p 741-744.

[17] Chowdhury, U.K., B.K. Biswas, T.R. Chowdury, G. Samanta, B.K. Mandal, G.C. Basu, C.R. Chanda, D. Lodh, K.C. Saha, S.K. Mukherjee, S. Roy, S. Kabir, Q. Quamruzzaman, and D. Chakraborti, 2000. "Groundwater arsenic contamination in Bangladesh and West Bengal, India." Environmental Health Prospectives. Vol 108, No 5, p 393-397.

[18] Chowdhury, A.M.R., M.Z. Hossain, R. Nickson, M. Rahman, M. Jakariya, and M. Shamimuddin, 2000. "Combating a Deadly Menace: Early Experiences with a community-based arsenic mitigation project in Bangladesh." BRAC Research and Evaluation Division, Research Monograph Series No 16. August 2000 .

[19] Chowdhury, A.M.R., 2004. "Arsenic Crisis in Bangladesh." Scientific American: Aug 2004. p 87-91.

[20] Cuda, G., 2005. "In Bangladesh, arsenic-free water set to flow from cheap new filter." Nature Medicine. Vol 11, No 11, p 1128.

[21] Daus, B. R. Wennrich, and H. Weiss, 2004. "Sorption materials for arsenic removal from water: a comparative study." Water Research. Vol 38, Issue 12, p 2948-2954.

[22] Davison, R.L., D.F.S. Natusch, and J.R. Wallace, 1974. "Trace elements in fly ash: dependence of concentration on particle size." Environmental Science and Technology. Vol 8, No 13, p 1107-1113.

[23] Dhar, R.K., B.K. Biswas, G. Samanta, B.K. Mandal, D. Chakraborti, S. Roy A. Jafar, A. Islam, G. Ara, S. Kabir, A.W. Khan, S.A. Ahmed, S.A. Hadi, 1997. "Groundwater arsenic calamity in Bangladesh." Current Science. Vol 73, No 1, p 48-59.

[24] Diamadopoulos, E., S. Ioannidis, and G. Sakellaropoulous, 1993. "As(V) removal from aqueous solutions by fly ash." Water Research. Vol 27, No 12, p 1773-1777.

[25] Duxbury, J.M. and G. Panaullah, 2007. "Remediation of arsenic for agriculture sustainability, food security, and health in Bangladesh." FAOWATER Working Paper.

[26] EPA, 2004. "Drinking Water Health Advisory for Manganese" EPA-822-R-04-003. http://www.epa.gov/OGWDW/ccl/pdfs/reg_determine1/support_cc1_magnese_dwreport.pdf

[27] Frazer, L., 2005. "Metal attraction: an ironclad solution to arsenic contamination?" Environmental Health Perspectives. Vol 113, No 6, p 399-401.

[28] National Academy of Sciences, 2004. "Dietary Reference Intakes (DRIs): Recommended Intakes for Individuals, Vitamins." Food and Nutrition Board, Institute of Medicine, National Academies. http://www.iom.edu/Object.File/Master/21/372/0.pdf

[29] Gadgil, A.J., L.A. Gundel, and C. Galitsky, 2008. "Arsenic Remediation of Bangladesh Drinking Water using Iron-oxide Coated Coal Ash." In Arsenic Contamination of Groundwater: Mechanism, Analysis, and Remediation. Ahuja, S. ed., John Wiley and Sons. (in press)

[30] Gadgil, A.J., L.A. Gundel, C. Galitsky, and R. Dod, 2008. "Low-Cost Arsenic Removal Technologies Using Treated Coal Ash." California Energy Commission, PIER Industrial/Agricultural/Water End-Use Energy Efficiency Program. (CEC number pending)

[31] Gelman, A., M. Trevisani, H. Lu, and A. van Geen, 2004. "Direct data manipulation for local decision analysis as applied to the problem of arsenic in drinking water from tube wells in Bangladesh." Risk Analysis. Vol 24, No 6, p 1597 - 1612

[32] Grafe, M., M.J. Eick, P.R. Grossl, and A.M. Saunders, 2002. "Adsorption of arsenate and arsenite on ferrihydrite in the presence and absence of dissolved organic carbon." Journal of Environmental Quality. Vol 31, p 1115-1123. 
[33] Gupta, V.K. A. Mittal, L. Krishnan, and V. Gajbe, 2004. "Adsorption kinetics and column operations for the removal and recovery of malachite green from wastewater using bottom ash." Separation and Purification Technology. Vol 40, p 87-96.

[34] Harvey, C.F., C.H. Schwartz, A.B.M. Badruzzaman, N. Keon-Blute, W. Yu, M.A. Ali, J. Jay, R. Beckie, V. Niedan, D. Brabander, P.M. Oates, K.N. Ashfaque, S. Islam, H.F. Hemond, M.F. Ahmed, 2002. "Arsenic mobility and groundwater extraction in Bangladesh." Science. Vol 298, p 1602-1606.

[35] Hering, J.G., P.Y. Chen, J.A. Wilkie, M. Elimelech, and S. Liang, 1996. "Arsenic removal by ferric chloride." Journal AWWA. Vol 88, Issue 4, p 155-167.

[36] Hira-Smith, M.M., Y. Yuan, X. Savarimuthu, J. Liaw, A. Hira, C. Green, T. Hore, P. Chakrabborty, O.S. von Ehrenstein, and A.H. Smith, 2007. "Arsenic concentrations and bacterial contamination in a pilot dugwell program in West Bengal India." Journal of Environmental Science and Health Part A. Vol 42 , p 89-95.

[37] Hoque, B.A., A.A. Mahmood, M. Quadiruzzaman, F. Khan, S.A. Ahmed, S.A.K.A.M. Shafique, M. Rahman, G. Morshed, T. Chowdhury, M.M. Rahman, F.H. Khan, M. Shahjahan, M. Begum, and M.M. Hoque, 2000. "Recommendations for water supply in arsenic mitigation: a case study from Bangladesh." Public Health. Vol 114, No 6, p 488-494.

[38] Hoque, B.A., M.M. Hoque, T. Ahmed, S. Islam, A.K. Azad, N. Ali, M. Hossain, and M.S. Hossain, 2004. "Demand-based water options for arsenic mitigation: an experience from rural Bangladesh." Public Health. Vol 118, p 70-77.

[39] Howard, G., M.F. Ahmed, A.J. Shamsuddin, S.G. Mahmud, and D. Deere, 2006. "Risk Assessment of Arsenic Mitigation Options in Bangladesh." Journal of Health, Population, and Nutrition. Vol 24, No 3, p 346-355.

[40] Howard, G., M.F. Ahmed, P. Teunis, S.G. Mahmud, A. Davison, and D. Deere, 2007. "Disease burden estimation to support policy decision-making and research prioritization for arsenic mitigation." Journal of Water and Health. Vol 5, No 1, p 67-81.

[41] Huang, C.P. and L.M. Vane, 1989. "Enhancing $\mathrm{As}^{5+}$ removal by a $\mathrm{Fe}^{2+}$-treated activated carbon." Journal of the Water Pollution Control Federation. Vol 61, No 9, p 1596-1603.

[42] Hug, S.J., L. Canonica, M. Wegelin, D. Gechter and U. Von Gunten, 2001. "Solar oxidation and removal of arsenic at circumneutral pH in iron containing waters." Environmental Science \& Technology. Vol 35, No 10, p 2114-2121.

[43] Hug, S.J., 2001. "An Adapted Water Treatment Option in Bangladesh: Solar Oxidation and Removal of Arsenic." Environmental Sciences. Vol 8, No 5, p 467-479.

[44] Hussam, A. and A.K.M. Munir, 2007. "A simple and effective arsenic filter based on composite iron matrix: Development and deployment studies for groundwater of Bangladesh." Journal of Environmental Science and Health Part A. Vol 42, p 1869-1878.

[45] Hymowitz, D., N. Spicer, S. Vergara, and S. Gani, 2006. "Integrating innovative water purification technology in the developing world.: comparing the socio-cultural viability and business feasibility of three different point-of-use water treatment technologies." Research results of the UNIDO-MOT Bridging the Divide program, University of California, Berkeley.

[46] Jakariya, Md., 2000. "The use of alternative safe water options to mitigate the arsenic problem in Bangladesh: a community prospective." MSc Thesis Department of Geography, University of Cambridge.

[47] Johnston, R. and H. Heijnen, 2001. "Safe Water Technology for Arsenic Removal." In Proceedings of BUET-UNU International Workshop on Technologies for Arsenic Removal from Drinking Water, Dhaka, 5-7 May 2001 Bangladesh University of Engineering and Technology and United Nations University, Bangladesh. p 251-269. 
[48] Khan, A.H., S.B. Rasul, A.K.M. Munir, M. Habibuddowla, M. Alauddin, S.S. Newaz, and A. Hussam, 2000. "Appraisal of a simple arsenic removal method for groundwater of Bangladesh." Journal of Environmental Science and Health Part A. Vol 35, No 7, p 1021-1041.

[49] Khan, A.H., S.B. Rasul, A.K.M. Munir, M. Alauddin, M. Habibuddowla, and A. Hussam, 2000. "On two simple arsenic removal methods for groundwater of Bangladesh." In Proceedings of the Bangladesh Environmental Network Conference, 14 Jan 2000, Dhaka, Bangladesh, p 12.

[50] Kinniburgh, D.G. and W. Kosmus, 2002. "Arsenic contamination in groundwater: some analytical considerations." Talanta. Vol 58, p 165-180.

[51] Katsoyiannis, I.A. and A.I Zouboulis, 2002. "Removal of arsenic from contaminated water sources by sorption onto iron-oxide-coated polymeric materials." Water Research. Vol 36, Issue 20, p 5141-5155.

[52] Le, X.C., X. Lu, and X.F. Li, 2004. "Arsenic Speciation." Analytical Chemistry. January 1, 2004.

[53] Lean, M.H., A. Kole, N. Chang, A.R. Volkel, J. Seo, and H.B. Hsieh, 2008. "Curved Fluidic Structures to Improve Aggregation Kinetics in Municipal Water Treatment." In Proceedings of Water Quality Technology Conference 2008.

[54] Leupin, O.X. and S.J. Hug, 2005. "Oxidation and removal of arsenic (III) from aerated groundwater by filtration through sand and zero-valent iron." Water Research. Vol 39, p 1729-1740.

[55] Lowry, J.D. and S.B. Lowry, 2002. "Oxidation of As(III) by aeration and storage." Environmental Protection Agency Document: EPA/600/R-01/102.

[56] MacPhee, M.J., J.T. Novak, R.N. Mutter, and D.A. Cornwell, 2003. "Disposal of wastes resulting from arsenic removal processes." In Arsenic Exposure and Health Effects V. W.R. Chappell et al. ed. Elsevier B.V.

[57] Manning, B.A. and S. Goldberg, 1996. "Modeling competitive adsorption of arsenate with phosphate and molybdate on oxide minerals." Soil Science Society of America Journal. Vol 60, p 121-131.

[58] Mathieu, J.L., A.J. Gadgil, K. Kowolik, and S.E. Amrose, 2008. "Removing arsenic from contaminated drinking water in rural Bangladesh: Recent fieldwork and policy implications." Proceedings of UNC Environmental Symposium: Safe Drinking Water, 5-6 Nov 2008.

[59] Mathieu, J.L., A.J. Gadgil, K. Kowolik, S. Qazi, and A.M. Agogino, 2008. "Multidisciplinary design and analysis of a low-cost arsenic removal system for rural Bangladesh." Submitted to 2009 WEDC Conference, Ethiopia. (acceptance pending)

[60] Mechanical Engineering Magazine, 2008. "Lightweight Material Provides New Use for Coal Ash." November 26, 2008. http://www.memagazine.org/Story.html?story_id=123765596\&ID=asme\&scategory=En gineering\&navStoryId=123763437:123765649:123765339:123771801:123768181:123738317:123765596:\& numhl $=7$

[61] Meharg, A.A. and Md. M. Rahman, 2003. "Arsenic contamination of Bangladesh paddy field soils: implications for rice contribution to arsenic consumption." Environmental Science and Technology. Vol 37, No 2, p 229-234.

[62] Meng, X., G.P. Korfiatis, S. Bang, and K.W. Bang, 2002. "Combined effects of anions on arsenic removal by iron hydroxides." Toxicology Letters. Vol 122, p 103-111.

[63] Mittal, A., L. Kurup (Krishnan), and V.K. Gupta, 2005. "Use of waste materials- bottom ash and de-oiled soya, as potential adsorbents for the removal of Amaranth from aqueous solutions." Journal of Hazardous Materials. Vol B117, p 171-178.

[64] The National Academy of Engineering, 2007. "National Academy of Engineering Announces Winners of $\$ 1$ Million Challenge to Provide Safe Drinking Water." The National Academies, Press Release. http://www8.nationalacademies.org/onpinews/newsitem.aspx?RecordID $=02012007$ 
[65] Navas-Acien A. E.K. Silbergeld, R. Pastor-Barriuso and E. Guallar, 2008. "Arsenic Exposure and Prevalence of Type 2 Diabetes in US Adults." Journal of the American Medical Association. Vol 300, p 814-822.

[66] Ng, K.S., Z. Ujang, and P. Le-Clech, 2004. "Arsenic removal technologies for drinking water treatment." Reviews in Environmental Science and Biotechnology. Vol 3, No 1, p 43-53.

[67] Ngai, T. and S. Walewijk, 2003. "The arsenic biosand filter (ABF) project: Design of an appropriate household drinking water filter for rural Nepal." Final Report for Prepared for Rural Water Supply and Sanitation Support Programme Butwal, Nepal and Environment and Public Health Organization Kathmandu, Nepal.

[68] National Research Council, 1999. Arsenic in Drinking Water. The National Academies Press.

[69] Pal, B.N., 2001. "Granular ferric hydroxide for elimination of arsenic from drinking water." In Proceedings of BUET-UNU International Workshop on Technologies for Arsenic Removal from Drinking Water, Dhaka, 5-7 May 2001 Bangladesh University of Engineering and Technology and United Nations University, Bangladesh. p 59-68.

[70] Patel, H. A.J. Gadgil, C. Galitsky, E. Chukwueke, D. Wang, M.R. Sippola, A.L. Blumstein, Y. Pang, L.A. Gundel, 2006. "A low cost method for removing arsenic from drinking water: Coal ash coated with ferric hydroxide." Proceedings of 2006 UNC Environmental Symposium, Safe Drinking Water: Where Science Meets Policy, March 16-17, 2006.

[71] Pattanayak, J., K. Mondal, S. Mathew, and S.B. Lalvani, 2000. "A parametric evaluation of the removal of $\mathrm{As}(\mathrm{V})$ and $\mathrm{As}(\mathrm{III})$ by carbon-based adsorbents." Carbon. Vol 38, p 589-596.

[72] Petrusevski, B., S. Sharma, J.C. Schippers, and K. Shordt, 2007. "Arsenic in Drinking Water." IRC International Water and Sanitation Centre Thematic Overview Paper 17.

[73] Queen's University Belfast, 2008. "Queen's Researchers Provide Solution to World's Worst Mass Poisoning Case." Medical News Today, August 30, 2008. http://www.medicalnewstoday.com/articles/119744.php

[74] Rau, I., A. Gonzalo, and M. Valiente, 2003. "Arsenic(V) adsorption by immobilized iron mediation. Modeling of the adsorption process and influence of interfering anions." Reactive \& Functional Polymers. Vol 54, p 85-94.

[75] Roberts, L.C., S.J. Hug, T. Ruettimann, Md M. Billah, A.W. Khan, and M.T. Rahman, 2004. "Arsenic removal with iron(II) and iron(III) in waters with high silicate and phosphate concentrations." Environmental Science and Technology. Vol 38, p 307-315.

[76] Roy, J., 2008. "Economic benefits of arsenic removal from groundwater- A case study from West Bengal, India." Science of the Total Environment. Vol 397, p 1-12.

[77] Sarkar, S., A. Gupta, R.K. Biswas, A.K. Deb, J.E. Greenleaf, and A.K. SenGupta, 2005. "Well-head arsenic removal units in remote villages of Indian subcontinent: Field results and performance evaluation." Water Research. Vol 39, Issue 10, p 2196-2206.

[78] Seo, J., M.H. Lean, and A. Kole, 2007. "Membraneless microseparation of asymmetry in curvilinear laminar flows." Journal of Chromotography. Vol 1162, p 126-131.

[79] Seo, J., M.H. Lean, and A. Kole, 2007. "Membrane-free microfiltration by asymmetric inertial migration." Applied Physical Letters. Vol 91.

[80] Smith, A.H., E. O. Lingas, and M. Rahman, 2000. "Contamination of drinking-water by arsenic in Bangladesh: A Public Health Emergency." Bulletin of the World Health Organization. Vol 78, No 9, p 1093-1103.

[81] Smith, S.D., and M. Edwards, 2005. "The influence of silica and calcium on arsenate sorption to oxide surfaces." Journal of Water Supply: Research and Technology. Vol 54, No 4, p 201-211. 
[82] Song, S., A. Lopez-Valdivieso, D.J. Hernandex-Campos, C. Peng, M.G. Monroy-Fernandez, and I. RazoSoto, 2006. "Arsenic removal from high-arsenic water by enhanced coagulation with ferric ions and coarse calcite." Water Research. Vol 40, p 364-372.

[83] Su, C. and R.W. Puls, 2001. "Arsenate and arsenite removal by zerovalent iron: kinetics, redox transformation, and implications for in situ groundwater remediation." Environmental Science and Technology. Vol 35, p 1487-1492.

[84] Su, C. and R.W. Puls, 2003. "In situ remediation of arsenic in simulated groundwater using zerovalent iron: laboratory column tests on combined effects of phosphate and silicate." Environmental Science and Technology. Vol 37, p 2582-2587.

[85] Sutherland, D., Md.O. Kabir, and N.A. Chowdhury, 2001. "Rapid Assessment of technologies for arsenic removal at the household level." In Proceedings of BUET-UNU International Workshop on Technologies for Arsenic Removal from Drinking Water, Dhaka, 5-7 May 2001 Bangladesh University of Engineering and Technology and United Nations University, Bangladesh. p 190-200.

[86] Thirunavukkarasu, O.S., T. Viraraghavan, and K.S. Subramanian, 2003. "Arsenic removal from drinking water using iron oxide-coated sand." Water, Air, \& Soil Pollution. Vol 142, No 1-4. p 95-111.

[87] Tyrovola, K., N.P. Nikolaidis, N. Veranis, N. Kallithrakas-Kontos, P.E. Koulouridakis, 2006. "Arsenic removal from geothermal waters with zero-valent iron-Effects of temperature, phosphate, and nitrate." Water Research. Vol 40, p 2375-2386.

[88] UNDP, 1997. "Human Development Report 1997: Human development to eradicate poverty." United Nations Development Program. http://hdr.undp.org/en/reports/global/hdr1997/chapters/

[89] UNICEF, 2006. "Arsenic Mitigation in Bangladesh." http://www.unicef.org/Bangladesh/Arsenic.pdf

[90] Vaishya, R.C. and S.K. Gupta, 2003. "Arsenic removal from groundwater by iron impregnated sand." Journal of Environmental Engineering. Vol 129, Issue 1, p 89-92.

[91] Velizarov, S., J.G. Crespo, M.A. Reis, 2004. "Removal of inorganic anions from drinking water supplies by membrane bio/processes." Reviews in Environmental Science and Biotechnology. Vol 3, No 4, p 361-380.

[92] Wang, S. and H. Wu, 2006. "Environmental-benign utilisation of fly ash as low-cost adsorbents." Journal of Hazardous Materials. Vol B136, p 482-501.

[93] Waypa, J.J., 1997. "Arsenic removal by RO and NF membranes." Journal AWWA. Vol 89, Issue 10, p 102-114.

[94] Welch, A.H. and K.G. Stollenwerk, 2003. Arsenic in Ground Water: Geochemistry and Occurrence. Kluwer Academic Publishers.

[95] Westerhoff, P., T. Karanfil, and J. Crittenden, 2006. "Aerogel \& Iron-oxide Impregnated Granular Activated Carbon Media for Arsenic Removal." Report prepared for AwwaRF and the U.S. Department of Energy. Project summary available: http://www.awwarf.org/research/TopicsAndProjects/execSum/3079.aspx

[96] WHO, 2000. "Towards an assessment of the socioeconomic impact of arsenic poisoning in Bangladesh." World Health Organization Water, Sanitation, and Health Programme. http://www.who.int/water_sanitation_health/dwq/arsenic2/en/

[97] Yavuz, C.T., J.T. Mayo, W.W. Yu, A. Prakash, J.C. Falkner, S. Yean, L. Cong, H.J. Shipley, A. Kan, M. Tomson, D. Natelson, and V.L. Colvin, 2006. "Low-field magnetic suspension of monodisperse $\mathrm{Fe}_{3} \mathrm{O}_{4}$ nanocrystals." Science. Vol 314, p 964-967. 